Portland State University

PDXScholar

$4-21-2021$

\title{
The Use of Mayflies, Stoneflies and Caddisflies as Indicators of Fine Sediment Pollution in Salmon- Bearing Streams of the Pacific Northwest
}

Cory Michael McCaffrey

Portland State University

Follow this and additional works at: https://pdxscholar.library.pdx.edu/open_access_etds

Digipalrt of the Environmental Sciences Commons

cemtnens know how access to this document benefits you. Network

Logo

Recommended Citation

McCaffrey, Cory Michael, "The Use of Mayflies, Stoneflies and Caddisflies as Indicators of Fine Sediment Pollution in Salmon-Bearing Streams of the Pacific Northwest" (2021). Dissertations and Theses. Paper 5670.

https://doi.org/10.15760/etd.7542

This Thesis is brought to you for free and open access. It has been accepted for inclusion in Dissertations and Theses by an authorized administrator of PDXScholar. Please contact us if we can make this document more accessible: pdxscholar@pdx.edu. 
The Use of Mayflies, Stoneflies and Caddisflies as Indicators of Fine Sediment Pollution in Salmon-Bearing Streams of the Pacific Northwest

by

Cory Michael McCaffrey

A thesis submitted in partial fulfillment of the requirements for the degree of

Master of Science

in

Environmental Science and Management

Thesis Committee:

Yangdong Pan

Patrick Michael Edwards

Eugene Foster

Portland State University

2021 
(C) 2021 Cory Michael McCaffrey 


\begin{abstract}
Fine sediment (particles $<2 \mathrm{~mm}$ in diameter) deposition is a natural component of streams but in excess amounts it is harmful to aquatic biota. Fine sediment is the main cause of impairment in streams and rivers of the Pacific Northwest and it can lead to unsuitable spawning and rearing habitat for Endangered Species Act (ESA) listed Salmon and steelhead. From a regulatory perspective, fine sediment presents a challenge because it is difficult to measure in situ and to establish criteria that would indicate stream impairment. Consequently, there is considerable effort to develop biocriteria using stream macroinvertebrates that would help regulators determine if a stream is impaired by excessive fine sediment.
\end{abstract}

Stream macroinvertebrates are widely used to monitor and assess stream degradation because they are affected by the physical, chemical and biological conditions in a stream. In particular, the stream insects known as mayflies (Ephemeroptera, E), stoneflies (Plecoptera, P) and caddisflies (Trichoptera, T) are commonly used as a metric referred to as EPT richness. EPT taxa are well known as pollutant intolerant insects and EPT richness in known to respond negatively to stream degradation. While the sensitivity of EPT to changing water chemistry, increased land use, and hydrologic alteration has been well established, the use of EPT as biocriteria to monitor fine sediment conditions in streams has not been fully evaluated.

Studies on the relationship between EPT and fine sediment have shown mixed results, which is likely due to the challenges of quantifying fine sediment in streams. For 
example, many studies use reach-scale pebble-counts to quantify sediments and reachscale macroinvertebrate samples to characterize their condition, but the processes that drive macroinvertebrate-sediment relationships primarily operate at the patch-scale. Another issue is the incomplete sediment gradient often observed in the randomized, reach-scale study designs frequently used to collect stream data for regulatory purposes.

The purpose of my thesis is to address the use of stream macroinvertebrates as indicators of excessive fine sediment in the regulatory setting. Specifically, I evaluated which aspect of the macroinvertebrate community should be used as an indicator for fine sediment, explored methods for better characterizing benthic fine sediment at the patchscale and conducted a spatially oriented study that contained a fine sediment gradient. I accomplished this by: 1) using Random Forest and generalized linear models (GLM) to explore relationships between environmental variables, macroinvertebrate metrics and fine sediment in the Pacific Northwest (PNW), 2) developing and validating a novel methodology that quantifies macroinvertebrates and fine sediment at the patch-scale, and 3) designing and conducting a field study in the John Day Basin that included a relatively complete gradient of fine sediment conditions.

The results of the exploratory analysis of the PNW data showed that EPT richness and percent EPT richness had the strongest association with fine sediment (model percent variance explained $=42.6 \%-44.5 \%$ ). Important environmental predictors of EPT richness included percent fine sediment cover, conductivity, chloride, canopy cover and fast-water habitat. Generalized linear models with EPT richness as the response variable and the same environmental predictor variables showed similar results (Pseudo $\mathrm{R}^{2}=0.43$ 
-0.50). Using the novel patch-scale sediment sampling methodology, I found that mass of fines and percent of fines was significantly and negatively correlated with velocity (rho $=-0.78, \mathrm{p}<0.001$ and rho $=-0.52, \mathrm{p}<0.05$, respectively). Percent EPT richness exhibited significant and positive correlations with velocity $(\mathrm{rho}=0.87, \mathrm{p}<0.001)$ and a significant and negative correlation with mass of fines (rho $=-0.70, p<0.01$ ). Nonerosional samples exhibited stronger relationships between velocity and mass of fines $($ rho $=-0.85, p<0.01)$ than erosional sampling locations (rho $=0.20, p>0.05)$. Results of the John Day study showed that EPT richness was strongly related to fine sediment mass and also positively related to orthophosphate $\left(\right.$ Pseudo $\left.\mathrm{R}^{2}=0.82\right)$. EPT richness decreased $12 \%$ between zero and seven percent fine sediment cover but increased between $8 \%$ and $10 \%$ fine sediment cover.

When compared to data collected using a traditional reach-scale approach, the John Day study resulted in stronger relationships between stream macroinvertebrates and fine sediment, and improved model $\mathrm{R}^{2}$ values by $52 \%$. These findings provide support for the conceptual premise that 1) EPT richness may be a useful indicator for excessive fine sediment conditions, 2) characterizing sediment and macroinvertebrates at the patch-scale and along non-erosional habitats results in better statistical relationships, and 3) a study design that is specifically focused on the fine sediment gradient resulted in better statistical models than the traditional reach-scale approach typically used in the regulatory setting.

The results of this study have several limitations that are important to acknowledge. First, the coefficients of the GLM models should not be used in basins 
other than John Day. Second, the novel patch-scale sediment sampling method is probably too time consuming for use in regulatory monitoring; however, its use to develop macroinvertebrate indicators of fine sediment would likely improve the ability to detect excessive fine sediment conditions. And finally, because EPT richness is known to vary with other environment stressors, caution should be exercised when applying this approach in basins with other environmental stressors. Further research assessing how EPT traits decline in response to fine sediment could help distinguish between changes due to excessive fine sediment and other stressors. 


\section{DEDICATION}

I dedicate this work to all the women in my life:

My mother Sally

My partner Molly

My daughter Naia 


\section{ACKNOWLEDGMENTS}

I'd like to thank my advisor Dr. Patrick Edwards for his guidance and patience throughout my graduate and undergraduate learning. This could not have been possible without his wisdom and encouragement. I would also like to thank my committee members Dr. Yangdong Pan and Dr. Eugene Foster who have provided thoughtful advice and questions that made me a better scientist.

I would also like to thank the students of Dr. Pan's lab for their time spent reviewing my thesis defense presentation and providing useful suggestions.

I am especially indebted to the field crew that helped with site surveys in the John Day area: Shauna Lodi, Dakota Hufford, Blair Gilwit, and Jarred Hasskamp. In particular I'd like to thank Hannah Smiley for helping me with field work throughout each stage of this project.

I am also very grateful to receive funding from the Environmental Professional Program to support field crew operations and laboratory fees to process water quality samples. Lastly, I'd like to give a whole hearted thanks to my mother Sally Bones for being my biggest supporter, and to my partner, Molly Vance, for all that you do for our family. 


\section{TABLE OF CONTENTS}

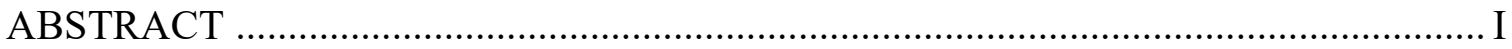

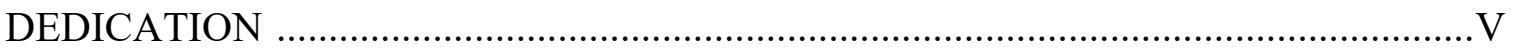

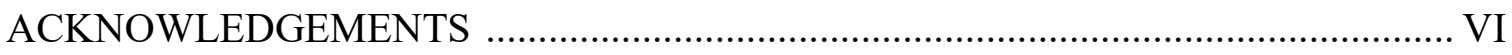

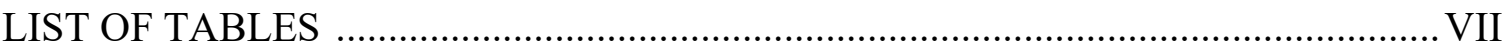

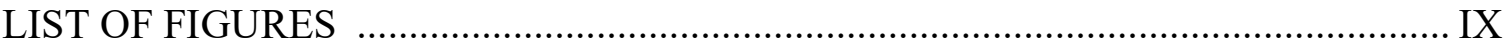

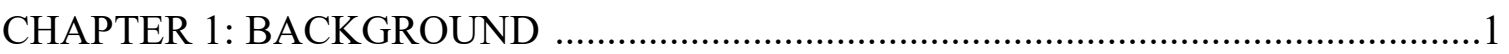

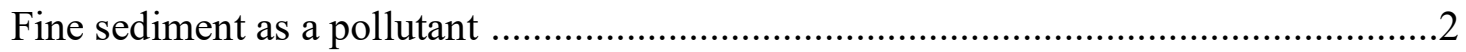

Developing fine sediment indicators: the issue of scale and gradients in

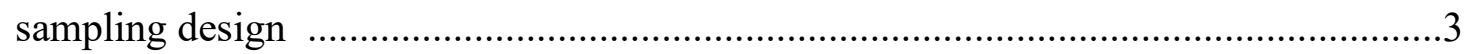

Biological assessment and monitoring as regulatory tools ........................................6

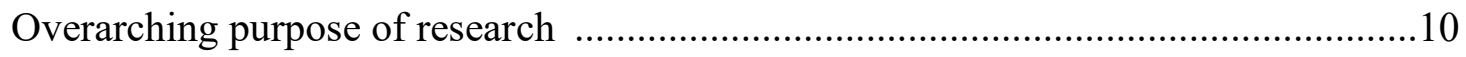

CHAPTER 2: PRELIMINARY INVESTIGATIONS ……............................................13

2.1 Exploratory Analysis: Using existing data to identify metrics for

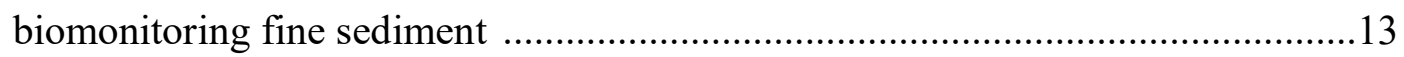

2.2 Feasibility Study: Evaluating a field method for simultaneously sampling

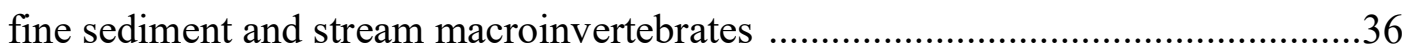

CHAPTER 3: THE USE OF EPT AS INDICATORS OF FINE SEDIMENT POLLUTION IN SALMON-BEARING STREAMS OF THE JOHN DAY BASIN ...... 58

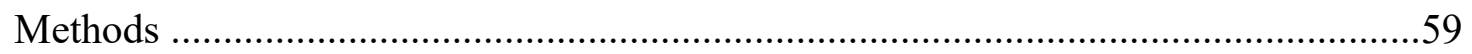

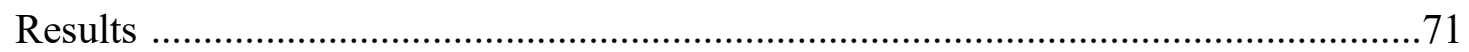

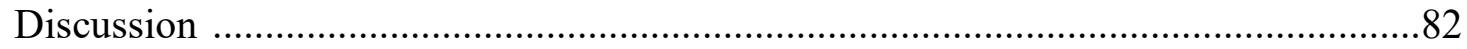

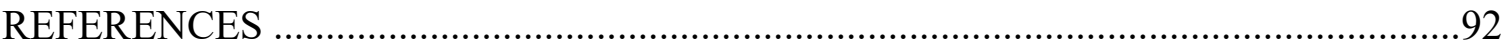

Appendix A-1: Environmental variable descriptions used in the WEMAP Random Forest analysis

Appendix A-2: Macroinvertebrate metrics and descriptions used in the WEMAP Random Forest analysis 116 Appendix A-3: Spearman's cross-correlation matrix with data from the feasibility study 


\section{LIST OF TABLES}

Table 1: Chapter objectives and corresponding predictions

Table 2.1.1: Summary of land use and relevant variables to the pilot study for each ecoregion

Table 2.1.2: Exploratory Analysis Random Forest results with the highest percent variance explained and model residuals

Table 2.1.3: Exploratory Analysis GLM model summaries 30

Table 2.2.1: The conventional approaches used for quantifying benthic fine sediment ...39

Table 2.2.2: Summary statistics of variables relevant to the purpose of the Feasibility Study

Table 3.1: Summary information on the 20 transects from the John Day Basin Field Study

Table 3.2: GLM model summaries from the John Day Basin Field Study .81 


\section{LIST OF FIGURES}

Figure 2.1.1: WEMAP survey sites used in Exploratory Analysis

Figure 2.1.2: Partial dependence plots showing the marginal effect percent fines has on

the predicted outcome in the Random Forest learning model

Figure 2.1.3: Variable importance plots from the EPT richness Random Forest model ..24

Figure 2.1.4: Variable importance plots from the \% EPT richness Random Forest model

Figure 2.1.5: Variable importance plots from the \% Plecoptera richness Random Forest model

Figure 2.1.6: Variable importance plots from the Ephemeroptera richness Random Forest model

Figure 2.1.7: Variable importance plots from the Trichoptera richness Random Forest model

Figure 2.2.1: Schematic diagram showing sources of fine sediment in streams and mechanistic effects on EPT and their habitat

Figure 2.2.2: Birds eye view of sampling schematic in transect, indicating place of D net, the five sampling locations, and typical thalweg location .45

Figure 2.2.3: Beckson 136 series pump used to vacuum suction sediment from sample location 46

Figure 2.2.4: Image of crew layout during the sampling process

Figure 2.2.5: Boxplots indicating fine sediment percent cover data by sampling location on transect

Figure 2.2.6: Boxplots indicating fine sediment mass data by sampling location on transect 
Figure 2.2.7: Scatterplots with 95\% confidence intervals showing mass of fines and velocity, and percent fines and velocity

Figure 2.2.8: Correlation matrix showing scatterplots and histograms .53

Figure 3.1: Schematic diagram of the site selection process 61

Figure 3.2: Map of study area and sample locations in the John Day Basin including dominant geology

Figure 3.3: Birds eye view of sampling schematic in transect indicating placement of D net, the two sampling locations to be composited, and typical thalweg location

Figure 3.4: Cross section diagram of sampling substrate and macroinvertebrates indicating placement of D net, bilge pump, and the two sampling locations to be composited

Figure 3.5: Schematic showing analytical pathway of this research and relevant figure or table .71

Figure 3.6: Variability of the mass of fine sediment at sites grouped by dominant geology of catchment .76

Figure 3.7: Spearman's cross-correlations including the EPT metrics and all environmental variables

Figure 3.8: Spearman correlation coefficients and scatterplots between variables selected and included in GLM models .78

Figure 3.9: John Day Basin Study PDP showing the expected response of EPT richness as a function of percent fine sediment cover (PCT_FN) when the other predictor variables are marginalized

Figure 3.10: Exploratory Analysis PDP showing the expected response of EPT richness as a function of percent fine sediment cover (PCT_FN) when the other predictor variables are marginalized .80 


\section{CHAPTER 1: BACKGROUND}

In 1998 the US Environmental Protection Agency identified deposited sediment as the primary source of stream impairment and habitat degradation in the nation (US Environmental Protection Agency, 2000). Fine sediment can be detrimental to the health of macrophytes (Jones, et al., 2012a), diatoms (Jones, et al., 2014), macroinvertebrates (Jones, et al., 2012b), and fish (Waters, 1995; Wood \& Armitage, 1997). The primary objective of the Clean Water Act (CWA) "is to restore and maintain the chemical, physical, and biological integrity of the Nation's waters". A primary driver for monitoring programs in the Pacific Northwest is the successful reproduction and rearing of Endangered Species Act (ESA) listed salmon and steelhead. Due to their anadromous life cycle and mobility, monitoring efforts require a great deal of resources.

Bioassessment using macroinvertebrates is widely used for measuring stream degradation, and as a regulatory tool to meet the biological integrity requirement of the Clean Water Act (Davies \& Jackson, 2006; Mazor, et al., 2016). Ephemeroptera, Plecoptera, Trichoptera (EPT) richness and its derivatives are common water quality indicator used in biomonitoring (Rosenberg \& Resh, 1993; Stoddard, et al., 2008). These taxa are sensitive to changes in water quality (Wallace, et al., 1996; Waite, et al., 2008) and widely used to indicate anthropogenic stress across many different geographic settings (Ligeiro, et al., 2013; Cuffney, et al., 2010; Waite, et al., 2010).

Because EPT are strongly related to natural sediment conditions (Beerman, et al., 2018) and anthropogenic stressors (Waite, et al., 2008), evaluating its use as an indicator requires a focus on the fine sediment gradient while controlling for the confounding 
effects of other watershed stressors. The John Day Basin of Oregon is ideal for testing relationships between fine sediment and EPT metrics as it contains a variety of geologic formations and has minimal anthropogenic disturbance at middle to high elevations (Butcher, et al., 2010). The Middle Fork John Day River is part of a long-term, largescale research project (Intensively Monitored Watershed) focused on how restoration influences spring Chinook salmon and summer steelhead. Furthermore, the John Day Basin is hydrologically unregulated and the largest tributary to the Columbia River in the US, with much of its headwaters and tributaries providing core cold water spawning and rearing habitat for sensitive steelhead and salmon (Butcher, et al., 2010).

\section{Fine sediment as a pollutant}

Deposited and suspended inorganic sediments less than $2 \mathrm{~mm}$ in size place stress on streams and rivers ecosystems (Waters, 1995; Jones, et al., 2012b). When a stream's transporting capacity is reduced, small sediment particles settle into and cover the substrate. Compared to suspended particles, sediment deposition on the benthos or sediment infiltration may have greater consequences due to its long-term ecological effects (Campbell \& Doeg, 1989). Fine sediment particles that settle into the benthos can reduce the distribution of particle sizes, resulting in a less heterogeneous substrate composition and more homogenous sand, clay, or silty stream bottom (Minshall, 1984).

Fine sediment particles are known to degrade habitat in streams which affects both fish and macroinvertebrates (Luedtke \& Brusven, 1976; Richardson, 1985; Harvey, et al., 2011; Kemp, et al., 2011; Jones, et al., 2012b). Fines have been found to clog 
interstitial spaces and limit habitat availability (Waters, 1995; Zanetell \& Peckarsky, 1996; Rehg, et al., 2005), bury periphyton (Suren, 2005), decrease primary productivity (Parkhill \& Gulliver, 2002), reduce the nutritional quality of periphyton (Peeters, et al., 2006), damage invertebrate mouthparts used for feeding on periphyton (Broekhuizen, et al., 2001), increase embeddedness (Brusven \& Prather, 1974), increase bedload movement and reduce attachment platforms (Jowett, 2003; Cobb, et al., 1992).

Hydrological regimes also play a critical role in both fine sediment dynamics (Leopold, et al., 1964) and macroinvertebrate community assemblage (Monk, et al., 2008). The interaction between hydrology and fine sediment dynamics (embedding or suspension and depositional processes) can cause a loss of diversity within macroinvertebrate communities when flow volume is reduced and sediments accumulate (Buendia, et al., 2014). Flow rate will greatly influence the proportion of fine sediments on the stream bottom as stronger flows in the thalweg and riffles move smaller size particles while stream margins and depositional zones will collect them.

\section{Developing fine sediment indicators: the issue of scale and gradients in sampling design}

There are several challenges for the management and regulation of excess fine sediment, including: 1) determining which aspect of the insect community is best as an indicator for excessive fine sediment conditions, 2) the use of traditional field collection methods that are focused on the reach-scale rather than the patch-scale (Longing, et al., 2010), which is the scale at which fine sediment processes occur, and 3) the need for 
study designs focused on the fine sediment gradient while minimizing confounding effects of other environmental stressors. The development of macroinvertebrate indicators for fine sediment will require a study design that is focused at the patch-scale in streams with a wide range of sediment conditions and relatively few other anthropogenic stressors.

The use of macroinvertebrates as a bioassessment tool for monitoring fine sediment presents several challenges that are yet to be fully addressed in the literature. First, bioassessment programs often utilize large spatially balanced regional or national survey datasets with hundreds of variables, designed with the intention of collecting water quality information for inferential value (Olsen \& Peck, 2008; Sheilbley, et al., 2015; USEPA , 2016). Though this is practical for assessing multiple stressors, it is not specifically designed for the assessment of fine sediment conditions. Second, a limited number of studies have focused on gathering empirical data with a targeted gradient of fine sediment to determine the corresponding sensitivity of macroinvertebrate metrics (Angradi, 1999; Relyea, et al., 2000; Zweig, et al., 2001; Kaller, et al., 2001; Buendia, et al., 2013; Wagenhoff, et al., 2012; Gieswein, et al., 2018).

Very few empirical studies have investigated metric responses to silt and clay fines $(<0.063 \mathrm{~mm})$. Most studies to date have examined the sensitivity of responses to a gradient of fines less than $2 \mathrm{~mm}$ in size (Jones, et al., 2012b), as the majority of bioassessment and sediment-related studies categorize fines as sediment less than $2 \mathrm{~mm}$. Although both size classes fall under the definition of sand, smaller particles tie more closely to research showing a reduction in salmonid egg-to-fry survival (Jensen, et al., 
2009). Sands and fines represent a 32x difference in size, therefore placing different forms of stress on macroinvertebrate taxa and their associated modalities. Fines show signs of being a chronic stressor that may lower productivity (Parkhill \& Gulliver, 2002), reduce food quality (Peeters, et al., 2006; Suren, 2005), and behave as a vector for infections (Lemly, 1982). Sands may represent a short-term pulse stress though physical abrasion and periphyton scouring (Bond \& Downes, 2003).

Empirical studies that have investigated the effects of sedimentation on macroinvertebrate communities primarily focus on erosional flow areas such as riffles. This is due to the systematic sampling design used to collect macroinvertebrates in stream monitoring programs. Transitional areas are likely more responsive to fine sediment accumulations because they are inherently depositional (Logan and Brooker 1983). Single habitat sampling presents some concerns such as 1) site taxa lists likely incomplete, 2) not all sites in a region contain similar habitat types so some sites inevitably go unsampled, and 3) the variable of interest may affect macroinvertebrates only in habitats that are not sampled (Kerans, et al., 1992; Roy, et al., 2003). Macroinvertebrate assemblages will naturally vary between habitat types within a reach or transect (Palmer, et al., 1991; Rabeni, et al., 2002). Considering an array of stream habitats is important when researching the relationships between macroinvertebrates and fine sediment.

EPT taxa are generally recognized as some of the most sensitive taxa in riverine systems and are used for biomonitoring (Bonada, et al., 2006; Waite, et al., 2010). They are used in ecological indices such as the Biological Condition Gradient (U.S. 
Environmental Protection Agency 2016), and the Benthic Index of Biological Integrity (Karr \& Chu, 1998). EPT richness has not been adequately studied for use in fine sediment bioassessment, and this study presents the first attempt to evaluate and validate EPT richness as a response metric specifically for fine sediment bioassessment. The sensitivity of biometrics under natural conditions along a fine sediment gradient warrants further investigation, particularly in regions supporting salmonid populations.

\section{Biological assessment and monitoring as regulatory tools}

The use of biota to evaluate ecological conditions is a common practice in water quality monitoring programs (U.S. Environmental Protection Agency, 2016). Currently, the most common tool for assessment of biological conditions in streams are the multimetric indices (Buss, et al., 2015). A multimetric index (MMI) considers the effects of many factors and aggregates individual biological, ecological, and functional measures into a unique value that is used to create a score, characterizing the general condition of a stream (Karr \& Chu, 1998; Hering, et al., 2006). The index of biotic integrity (IBI) is a MMI that was introduced by Karr (1981) to measure stream conditions based on fish assemblages, but IBIs have been developed for macroinvertebrates (Kerans \& Karr, 1994) and periphyton as well (Pan, et al., 1996). An environment that supports a community of organisms similar to that shaped by longstanding evolutionary processes has high biological integrity. Indices such as the IBI provide narrative ratings of ecological status (e.g., pristine, moderate, or very bad), that are easy to understand for decision-makers and thus has been introduced into aquatic ecosystem management. State 
and tribal Water Quality Standard programs can use biological assessment to develop descriptions of CWA-designated aquatic life uses in terms of the anticipated biological assemblage (U.S. Environmental Protection Agency, 2011).

Biomonitoring using biological assemblages to assess the environment is a practical approach for characterizing ecological conditions of streams because of the ability to integrate multiple stressors and stream conditions over time (Rosenberg \& Resh, 1993; Barbour, et al., 1999). Aquatic organisms cope with the chemical, physical, and biological impacts of their surroundings over the course of their aquatic life cycle, which can last up to several years. Using macroinvertebrates offers certain advantages such as their ubiquitous nature, high species richness that offers a spectrum of environmental responses, longer life cycles of some taxa, easy sampling methods, and suitability of certain taxa for experimental studies of pollution effects (Bonada, et al., 2006). A number of indices have been developed to measure macroinvertebrate responses to pollutants such as acidification, flow alteration, habitat degradation, and organic pollution, for use in the regulatory setting (Extence, et al., 1999; Lorenz, et al., 2004; Bonada, et al., 2006).

Biomonitoring using macroinvertebrates may be useful for specific pollutants such as fine sediment because substrate is thought to be the most important characteristic regulating macroinvertebrate distribution and abundance at the local or reach scale (Minshall, 1984). Recently, federal and state agencies have increased their efforts in the development of biologically based sediment criteria (Cormier, et al., 2008). Though the mechanisms underlying sensitivity to fine sediment are not wholly agreed upon, the 
documented relationship between fine sediment and macroinvertebrates make them an appealing option for monitoring and for evaluating impacts of excess fine sediment. Therefore, there is a large interest in improving and utilizing macroinvertebrate-based metrics and indices that function as proxies for traditional sediment measurement techniques (Zweig, et al., 2001; Hubler, et al., 2016; Gieswein, et al., 2018; Buendia, et al., 2013). For the sake of clarity, both metric and index (indices) are used interchangeably throughout this document. Both terms refer to a collection of measurements generating a score or value that has meaningful information pertaining to the macroinvertebrate community and how they respond to stress.

There has been considerable effort to develop diagnostic indices based on the responses of sensitive macroinvertebrates to fine sediment. Relyea et al. (2012) developed a fine sediment biotic index (FSBI) for Northwest streams by classifying taxa into four categories of fine sediment $(<2 \mathrm{~mm})$ sensitivity then weighting each category. FBSI scores were calculated by summing the sensitive taxa found in a stream. Extence et al. (2011) used a proportion of sediment sensitive invertebrates (PSI) metric that placed taxa into four fine sediment $(<2 \mathrm{~mm})$ sensitivity categories and assigned PSI scores to streams by summing the scores of taxa in sensitive categories divided by scores for taxa in all the categories. Murphy et al. (2015) derived a gradient of sediment data from streams in England and Wales to produce a combined fine sediment index (CoFSI $\left.{ }_{\text {sp }}\right)$ that considered both organic and inorganic fine sediment particles $(<2 \mathrm{~mm})$ in erosional or depositional patches. More recently, Hubler et al. (2016) examined smaller particle sizes than previous studies $(<0.06 \mathrm{~mm})$ to create the Biological Sediment Tolerance Index 
(BTSI) for inferring fine sediment conditions in Oregon streams. For biomonitoring and remediation, it is important to be able to quantify ecologically meaningful impacts and discriminate the cause of pollution through diagnosing response patterns. There is an abundance of work characterizing sediment and macroinvertebrates at the reach scale, but the literature is lacking an empirical investigation of macroinvertebrate response patterns at the patch scale where sediments are measured concurrently.

Macroinvertebrate assemblage responses to pollutants commonly include a shift in dominance from Ephemeroptera, Plecoptera, and Trichoptera, to one dominated by taxa adapted to burrowing such as Oligochaeta, Chironimidae, and Bivalva (Wood \& Armitage, 1997; Wagenhoff, et al., 2012; Gerth, et al., 2016). In high quality habitat, long-lived and ecologically specialized taxa are abundant while the relative abundances of generalists and pollution-tolerant taxa are low (Davies \& Jackson, 2006). Some taxa respond to fine sediment stress as a function of their morphological attributes or traits (Bona, et al., 2015; Doretto, et al., 2017). Because of the difficulties predicting taxonomic composition in streams, ecologists have developed classifications of species into groups with similar biological and ecological traits (i.e. feeding habits, anatomy, voltinism, thermal preference). Traits are the macroinvertebrate's attributes that can have multiple potential states (modalities) (Poff, et al., 2006). The trait modalities evolved in response to the environment and can be discrete (i.e. multivoltine, univoltine) or found along a gradient (i.e. body size, thermal preference).

Recently, there has been a growing interest in the incorporation of taxa traits within biomonitoring to address changes that occur to assemblage structures in streams 
(Gothe, et al. 2016). Trait composition can be used to detect sources of environmental impairment associated with anthropogenic and natural stressors. The stressors act as 'filters', selecting taxa and their traits that conform to an environment (Poff, 1997; Statzner, et al., 2001). Thus, certain traits may respond to specific environmental stressors, which has motivated the developing use of biological traits in biomonitoring (Poff, et al., 2006; Statzner, et al., 2004; Turley, et al., 2016). The use of traits may provide valuable insight of mechanistic relationships to anthropogenic stressors such as fine sediment (Pollard \& Yuan, 2010). Using EPT metrics, such as EPT richness, are essentially a trait-based approach, due to their documented sensitivity to changes in water quality. Previous studies investigating the responsiveness of EPT-based metrics to fine sediments have mixed results. A number of studies have reported EPT metrics to be sensitive to accumulations in fine sediment (Zweig, et al., 2001; Edwards, et al., 2020; Waters, 1995; Angradi, 1999; Wagenhoff, et al., 2012; Kaller \& Hartman, 2004; Herbst \& Kane, 2006), while others have reported no and or weak relationships (Wood \& Armitage, 1997; Beerman, et al., 2018; Gieswein, et al., 2018; Relyea, et al., 2000; Buendia, et al., 2013). The wide range of particle sizes classified as fines and may attribute to inconsistencies in outcomes within the literature (Jones, et al., 2012b).

\section{Overarching purpose of research}

The purpose of the research is to examine the use of stream macroinvertebrates as bioindicators of excessive fine sediment in salmon-bearing streams of Oregon. It is important to accurately quantify the effect of fine sediment on macroinvertebrate 
communities in order to assess impairment and develop reliable biocriteria for indication of recovery when sedimentation TMDLs are in place. The objectives of this study are to address three regulatory issues related to fine sediment: 1) which aspect of the insect community should be used as an indicator for fine sediment, 2) how can we better characterize benthic fine sediment conditions when developing macroinvertebrate indicators, and 3) how can we develop and implement a study design focused on the fine sediment gradient while controlling for the confounding effects of other watershed stressors. The objectives and predictions for each chapter of my thesis are summarized in Table 1. 
Table 1. Study objectives and corresponding predictions for each chapter of my thesis.

\begin{tabular}{|c|c|c|}
\hline \multirow[b]{2}{*}{$\begin{array}{l}\text { Chapter } \\
2.1 \\
\text { Exploratory } \\
\text { Analysis: } \\
\text { Existing Data }\end{array}$} & Objectives & Prediction \\
\hline & $\begin{array}{l}\text { Examine relationships between } \\
\text { macroinvertebrates and environmental } \\
\text { conditions in wadeable streams to identify } \\
\text { metrics for biomonitoring fine sediment. } \\
\text { Build several linear models quantifying } \\
\text { the relationship between the most sensitive } \\
\text { metrics and important environmental } \\
\text { predictors. } \\
\text { Utilize the findings to design an } \\
\text { experiment and select future sampling } \\
\text { sites with a gradient of sediment } \\
\text { conditions. }\end{array}$ & $\begin{array}{l}\text { Exploratory, no a priori } \\
\text { predictions. }\end{array}$ \\
\hline $\begin{array}{l}2.2 \\
\text { Feasibility Study: } \\
\text { Field Method }\end{array}$ & $\begin{array}{l}\text { Experimentally test a sediment extraction } \\
\text { methodology to validate its use in } \\
\text { characterizing relationships between } \\
\text { velocity, fine sediment, and } \\
\text { macroinvertebrates. }\end{array}$ & $\begin{array}{l}\text { Positive correlations } \\
\text { exist between } \\
\text { depositional/mixed zones } \\
\text { and fines. } \\
\text { EPT taxa negatively } \\
\text { correlated with fines. }\end{array}$ \\
\hline $\begin{array}{l}3 \\
\text { John Day Basin } \\
\text { Field Study }\end{array}$ & $\begin{array}{l}\text { Develop a linear model to evaluate the } \\
\text { response of two EPT related metrics (EPT } \\
\text { richness and \% EPT richness) along a } \\
\text { gradient of fine sediment (less than } 0.063 \\
\text { mm) conditions. }\end{array}$ & $\begin{array}{l}\text { EPT metrics would } \\
\text { decline as fine sediment } \\
\text { increased in relation to } \\
\text { its proportion and its } \\
\text { mass. }\end{array}$ \\
\hline
\end{tabular}




\section{Chapter 2: Preliminary Investigations}

\subsection{Exploratory Analysis: Using existing data to identify metrics for biomonitoring fine sediment}

\section{Introduction}

Throughout Oregon, Washington, and Idaho there are nearly 27,000 miles of sediment related impairment and 557 sediment related TMDLs (United States Environmental Protection Agency, 2017). Excess fine sediment may lead to unsuitable spawning and rearing habitat for ESA listed Salmon and steelhead, primary drivers of stream monitoring and restoration efforts in the Northwest. Investigating the use of macroinvertebrates as indicators of sediment pollution is a continuing concern in the Northwest and within the field of bioassessment (Relyea, et al., 2012; Hubler, et al., 2016; Bryce, et al., 2010). One of the major challenges for stream regulators in the region is determining which aspect of the macroinvertebrate community is best for detecting excess fine sediment impairment in streams.

The purpose of the exploratory analysis is to examine relationships between macroinvertebrate metrics and fine sediment in watersheds of the Northwest with minimal human pressure. In response to information gaps regarding meeting requirements of the Clean Water Act, the US EPA conducted an ecological assessment of streams and rivers of the West in the early 2000's known as WEMAP (Western Environmental Monitoring and Assessment Program) (Stoddard, et al., 2005). Of the 
relevant aquatic stressors, the EPA found streambed stability (i.e., finer particles, more unstable streambed) to be both widespread and pose a moderate to high risk to biotic integrity. WEMAP sampling designs included monitoring tools that provided indicators of ecological conditions, detection of regional trends, and approaches to characterize reference conditions. The first objective of analyzing this dataset were to examine relationships between macroinvertebrates and environmental conditions in wadeable streams across minimally disturbed ecoregions, to identify metrics for biomonitoring fine sediment. The second objective was to quantify the relationship between the most sensitive macroinvertebrate metrics and important environmental predictors, then utilize the findings to design an experiment and select future sampling sites with a gradient of benthic sediment conditions.

\section{Methods}

To meet the needs of the study objectives, I used spatially balanced survey data from WEMAP to explore data and generate specific hypotheses. I selected watersheds within the WEMAP dataset with minimal human pressure, to minimize confounding factors associated with urbanization and agriculture. The study design investigated as many metrics and environmental predictors as possible to assess a wide range of stressors. The study sites were located in the Pacific Coast Range (California, Oregon, Washington), the Cascade Mountains (Oregon and Washington), and primarily the John Day Basin within the Blue Mountains of Oregon (Figure 2.1.1). Watersheds of the Survey sites had low population density, a range of dominant geology, and streams with 
high macroinvertebrate taxa richness, which offered the appropriate conditions to address the objectives of this Exploratory Analysis. The Coastal and Cascade ecoregions are dominated by moist climates with productive evergreen forests and steep sided stream valleys, while the Blue Mountains are comprised of open lower mountain ranges and an arid climate. The Cascades are primarily volcanic rock, while the Coastal and Blue mountains are comprised of an array of geologic types. Land use disturbances are logging, road building, and cattle grazing, which characterize the anthropogenic sources of fine sediment in these streams (Binkley and Brown 1993; McCullough and Greene 2003). With a combined estimated average population density less than two people per square kilometer, these survey sites allow for the evaluation of fine sediments without the confounding influence of urbanization and agricultural disturbances. Table 2.1.1 summarizes notable variables from each ecoregion as they relate to this investigation.

The WEMAP data collection took place during low-flow conditions in 2000-2002 using 11 evenly spaced transects at each sample reach and summarized for each reach (Peck, et al., 2006). The stream reach refers to the stream segment that was surveyed, and was at minimum 150 meters. Reach length was determined based on the stream width at five locations adjacent to the sampling coordinates. Land use and watershed data were also summarized for each reach. Sediments distributions were quantified using a pebble count protocol: by randomly selecting five particles at each transect for 55 total particle measurements, then determining the percent of each sediment size component (i.e. fines, sand, gravel) for the stream reach (Kaufmann, et al., 1999). 
Macroinvertebrate samples were collected by using a D-frame net technique from a $0.09 \mathrm{~m}^{2}$ area in each transect. Technicians kicked and agitated in the $0.09 \mathrm{~m}^{2}$ quadrat for 30 seconds beginning at the downstream transect, then preserved it in a container. At each of the 11 transects the process was repeated in a zig zag pattern for a $0.99 \mathrm{~m}^{2}$ composite that was indexed (Peck, et al., 2006). In the laboratory macroinvertebrates were identified to the genus and species level where practical, to a subsample goal of 500 organisms $($ median $=517)$. For more information regarding how the environmental and macroinvertebrate data were collected, a detailed description of field operations can be found in the WEMAP Field Operations Manual (Peck, et al., 2006).

\section{Data reduction and variable selection}

The objective of the analysis was to evaluate which macroinvertebrate metrics were most sensitive to changes in fine sediment. The machine learning technique known as Random Forest (Breiman, 2001) was used to select which macroinvertebrate metrics and environmental variables would be included in linear model development. Random Forest is a permutation-based technique that utilizes many decision trees (De'ath \& Fabricius, 2000) then utilizes the mean of those trees to find the optimal model and contribution of each predictor variable (Breiman, 2001). Regression decision trees were applied in this case because the response variables were numeric (counts of macroinvertebrates) and not categorical. I used Random Forest because it is commonly used for variable selection in environmental research (Mazor, et al., 2016), it includes a 
measure of variable importance, and because there is a large amount of predictor variables relative to the sample size with nonlinear interactions among variables. (De'ath \& Fabricius, 2000). The explanatory strength of each model was determined by the mean percent variance and mean square error of predictors. The Random Forest models included 60 environmental predictors (i.e. land use, chemical variables, and riparian characteristics) and 51 macroinvertebrate response metric variables (i.e., taxonomic and trait based). I ran the Random Forest for each response metric separately for a total of 51 Random Forest models. A list and description of those respective variables can be found in the appendix (Table A1-A2).

I selected five high performing Random Forest models. The determining factors were a combination of the highest percent variance explained (PVE), and highest mean square error (MSE) of percent fines. In the permutation-based approach used to determine variable importance within Random Forest, an Out-Of-Bag (OOB) sample is passed down each tree and the prediction accuracy is recorded. The values for each variable are permuted randomly and the accuracy is again recorded. The decrease in accuracy as a result of this randomly shuffling of predictor values is averaged over all the trees for each predictor. The variables with the largest average decrease in accuracy are considered the most influential (Friedman, et al., 2001). I added the PVE and percent fines MSE of every model to determine which models had the highest explanatory strength. I chose the five best models to detect which predictors are influencing the respective response variable, so that I could further assess their importance in a linear model. I used partial dependence plots to check that the Random Forest models with the 
highest explanatory strength were negatively associated with percent fines (Figure 2.1.2). Partial dependence plots show the marginal effects a predictor variable may have on the predicted outcome of a model (Friedman, 2001).

Environmental predictor variable inclusion in linear model development was based on the criteria that they had a mean square error (MSE) greater than eight and persisted in two or more of the five strongest Random Forest models (Figure 2.1.3 2.1.7). I dropped tolerant taxa richness and percent tolerant taxa from model development because partial dependence plots indicated positive correlations with percent fines. Positive correlations with fine sediment were not relevant to the study objectives. Based on the selection criteria and patterns in the variable importance plots (Figure 2.1.3 2.1.7), five environmental predictors were selected for model development: percent fines, percent fast water, conductivity, chloride, and riparian canopy density. The variable importance plot lists the predictor variables in order of their MSE. I evaluated collinearity between candidate variables with correlation coefficients and bivariate scatter plots. Percent fast water and percent slow water met the criteria but were highly correlated (rho $>0.75)$, so I removed percent slow water from further analysis.

\section{Linear model}

I used generalized linear modeling (GLM) to model the effects of the environmental predictors on the response metrics. I used a Poisson distribution to model the residual variation because the response metrics were derived from count data. I scaled predictor variables prior to the analysis to standardize variables having different units of 
measurement and have the ability to compare model coefficients. I used an AIC stepwise variable selection procedure for model fitting. This procedure adds or subtracts predictor variables one at a time (at each step) in an effort to sequentially add the most contributive predictors and remove any ones that do not provide an improvement to the model fit and lower the AIC statistic. The proportion of deviance explained by the fitted model determined the goodness of fit:

Pseudo $R^{2}=1-\frac{\text { residual deviance }}{\text { null deviance }}$

The models with the lowest AIC were selected as final models. I used R 3.5.2 (R Core Team, 2020) with the additional package MASS (Ripley, et al., 2019), and Random Forest (R Core Team, 2020) for statistical analysis. 


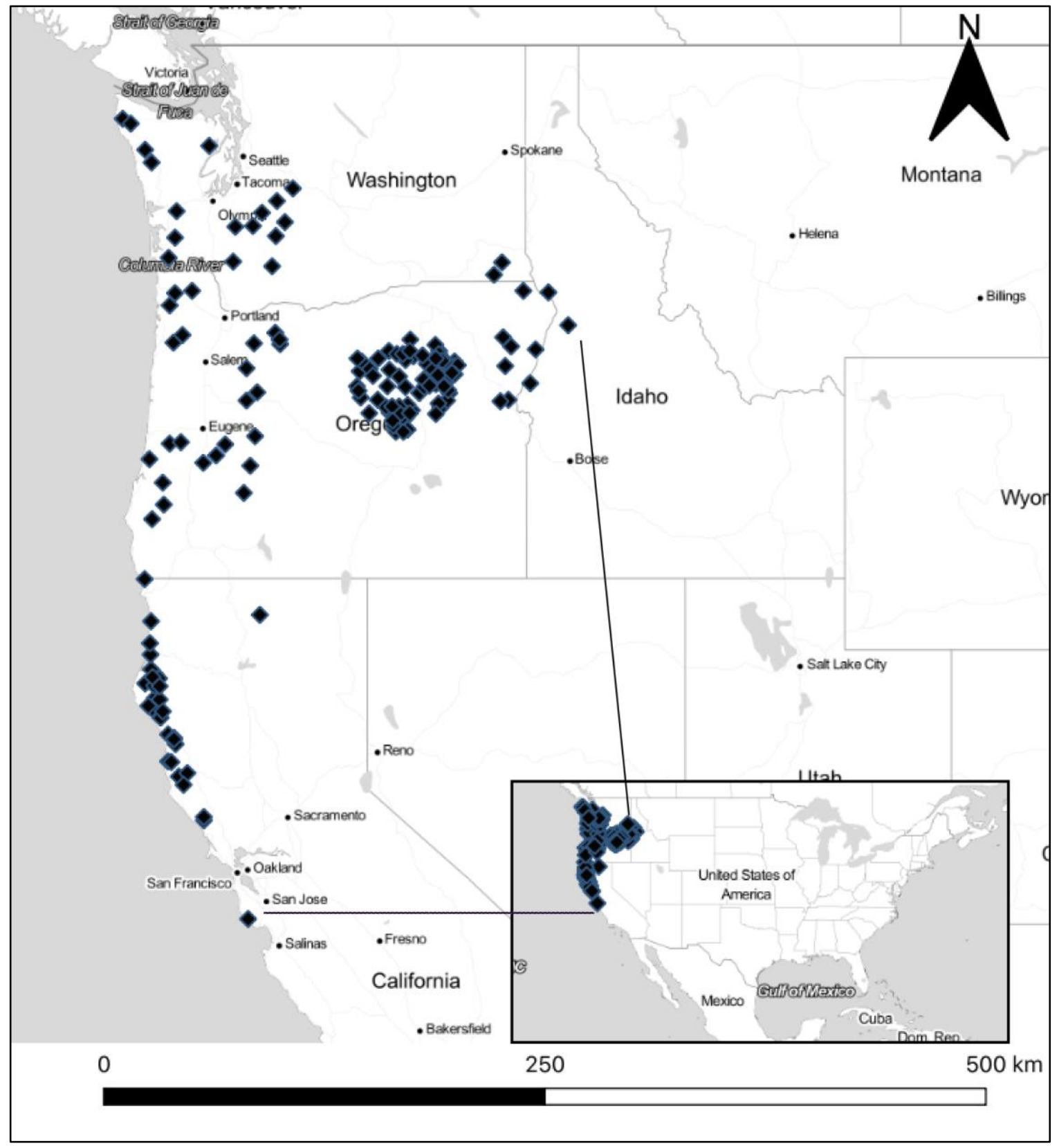

Figure 2.1.1 WEMAP survey sites used in Exploratory Analysis. 
Table 2.1.1 Summary median and range of land use and relevant variables to the Exploratory Analysis for each ecoregion. Values are median, range values are in parenthesis.

\begin{tabular}{|c|c|c|c|}
\hline & $\begin{array}{l}\text { Coast } \\
\text { Range }\end{array}$ & Cascades & $\begin{array}{l}\text { Blue } \\
\text { Mountains }\end{array}$ \\
\hline Number of sites & 48 & 23 & 81 \\
\hline Percent Fines (\%) & $\begin{array}{l}2.85(0- \\
76.2)\end{array}$ & $\begin{array}{l}0.95(0- \\
36.2)\end{array}$ & $11.4(0-92.4)$ \\
\hline Percent watershed in urban land (\%) & $0(0-0.5)$ & $0(0-0.5)$ & $0(0-.2)$ \\
\hline Population density (pop. est/sq. km) & $0.6(0-63.2)$ & $0(0-2.7)$ & $0(0-0.6)$ \\
\hline $\begin{array}{l}\text { Percent watershed in agricultural } \\
\text { lands }(\%)\end{array}$ & $0(0-4.6)$ & $0(0-0.1)$ & $0(0-16.9)$ \\
\hline Percent watershed in rangelands (\%) & $4.3(0-49.9)$ & $2.6(0-15.1)$ & $18.4(1.3-87.3)$ \\
\hline Total richness & $60.5(36-93$ & $60(6-90)$ & $56(34-82)$ \\
\hline EPT richness & $21.5(6-38)$ & $34(1-47)$ & $22(2-39)$ \\
\hline
\end{tabular}




\section{Results}

Data reduction and variable selection

The response metrics for the Random Forest models with the most explanatory strength were all derivatives of EPT: EPT richness, \% EPT richness, \% Plecoptera richness, Trichoptera richness, and Ephemeroptera richness. Partial dependence plots indicated negative relationships between each metric and percent fines in a non-linear fashion (Figure 2.1.2). The ticks along the $\mathrm{X}$-axis indicates the distribution of the data. Most of the sample reaches contained less than $40 \%$ percent fines coverage which is shown in the PDP (Figure 2.1.2.). EPT richness and Trichoptera richness exhibited the highest average change along the fine sediment gradient up to roughly $40 \%$. Besides Plecoptera $\%$ richness, each response metric shows a distinct decline at about $20 \%$ fine sediment coverage. Random Forest model percent variance explained ranged from $28.0 \%$ for Ephemeroptera richness to $44.5 \%$ for percent EPT richness (Table 2.1.2).

\section{Linear models}

AIC stepwise selection did not filter out any predictors for either EPT response model, but reduced the number of predictors in the other three models (Table 2.1.3). Fines was the only predictor variable to be AIC selected for all five models, and was highly significant in all but the $\%$ Plecoptera richness model $(\mathrm{p}<0.001)$. Models with the largest fines coefficients were EPT richness, Ephemeroptera richness, and Trichoptera richness. Pseudo $\mathrm{R}^{2}$ values ranged from 0.30 for the Trichoptera richness model, up to 0.50 for $\%$ EPT richness model. Although likely covariates, chloride and conductivity 
were both kept in the analysis because they met the selection criteria and were weakly correlated $($ Spearman's rho $=0.30)$. Correlations with Trichoptera richness was very low for both conductivity and chloride.
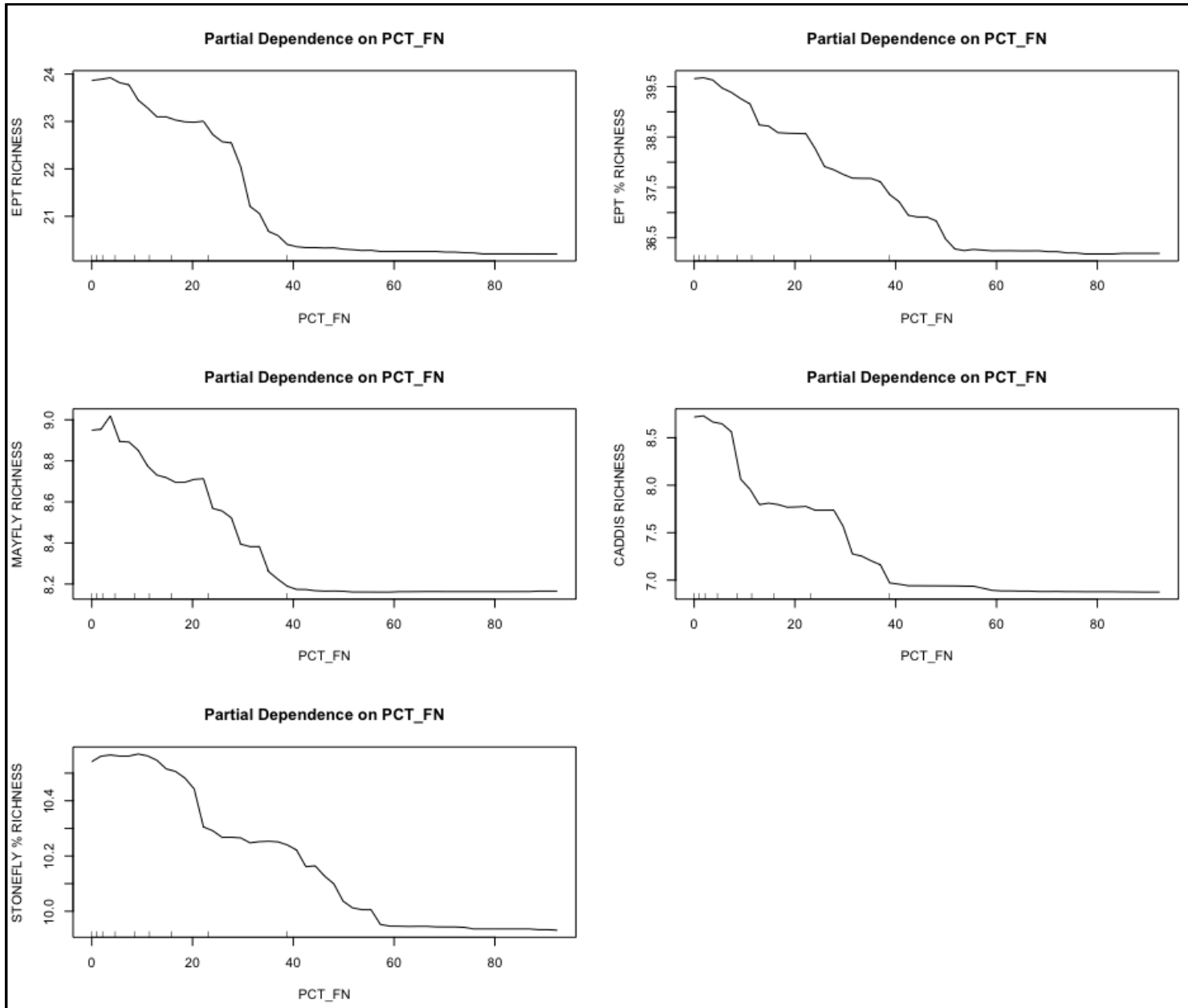

Figure 2.1.2. The partial dependence plot (PDP) shows the marginal effect percent fines has on the predicted outcome in the Random Forest learning model. This shows whether the relationship between the metric and predictor is linear or more complex. 


\section{EPT Richness}

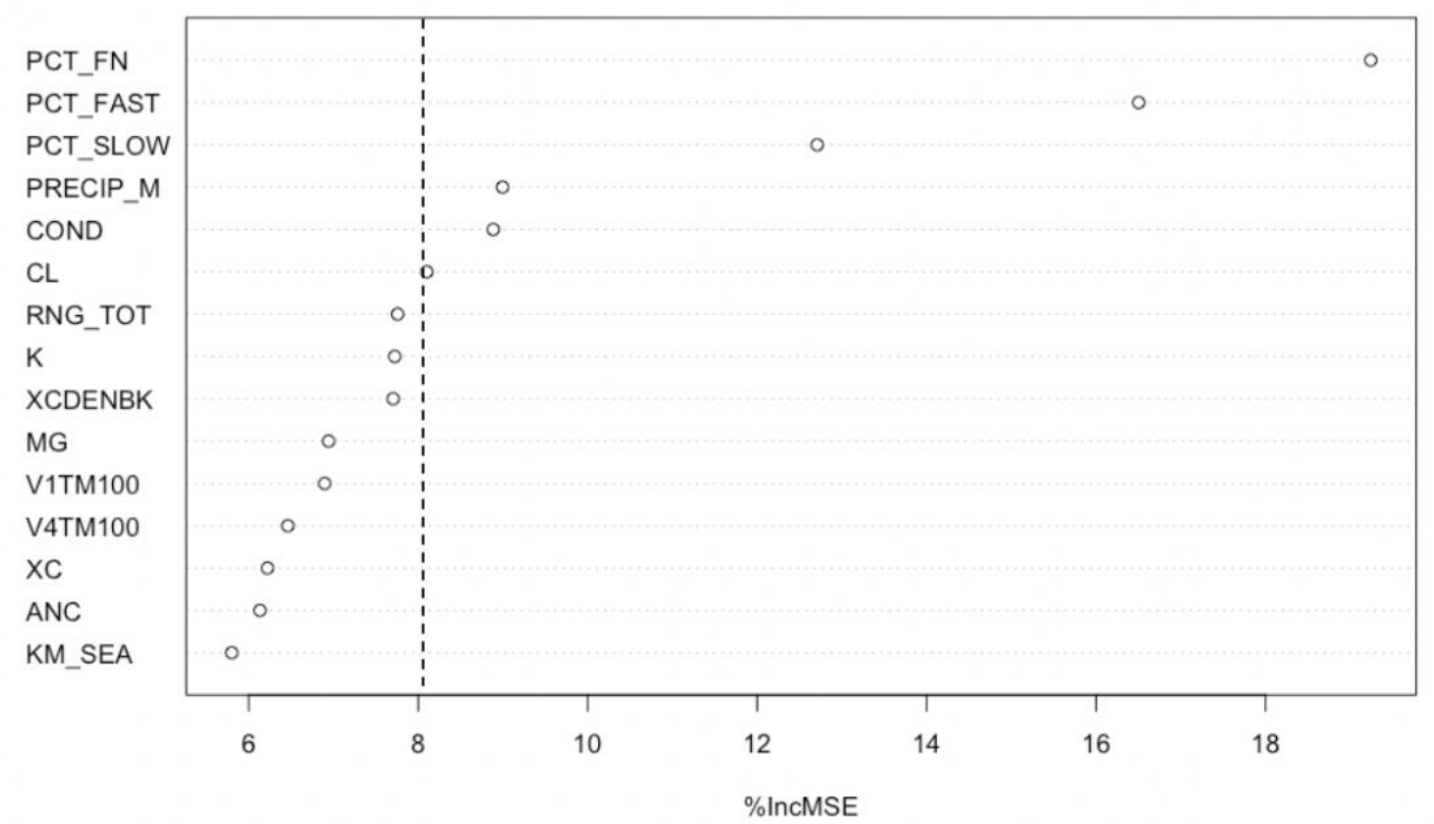

Figure 2.1.3. Variable importance plots from the EPT richness Random Forest model in Chapter 2.1. Dashed lines indicate the cut off for selecting predictor variables to be used in linear models. The X-axis shows the increase in mean square error (\%IncMSE) when a predictor variable is not included in the model. 


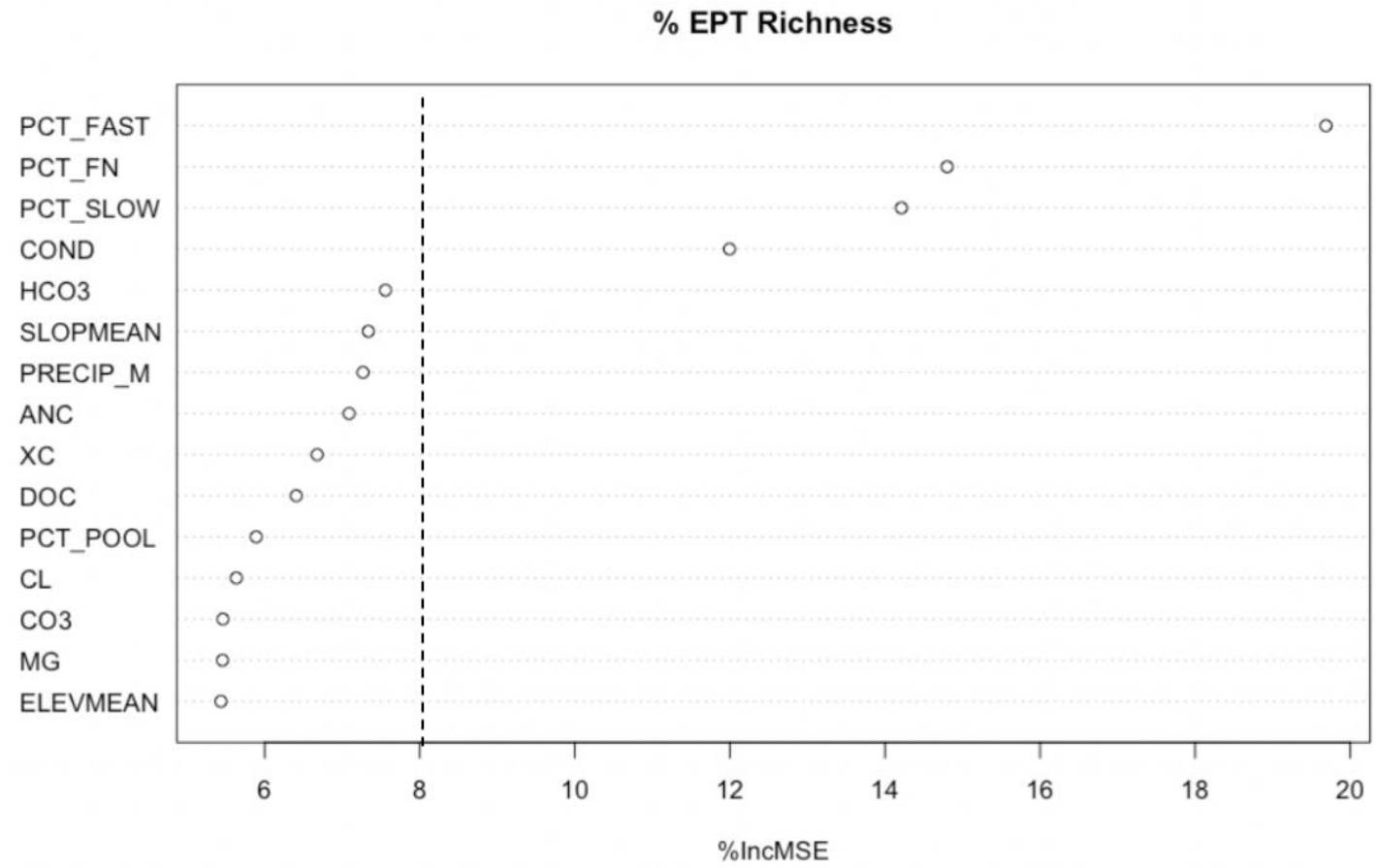

Figure 2.1.4. Variable importance plots from the \% EPT richness Random Forest model in Chapter 2.1. Dashed lines indicate the cut off for selecting predictor variables to be used in linear models. The $\mathrm{X}$-axis shows the increase in mean square error (\%IncMSE) when a predictor variable is not included in the model. 


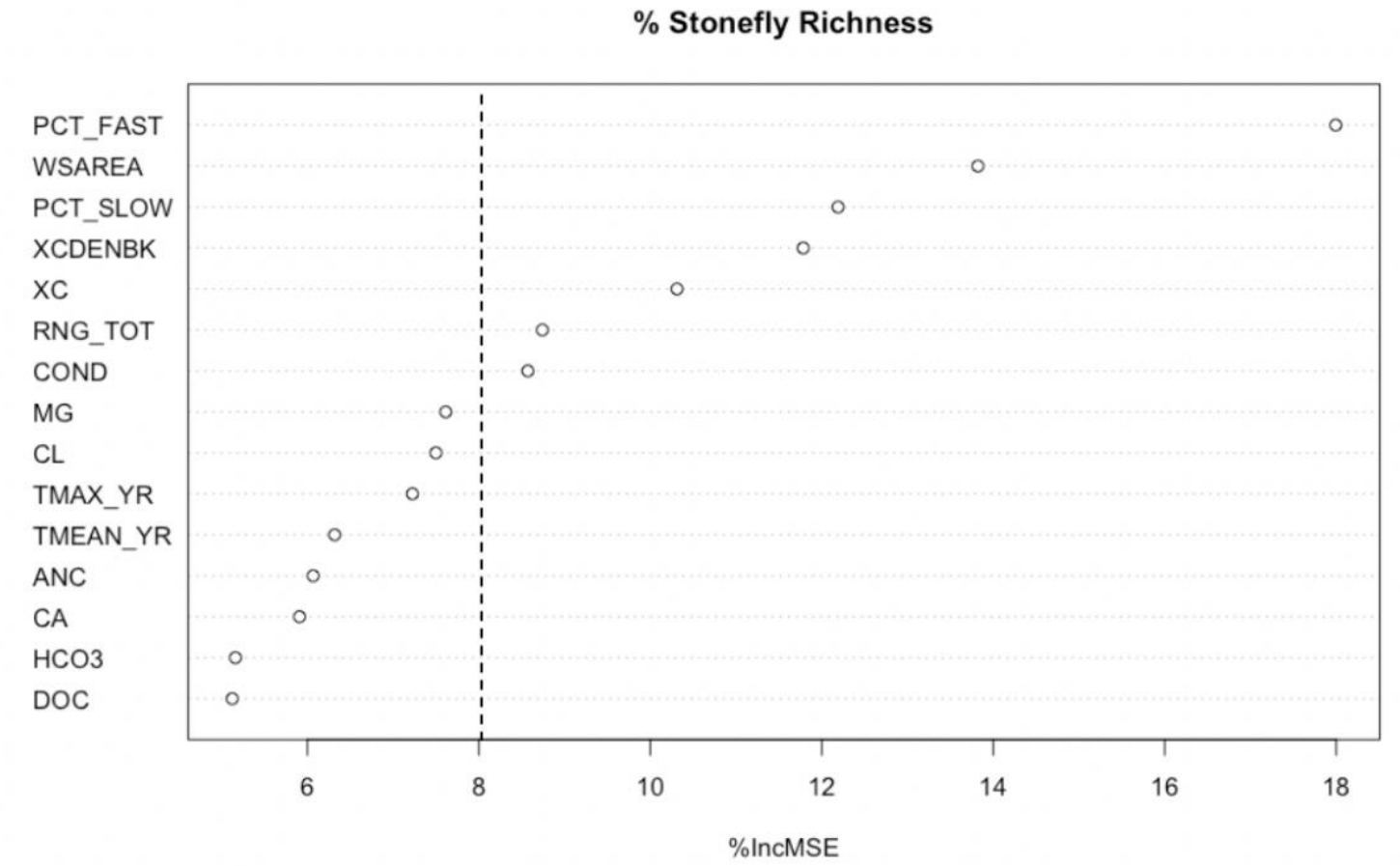

Figure 2.1.5. Variable importance plots from the \% Plecoptera (Stonefly) Random Forest model in Chapter 2.1. Dashed lines indicate the cut off for selecting predictor variables to be used in linear models. The Xaxis shows the increase in mean square error (\%IncMSE) when a predictor variable is not included in the model. 


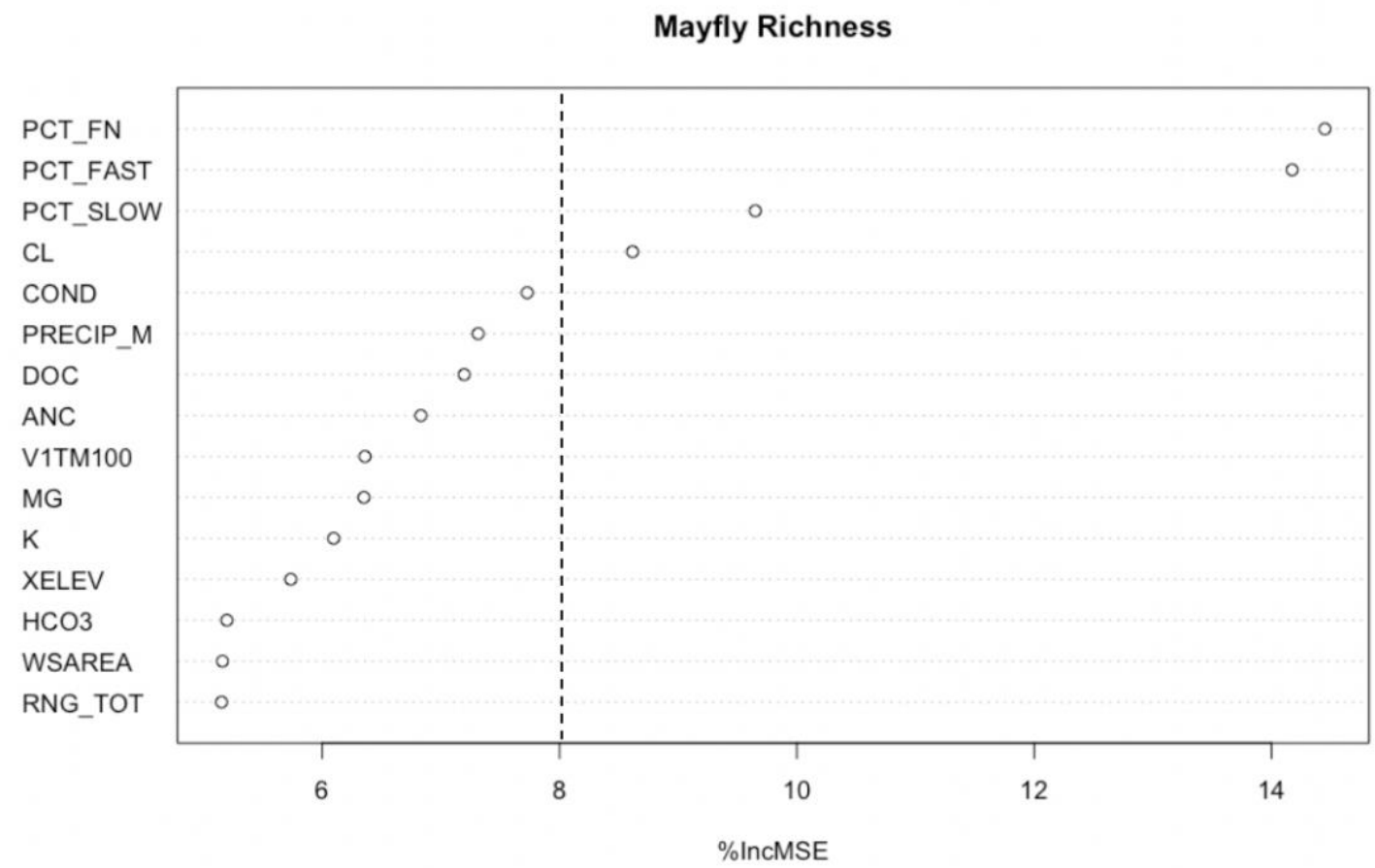

Figure 2.1.6. Variable importance plots from the Ephemeroptera (Mayfly) richness Random Forest model in Chapter 2.1. Dashed lines indicate the cut off for selecting predictor variables to be used in linear models. The X-axis shows the increase in mean square error (\%IncMSE) when a predictor variable is not included in the model. 


\section{Caddisfly Richness}

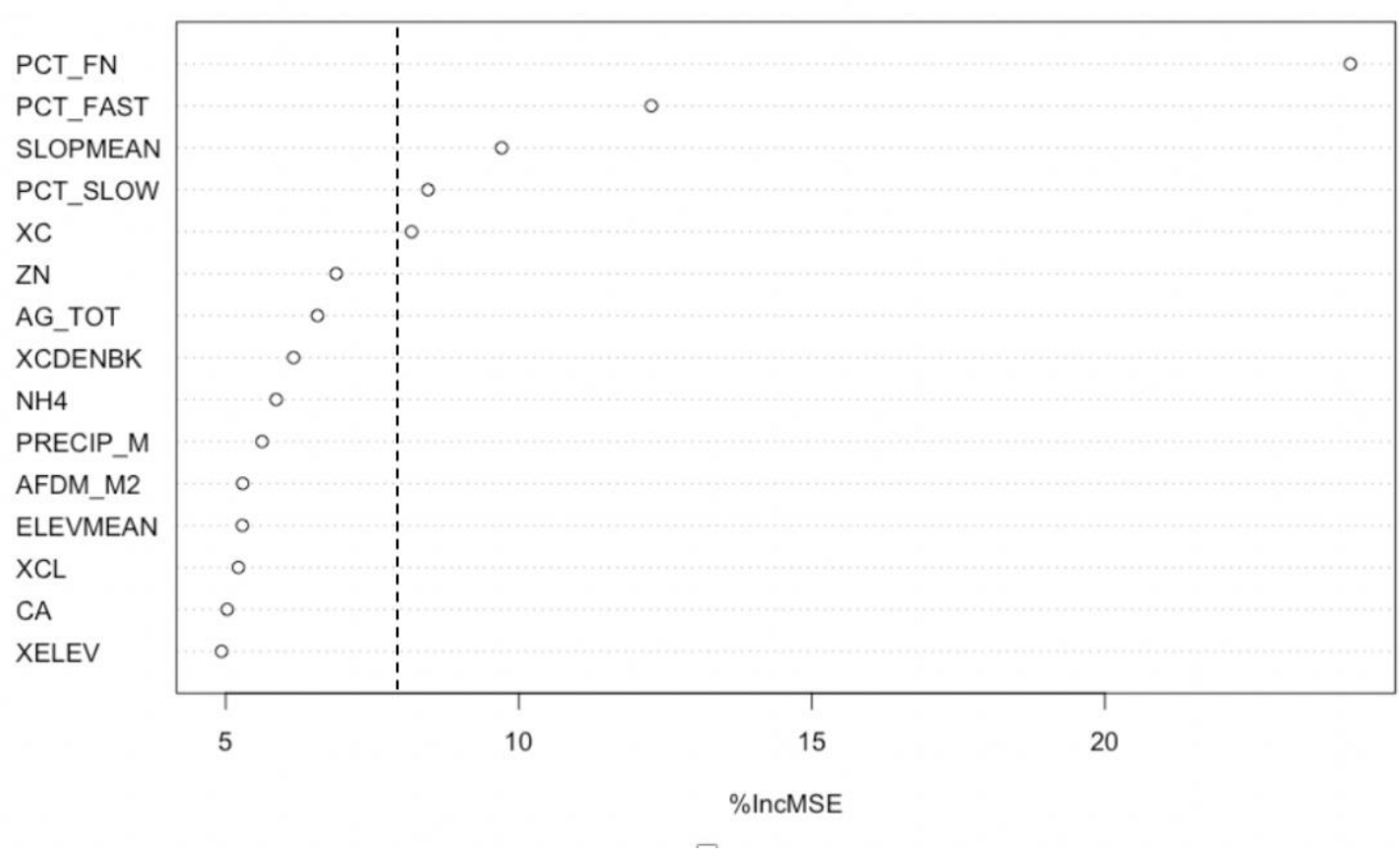

Figure 2.1.7. Variable importance plots from the Trichopera (Caddisfly) richness Random Forest model in Chapter 2.1. Dashed lines indicate the cut off for selecting predictor variables to be used in linear models. The $\mathrm{X}$-axis shows the increase in mean square error (\%IncMSE) when a predictor variable is not included in the model. 
Table 2.1.2 Random Forest development model results with the highest percent variance explained and model residuals. \% Fines mean square error is the percent increase in MSE and is a measure of variable importance affecting the accuracy of the model when \% Fines is removed. Each Random Forest development model included 60 environmental predictors.

\begin{tabular}{lll}
\hline Response (y) & $\begin{array}{l}\text { Model \% variance } \\
\text { explained }\end{array}$ & $\begin{array}{l}\text { \% Fines mean square } \\
\text { error }\end{array}$ \\
\hline \% EPT richness & 44.5 & 14.8 \\
EPT richness & 42.6 & 19.2 \\
\% Plecoptera richness & 43.4 & 3.8 \\
Trichoptera richness & 35.5 & 24.2 \\
Ephemeroptera & & \\
Richness & 28.0 & 14.5 \\
\hline
\end{tabular}


Table 2.1.3 GLM model summaries. Models were selected using an AIC step-wise selection. Predictor variables: Fines ( $\%$ benthic cover that is $<0.06 \mathrm{~mm}), \%$ of reach that is fast water (Fast), conductivity (Cond), chloride (CL), canopy density (XC). p $<0.05^{*}, \mathrm{p}<0.01^{* *}, \mathrm{p}<0.001^{* * *}$

\begin{tabular}{|c|c|c|c|}
\hline Response (y) & $\begin{array}{l}\text { Predictor variable and model } \\
\text { coefficient }\end{array}$ & Pseudo $R^{2}$ & $\begin{array}{l}\text { Residua } \\
\text { DF }\end{array}$ \\
\hline$\%$ EPT richness & $\begin{array}{l}\mathrm{y}=-0.11 \text { Fines } * * *+0.11 \text { Fast } * * *-0.06 \\
\text { Cond } * * *-0.03 \mathrm{CL}+0.11 \mathrm{XC}^{* * *}\end{array}$ & 0.5 & 145 \\
\hline EPT richness & $\begin{array}{l}\mathrm{y}=-0.19 \text { Fines } * * *+0.09 \text { Fast } * * *-0.09 \\
\text { Cond }-0.05 \mathrm{CL}^{*}+0.07 \mathrm{XC} * * *\end{array}$ & 0.43 & 145 \\
\hline$\%$ Plecoptera richness & $\begin{array}{l}\mathrm{y}=-0.04 \text { Fines }+0.21 \text { Fast } * * *-0.16 \\
\text { Cond } * * *+0.13 \mathrm{XC}^{* * *}\end{array}$ & 0.37 & 146 \\
\hline $\begin{array}{l}\text { Ephemeroptera } \\
\text { richness }\end{array}$ & $\begin{array}{l}y=-0.19 \text { Fines } * * *-0.10 \text { Cond }^{* *}-0.11 \\
C L^{* *}\end{array}$ & 0.32 & 147 \\
\hline Trichoptera richness & $\begin{array}{l}\mathrm{y}=-0.25 \text { Fines } * * *+0.10 \text { Fast }^{* * *}+0.08 \\
\mathrm{XC} * *\end{array}$ & 0.3 & 147 \\
\hline
\end{tabular}




\section{Discussion}

The results from the exploratory analysis suggest that the metrics with the most explanatory strength related to fines were EPT metrics or derivatives of EPT. Previous studies have emphasized that many EPT taxa are sensitive to fine sediment and are less abundant as deposition of fines increases (Waters 1995; Descloux, et al., 2013). Possible mechanisms are loss of habitat (Burdon, et al., 2013), reduction in food quality (Broekhuizen, et al., 2001; Hornig \& Brusven, 1986), wearing of mouthparts (Arens 1990), among many others (Jones, et al., 2012b). Furthermore, fines were the only variable to be AIC selected in all five models, illustrating its significance as an informative parameter affecting the three orders of EPT.

Trichoptera taxa appear to be more affected by fine sediments than Ephemeroptera or Plecoptera, as indicated by the linear model coefficients and \% fines mean square error (Table 2.1.3). This may be due to Trichoptera larvae dependence on silk to build nets, retreat cases, attach to the substrate, and locate prey (Merritt, et al., 2008). In this Exploratory Analysis there were over 44 case-making Trichopteran genus, and on average made up nearly $20 \%$ of the richness within EPT. I found strong negative and significant correlations between case-making Trichopteran richness and percent fines $($ rho $=-0.43, \mathrm{p}<0.001)$ as well as moderate correlations between net spinning Trichopteran richness and percent fines $($ rho $=-0.28, \mathrm{p}<0.001)$.

Research has elucidated a linkage between the tensile properties of individual Trichoptera silk fibers upon removal of multivalent cations through ethylenediaminetetraacetic acid (EDTA) chelation (Ashton, et al. 2013). A more recent 
study used Nuclear magnetic resonance and X-ray diffraction to further reveal the importance of divalent cations in the formation of aquatic silk from caddisfly larvae. These findings indicate that when the silk is treated with a cation exchange solution, the fiber morphology is demolished, leaving the silk nanofibrals warped and inconsistent (Weber, et al. 2014). This is of interest because the two most common multivalent cations found in streams are calcium and magnesium which are vital to maintaining the rigid structure of the caddis silk's beta-sheet protein structure. Sand, because of its large size, has a low surface-to-volume ratio and therefore a low electrical charge. Silt is smaller and contains a greater surface-to-volume ratio, and consequently has a higher charge. Clay is the smallest sediment particle size, and it has the highest surface-to-volume ratio, and therefore a high charge. Therefore, the smaller the particle, the more concentrate the charge. This charge allows mineral ions to adhere to the constituent soil particles. Clay, small silts, and organic matter particles are predominantly negatively charged (anions), and have the ability to hold cations from being leached or washed away. This may be topical for future studies on fines and their impact on stream insects because fines will carry a higher negative charge and potentially stick to multivalent cations making them less bioavailable. This may also be why conductivity showed up as one of the more significant predictors in regards to the EPT related metrics within the Random Forest model. Currently, research is being published touting caddisfly larvae as "ecosystem engineers", indicating their silken fibers may modify sediment transport regimes along stream bottoms (Albertson, et al. 2019). Furthermore, Trichoptera nets and cases may be 
clogged with fine sediment, leading to an increase in cleaning or abandonment (Edington \& HIldrew, 1995; Strand \& Merritt, 1997).

Plecoptera are much larger and typically prey on smaller insects. Their larger size might make them less vulnerable to the effects of saltating sediments and abrasion. The effect of fines on Plecoptera taxa in the literature is varied, with some showing a sensitivity to increasing fines (Hubler, et al., 2016; Gieswein, et al., 2018) and others showing no effect (Peckarsky, 1991). This may be due to their distribution in currents with higher velocities and increased oxygen supply (Gentai-Kato, et al., 2005); areas of the streambed where fines are unlikely to settle. Two studies have shown Plecoptera to be tolerant of fine sediment and dig through it to feed (Peckarsky, 1991; Zanetell \& Peckarsky, 1996).

Other environmental variables affecting EPT and its derivatives included canopy cover and percent fast water, the mechanisms of which are likely related to natural gradients in stream size. In these ecoregions, I found high EPT richness associated with headwater streams, steep slopes, and cooler stream temperatures. This makes sense under the River Continuum Concept, which describes a downstream longitudinal shift of macroinvertebrate communities due to habitat change and energy inputs (Vannote, et al., 1980). Both chloride and conductivity were also important chemical predictors associated with EPT which supports other studies that have found increased salt concentrations to negatively impact Ephemeroptera taxa (Beerman, et al., 2018). Macroinvertebrate toxicity to high freshwater salinity may be the result of ion turnover (to maintain homeostasis) being energetically costly, uptake of $\mathrm{Na}+$ exchanged for hydrogen ion 
leading to a loss of $\mathrm{pH}$ regulation, or localized $\mathrm{Na}+$ toxicity from high ion turnover as salinity increases (Kefford, 2018). Solutes including chloride and fine inorganic sediment obey similar hydrologic routes into streams and are likely elevated in tandem (Feller, 2005). In both the Coast Range and Cascades, elevated solute sources in streams may be derived from timber harvesting within the watershed and (or) proximity to the ocean (Feller, 2005). Precipitation close to the ocean often contain relatively high concentrations of sea salts (Edmonds, et al., 1998), and subsequently $\mathrm{Na}+$ and $\mathrm{Cl}-$ concentrations near the west coast of North America having heavy rainfall (i.e. Coast Range and Cascades) could be influenced by precipitation (Dethier, 1979; Wigington Jr., et al., 1998), but not always (Feller \& Kimmins, 1979). These natural gradients present a challenge to using EPT richness metrics as bioindicators for regulatory purposes (Wagenhoff, et al., 2012).

Acknowledging that natural gradients (i.e. stream size, slope) affect EPT (Beerman, et al., 2018) makes confident applications of EPT richness as an indicator for fine sediment difficult for stream managers. EPT metrics are related to changes in water quality degradation from different sources including urban development, agriculture, and sediment. Biological responses to anthropogenic pollution also rely on natural conditions. The main limitation in the regulatory setting is determining EPT declines from excess fine sediment and not from other sources. Disentangling natural variability from anthropogenic fine sediment by-products presents a major issue. The objective for watershed management measures should be to detect excess fine sediment, not natural variability, using appropriate diagnostic indices and metrics (Collins, et al., 2012). Since 
the predictors were standardized in the models, the importance of fine sediment is supported by its steep negative coefficients compared to other predictors.

This analysis suggests that EPT metrics may be a good candidate biomonitoring tool for fine sediments; however, these findings need further validation by studies specifically designed for a gradient of fine sediment conditions. Selecting future watersheds to test how EPT taxa respond to a gradient of fine sediment should consider stream size, proximity to ocean, and local timber harvest practices to control for variables that covary with fines. Future experiments investigating EPT as a bioindicator for fines could benefit from 1) utilizing or developing a sediment extraction methodology that objectively quantifies both sediment mass and proportions of the substrate, 2) sampling in areas that are less influenced by salt solutes from precipitation or ocean proximity, and 3) exploring EPT functional trait responses to distinguish sediment stressors from other forms of pollution. Developing a method to simultaneously sample fine sediment and macroinvertebrates would provide a more in-depth understanding than reach-scale sampling methods used in the WEMAP study. 


\subsection{Feasibility Study: Evaluating a field method for simultaneously sampling fine sediment and stream macroinvertebrates}

\section{Introduction}

Studies investigating the relationship between macroinvertebrates and fine sediment do not routinely collect them together. In most large-scale monitoring efforts, sediment measurements are estimated for the entire reach (Peck, et al., 2006; USEPA, 2017). Processing the large amount of benthic material and its associated costs are the limiting factor in benthic research. The amount of time and resources to collect, sort, identify, and measure both sediments and macroinvertebrates is not always available to stream monitoring programs. To meet monitoring and assessment needs, federal contracting is not uncommon. Given those constraints, it can be a challenge to detect impacts to macroinvertebrates due to sample processing concerns. This may result in compromises in sample design, limiting sample size and statistical power (Lorenz, et al., 2004; Carter \& Resh, 2001).

Protocols to quantify deposited fine sediment are routinely called into question due to their subjective nature. Common methods used by both researchers and monitoring agencies are rapid assessments (Faustini \& Kaufmann , 2007), involving visual estimates of the substrate (Descloux, et al., 2010) or the Wolman pebble count (Wolman, 1954). Uncertainties associated with these methods include observer bias, variability between operators, and inconsistent training among field crews. These involve technicians estimating the fine sediment in terms of the percent cover of a reach, measuring $100-$ 
110 particles to represent the entire reach. Pebble counts are synoptic, encountering a variety of habitats that may not characterize stream substrate heterogeneity.

Classifications commonly follow the Wentworth system (Wentworth, 1922): silt and clay $(<0.06 \mathrm{~mm})$, sand $(<2 \mathrm{~mm}>0.06 \mathrm{~mm})$, gravels/pebbles $(2-64 \mathrm{~mm})$, cobbles $(64-256$ $\mathrm{mm}$ ), and boulder (>256 mm) (Clapcott, et al., 2011). The precision error (Root Mean Square Error) for WEMAP's fine sediment protocol was $7.4(\%)$ for Oregon replicate samples (Kaufmann, et al., 1999). This indicates that the average estimation difference between visits was $7.4 \%$. High measurement precision for the visually estimated data may be due to observers placing data into just seven size classes (Whitacre, et al., 2007).

A number of other technical approaches to quantify fine sediment in streams exist (Bunte \& Abt, 2001; Sutherland, et al., 2010; Clapcott, et al., 2011). Such techniques vary from accumulation methods like sediment traps (Kozerski, 2002), adhesives (Marion \& Faccarollo, 1997), remobilization methods (Duerdoth, et al., 2015), and freeze-core methods (Carling \& Reader, 1981). Table 3.2.1 lists the conventional approaches used for quantifying benthic fine sediment, adapted from Turley et al. (2017).

Findings from my Exploratory Analysis indicated that much of the change in EPT and its derivatives can be attributed to changes in fine sediment percent cover $\left(R^{2}=0.3-\right.$ 0.5). I needed to develop a methodology that would capture both the fine sediment percent cover, the magnitude of benthic fines, and macroinvertebrates from the same sampling location. Having an absolute mass measurement for each sediment size class is important to quantify because fine sediment percent cover is contingent upon other sediment size classifications. Each measurement has its own drawbacks (total mass 
contingent upon methodology), but together could represent an improved interpretation of how fine sediment affects macroinvertebrates (Figure 2.2.1).

For bioassessment, pebble count measurements are often used for streambed assessment and are conducted concurrently with macroinvertebrate sampling (USEPA, 2017), then used as indicators of sedimentation in TMDLs or other modeling efforts to limit sediment loading. At the reach-scale, pebble count measurements may be improper for detecting excess fine sediment impacts on macroinvertebrate assemblages.

Relationships between macroinvertebrates and substrates could be poorly characterized due to the wide range of habitats which are sampled and composited using pebble counts and reach-scale macroinvertebrate samples (Longing, et al., 2010; Bryce, et al., 2010). I conducted a feasibility study in June 2018 to test methodology for extracting benthic sediments and macroinvertebrates in tandem. Since sediment size and carrying capacity are primarily determined by stream flow velocity, reduction in flow velocities should cause fine particle in suspension to deposit. In essence, do higher velocity flows allow fine sediment deposition or are stream margins a more predictable location to sample when investigating benthic fines and macroinvertebrates? The research questions were 1) do positive correlations exist between depositional/mixed zones and fines and 2) do EPT taxa negatively correlate with fines? 
Table 2.2.1 The conventional approaches used for quantifying benthic fine sediment, adapted from Turley et al., 2017.

\begin{tabular}{|c|c|c|}
\hline Technique & Description & Reference \\
\hline Particle Counts & $\begin{array}{l}\text { - Wolman pebble count. Particles are selected at random, by } \\
\text { sampling using toe-to-heel spacing and selecting the first } \\
\text { particle touched by a finger at the toe of the operator's boot. } \\
\text { Transects between bankfull widths within habitats of interest } \\
\text { (or a zigzag pattern) are followed until } 100 \text { particles are } \\
\text { selected. } \\
\text { - Wolman pebble count (modified). Grid-by-number methods } \\
\text { using a measuring tape, wire mesh or frame with elastic bands } \\
\text { to select particles. } \\
\text { - Wolman pebble count (modified). Toe-to-heel approach is } \\
\text { used in conjunction with a clay disc and piston, which is } \\
\text { pressed onto the streambed to sample fine sediment. }\end{array}$ & $\begin{array}{l} \\
\text { (Kellerhals \& } \\
\text { Bray, 1971) } \\
\text { (Fripp \& Diplas, } \\
\text { 1993) }\end{array}$ \\
\hline $\begin{array}{l}\text { In-stream visual } \\
\text { estimate }\end{array}$ & $\begin{array}{l}\text { - A measuring tape is placed between the beginning and end of } \\
\text { a transect. At } 0.3 \mathrm{~m} \text { increments, the dominant sediment class } \\
\text { over the length is recorded. } \\
\text { - Using an underwater viewer, the percentage cover of fine } \\
\text { sediment is then estimated. }\end{array}$ & $\begin{array}{l}\text { (Platts, et al., } \\
\text { 1983) } \\
\text { (Matthaei, et al., } \\
\text { 2006) }\end{array}$ \\
\hline $\begin{array}{l}\text { Bankside visual } \\
\text { Estimate }\end{array}$ & $\begin{array}{l}\text { - Substrate composition is estimated upon a visual inspection of } \\
\text { the reach from the stream bank. }\end{array}$ & $\begin{array}{l}\text { (Environmental } \\
\text { Agency, 2003) }\end{array}$ \\
\hline $\begin{array}{l}\text { Photographic } \\
\text { image analysis }\end{array}$ & $\begin{array}{l}\text { - Above water image capture. Areas of substrate are } \\
\text { photographed using a photographic film camera, an underwater } \\
\text { viewer and a structure to isolate the area of streambed. } \\
\text { Photographic transparencies were then projected at three times } \\
\text { life size and onto a grid with } 400 \text { squares. The predominant } \\
\text { particle size in every fourth square was then recorded. } \\
\text { - Similar to the technique used by Gee (1979), with the addition } \\
\text { of a digitizing program to obtain the particle size distribution. } \\
\text { Ibbeken and Schleyer, } 1986 \\
\text { - Areas of substrate are photographed from above the water } \\
\text { using a photographic film camera and underwater viewer. } \\
\text { Photographic transparencies are digitized and analyzed using } \\
\text { Geographic Information Software. }\end{array}$ & $\begin{array}{l}\text { (Ibbeken \& } \\
\text { Schleyer, 1986) } \\
\text { (Whitman, et al., } \\
\text { 2003) }\end{array}$ \\
\hline Artificial Mats & $\begin{array}{l}\text { - Artificial turf mats }(0.15 \mathrm{~m} \times 0.10 \mathrm{~m}) \text { are fixed to the } \\
\text { streambed and left for } 3 \text { weeks. Mats are carefully retrieved and } \\
\text { placed in zip-lock bags and returned to the laboratory where the } \\
\text { sediment is washed out, sieved and collected for drying and } \\
\text { weighing. }\end{array}$ & $\begin{array}{l}\text { (Von Bertrab, et } \\
\text { al. 2013) }\end{array}$ \\
\hline Resuspension & $\begin{array}{l}\text { - A steel cylinder measuring } 1 \mathrm{~m} \text { in height is pushed } 0.1 \mathrm{~m} \text { into } \\
\text { the streambed. The water within the cylinder is agitated, } \\
\text { artificially suspending the surficial fine sediment, allowing for } \\
\text { three } 0.5 \mathrm{~L} \text { samples to be collected. This process is carried out } \\
\text { at three or more 'representative' sites, and samples are used to } \\
\text { determine the mean mass of sediment released. } \\
\text { - Modified from Lambert and Walling (1988), using a steel } \\
\text { cylinder measuring } 0.75 \mathrm{~m} \text { in height. Samples of } 0.05 \mathrm{~L} \text { are }\end{array}$ & $\begin{array}{l}\text { (Duerdoth, et al., } \\
\text { 2015) }\end{array}$ \\
\hline
\end{tabular}




\begin{tabular}{|c|c|c|}
\hline & $\begin{array}{l}\text { collected from two depositional and two erosional patches at } \\
\text { each site. }\end{array}$ & \\
\hline Adhesive plates & $\begin{array}{l}\text { - A plate is covered with a thin layer of adhesive material (i.e. } \\
\text { clay) and is pressed onto the streambed. The sample is then } \\
\text { wet-sieved to remove the clay. }\end{array}$ & $\begin{array}{l}\text { (Fripp \& Diplas, } \\
\text { 1993) }\end{array}$ \\
\hline Embeddedness & $\begin{array}{l}\text { - Qualitative assessment using five categories relating to the } \\
\text { percentage that large particles were covered by fine sediment. } \\
\text { Platts et al., } 1983 \\
\text { - Qualitative assessment of embeddedness using three } \\
\text { categories: } 1 \text { = lying loosely on top of the bed, } 2=\text { partly } \\
\text { covered by surrounding substratum, } 3 \text { = well buried in the } \\
\text { surrounding substratum or firmly wedged in by surrounding } \\
\text { stones. Matthaei et al., } 1999 \\
\text { - Assessment of embeddedness over } 11 \text { transects ( } 55 \text { particles) } \\
\text { by estimating the percentage embeddedness of each particle. }\end{array}$ & $\begin{array}{l}\text { (Platts, et al., } \\
\text { 1983) } \\
\text { (Matthaei, et al., } \\
\text { 1999) } \\
\text { (Peck, et al., } \\
\text { 2006) }\end{array}$ \\
\hline
\end{tabular}




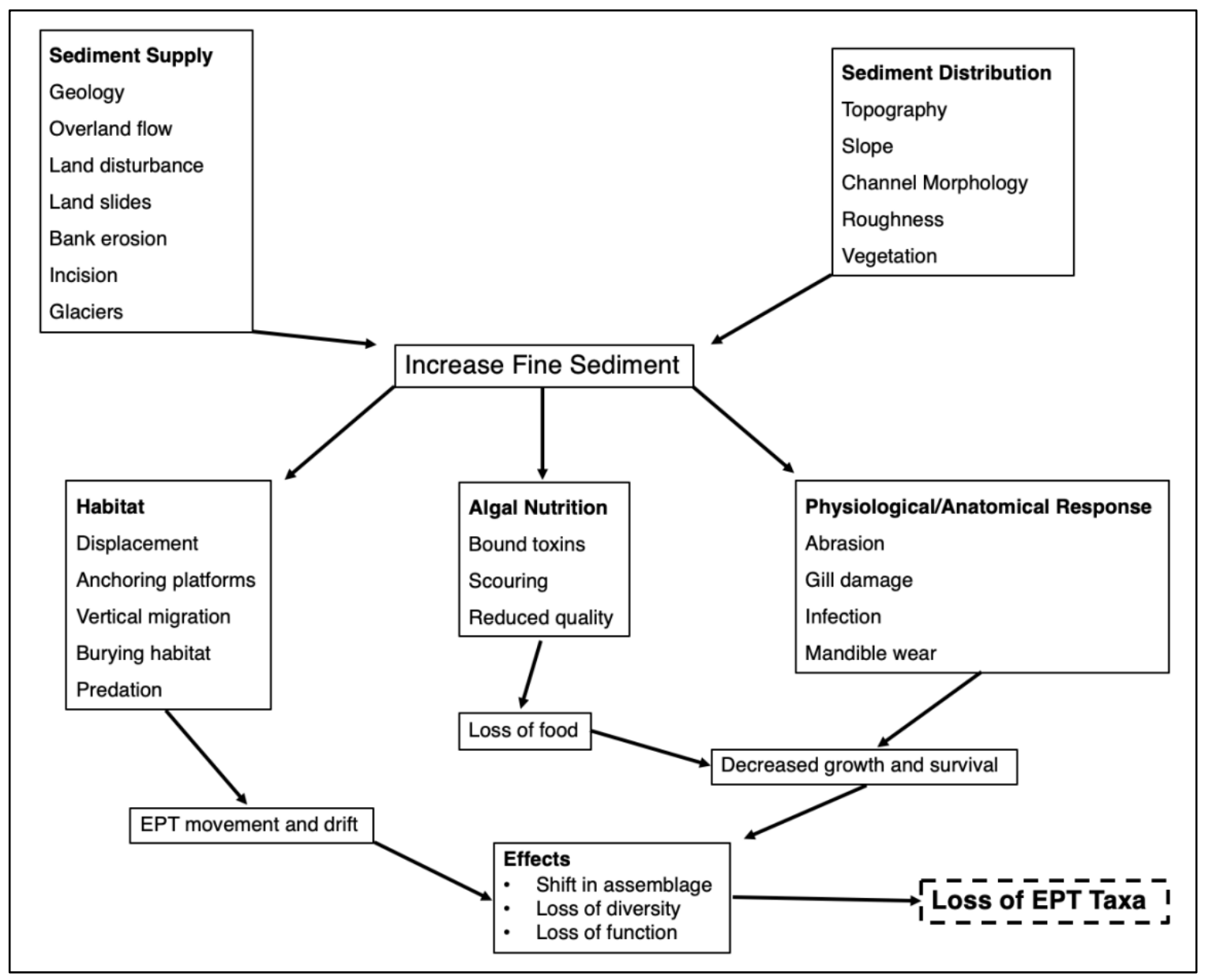

Figure 2.2.1. Schematic diagram showing sources of fine sediment in streams and mechanistic effects on EPT and their habitat.

\section{Methods}

The study took place near the mouth of Clear Creek, a tributary of the Clackamas River in the Willamette Valley of Oregon. The watershed is $189 \mathrm{~km}^{2}$, made up primarily of evergreen forest (47\%), pasture (18\%), and cultivated crops $(5 \%)$, with $11.3 \mathrm{~km}$ of its length in agricultural areas (Homer, et al., 2011). Soil in the watershed is predominantly Type C with moderately high runoff potential (United States Department of Agriculture, National Resource Conservation Service., 2019). Elevation ranges from 28.4 meters to 1287.4 meters, and annual precipitation is $172.8 \mathrm{~cm}$. I selected this stream because it was 
easily accessible, included mixed land uses, and contained a visible lateral gradient of sedimentation across the channel width.

Three transects were selected roughly $100 \mathrm{~m}$ apart from one another in run or glide hydrology (not pools or riffles). I selected uniform runs and glides because it is easier to locate when the thalweg is in the middle of the channel, which was desirable in this case. Transects were 100 meters apart because it was the maximum distance that was feasible to transport gear and equipment to the staging area.

I measured the wetted width (WW) at each transect, and sampling locations were at $5 \% \mathrm{WW}, 25 \% \mathrm{WW}$, thalweg (point in transect with the deepest depth), $75 \% \mathrm{WW}$, and 95\% WW (Figure 2.2.1). This yielded 5 samples per transect and 15 samples total. I considered sample locations erosional if they were from the thalweg or measured with a velocity exceeding $1 \mathrm{~m} / \mathrm{s}$. I demarcated sampling sites with washers covering a $0.09 \mathrm{~m}^{2}$ area. I sampled sites by placing a $0.30 \mathrm{~m}$ wide aquatic $\mathrm{D}$ net (500 micron mesh) directly downstream of the sample location into the substrate and using a hand-operated bilge pump (Beckson 136 Series (Figure 2.2.2)) to vacuum both macroinvertebrates and sediments simultaneously. By removing the filtering end cap, the pump and hose attachment vacuumed all sediment (up to $10 \mathrm{~g}$ gravels) and macroinvertebrates. I used a five-gallon paint bucket to collect the vacuumed material (Figure 2.2.3).

I vacuumed sample locations for 30 seconds (16 pumps roughly equivalent to 30 seconds $=\sim 4$ gallons) in a continuous configuration across the sample area. Upon removal of the bilge pump, I used an additional vacuum pump of surface water to clear any residual sediments or macroinvertebrates through the bilge hose. There was an 
additional thirty seconds of agitation to the substrate to collect any remaining macroinvertebrates in the D net after removal of the bilge pump. I emptied the D net accumulations into their respective buckets. This resulted in roughly 4-5 gallons of water and benthic material per each sample location. I mixed each sample bucket with one pint of $70 \%$ isopropyl alcohol to preserve specimens until the following day. I decanted the buckets then filled them with one pint of 70\% isopropyl alcohol. At each sample location, I also measured velocity, chlorophyll a, and depth. Depth was measured at each sampling location using a rod and tape measure. I measured stream velocity using a velocimeter (Flo-Mate Model 2000) at each sampling location by placing the velocimeter probe on the wading rod at 0.6 of the measured depth below the water surface, and placing the probe directly into the current. Measurements were taken after 30 seconds. I measured chlorophyll a by scraping periphyton off of three rocks, then using an Aquaflour fluorometer following EPA methodology 445.0 (Arar \& Collins, 1997).

I individually removed macroinvertebrates from sediments in the five-gallon bucket, then identified them to the family level and completely counted. I identified macroinvertebrates using Aquatic Insects of North America (Merritt, et al., 2008). I labeled samples and specimens then preserved them for quality control. I calculated macroinvertebrate metrics and entered them into a data table. Metrics included total abundance, total richness, EPT richness, EPT abundance, percent EPT richness, percent EPT individuals, and EPT derivatives (i.e. Ephemeroptera richness, abundance, \% Ephemeroptera richness, \% Ephemeroptera abundance). 
I established sediment percent cover by decanting water out of the buckets and retaining what remained at the bottom. I then placed the sediment into a tray and dried it in the oven at 100 degrees Celsius for 24 hours. The mass of the dried material was taken for each sample. I converted the dried material into ash free dry weight (AFDW) using a muffle furnace at 500 degrees Celsius for one hour. I sieved samples into three size classes: course substrate greater than $2 \mathrm{~mm}$ in diameter, sands smaller than $2 \mathrm{~mm}$ in diameter and larger than $0.063 \mathrm{~mm}$ diameter, and fines smaller than $0.063 \mathrm{~mm}$ in diameter. I weighed the size classes to achieve class mass and sediment percent cover at each sample location. I calculated sediment percent cover by dividing the mass of the class (i.e. sand) by the total inorganic mass and multiplying by 100 .

Data analysis

The objective of the analysis was to evaluate if the methodology found expected correlations between EPT metrics and environmental predictors. Prior to the correlation analysis I checked distributions of my data for normality and linearity using frequency distributions, boxplots, and q-q plots. I used Spearman's correlation analysis to investigate bivariate relationships between all macroinvertebrate metrics and environmental predictors (Appendix A-3). I used Spearman's correlation because it is more appropriate for data that does not have a normal distribution. 


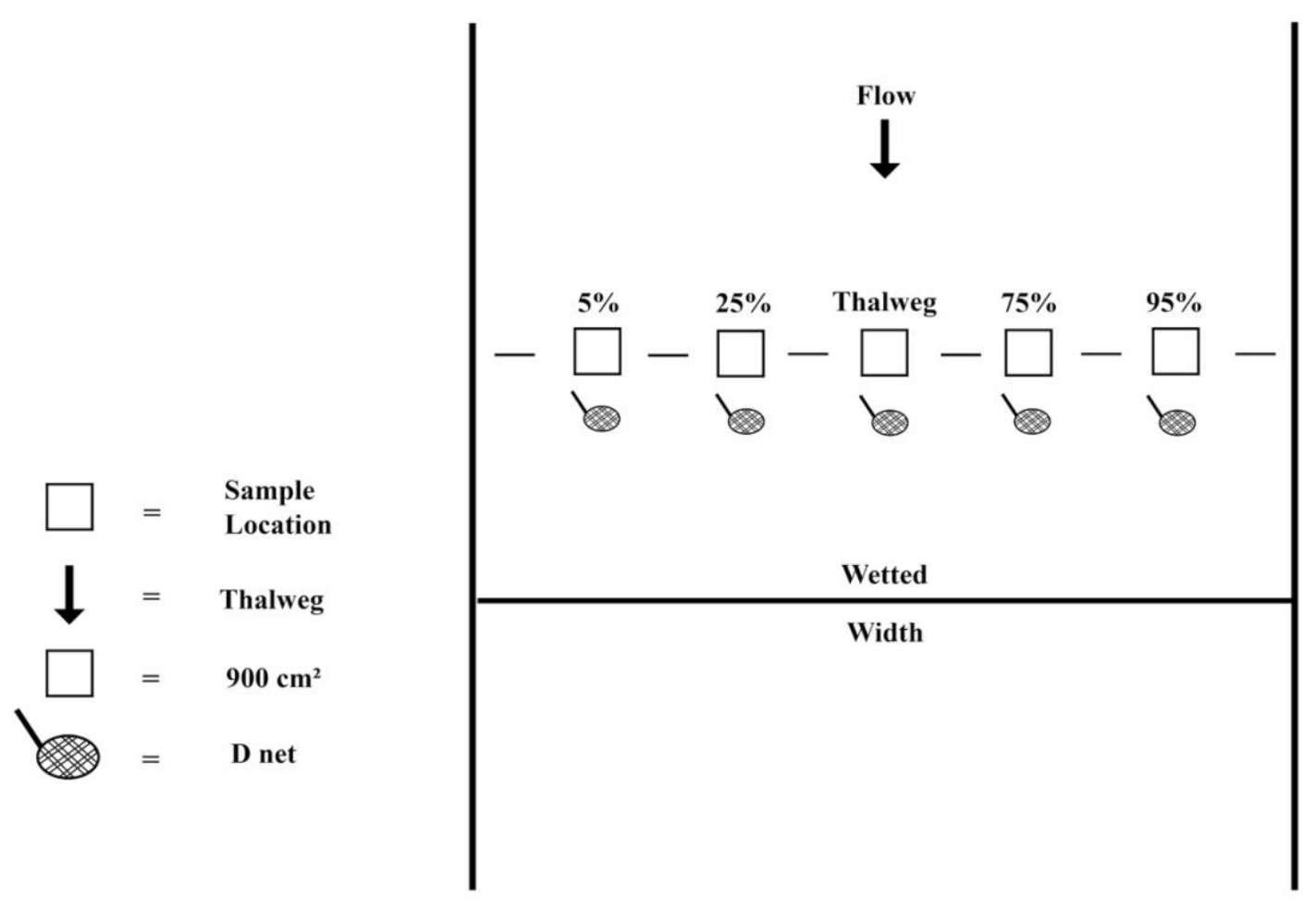

Figure 2.2.2 Sampling schematic in transect indicating placement of D net, the five sampling locations, and typical thalweg location. 


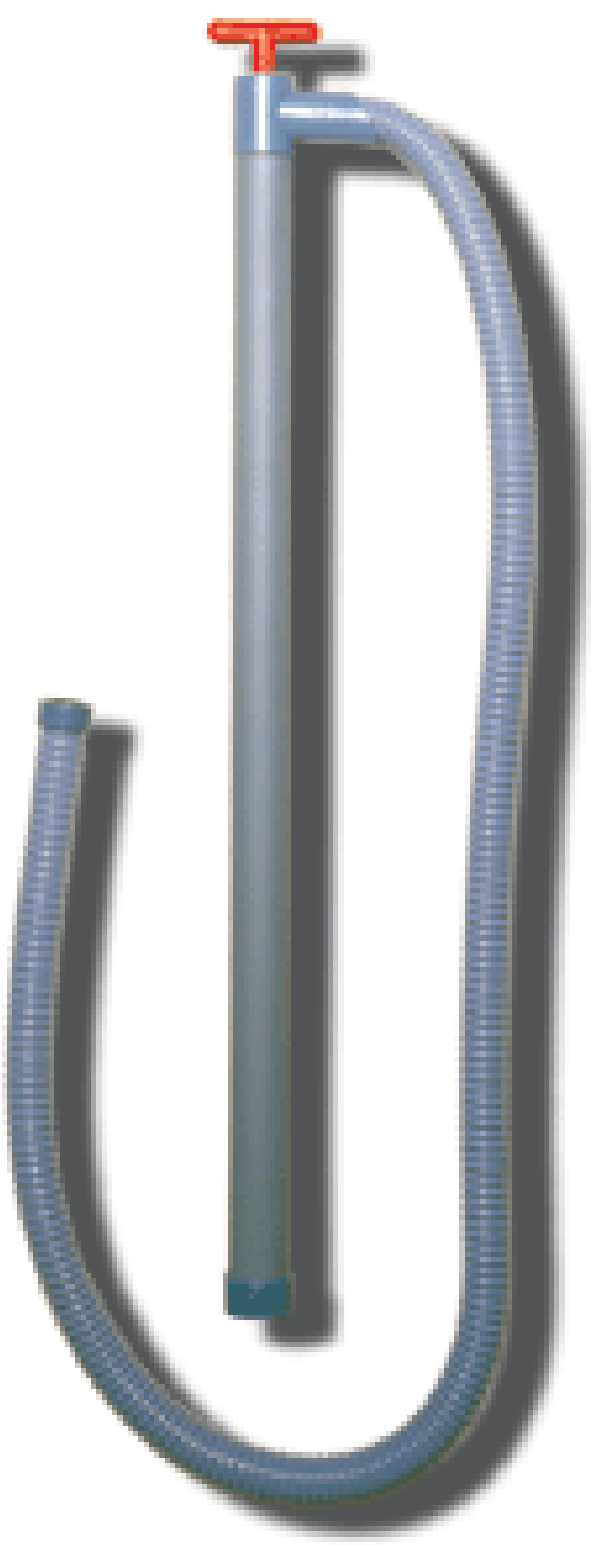

Figure 2.2.3 Beckson 136 series pump used to vacuum suction sediment from sample location. 


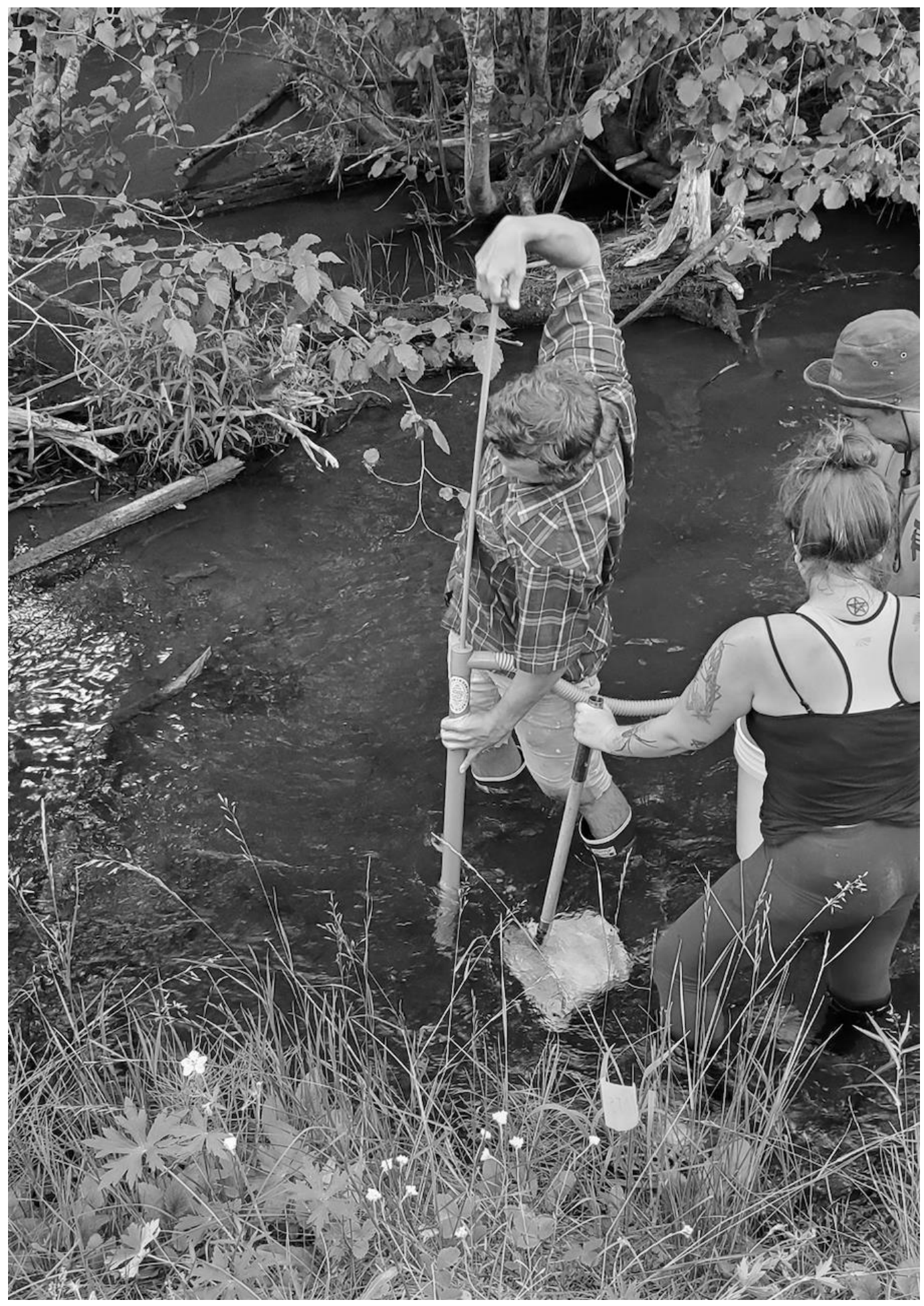

Figure 2.2.4 Image of crew layout during the sampling process. One crew member is operating the vacuum bilge pump in a continuous pattern across sample space while the other crew members hold the $\mathrm{D}$ net and five-gallon collection bucket. 
Results

Ten samples were depositional and five were erosional. Inorganic sediment mass per sample ranged from around $22 \mathrm{~g}$ to $677 \mathrm{~g}$ with a mean of $122 \mathrm{~g}$. The proportion of benthic fines ranged from $0.46 \%$ to $8.80 \%$ with a mean of $3.23 \%$ (Figure 2.2 .4 ). Mass of fines ranged from $0.15 \mathrm{~g}$ to $24.20 \mathrm{~g}$, with a mean of $4.81 \mathrm{~g}$ (Figure 2.2.5). Sand was the dominant substrate at nearly all sample locations $(7.04 \mathrm{~g}-641.33 \mathrm{~g})$ followed by gravel (4.40 g - 78.69 g). On average, depositional sample locations had six grams more fine sediment and were $2 \%$ higher (Table 2.2.2). Although the depositional samples had more macroinvertebrates per sample, on average there were less EPT taxa and EPT richness, with most of the abundance from Chironimidae taxa (Table 2.2.2). The Glossomatidae family was the overall dominant taxa in the erosional samples (median abundance $=15$ ), while Heptageniidae was the dominant EPT taxa in the depositional samples (median abundance $=11)$

The association between mass of fines and velocity (Figure 2.2.6) was significantly and negatively correlated (Spearman's rho $=-0.78, \mathrm{p}=<0.001$ ) while percent fines and velocity were also significantly and negatively correlated (Spearman's rho $=-0.52, p=0.049)$. The total abundance of macroinvertebrates was positively correlated with both the mass of fines and sands, but negatively correlated with velocity (include correlation coefficients). Of the EPT metrics, percent EPT richness was strongly negatively correlated with mass of fines, but not percent fines (Figure 2.2.7), while EPT abundance was weakly negatively correlated with percent fines. Both EPT richness and percent EPT richness were strongly positively correlated with velocity (Figure 2.2.7). 
Table 2.2.2 Summary statistics of variables relevant to the purpose of the Feasibility Study. Erosional samples were defined as being in the thalweg or having a velocity greater than $1 \mathrm{~m} / \mathrm{s}$. Numbers in parenthesis are the range of values.

\begin{tabular}{llll}
\hline & Depositional & Erosional & Combined \\
\hline Samples & 10 & 5 & 15 \\
$\begin{array}{l}\text { Median mass of } \\
\text { Fines }\end{array}$ & 1.7 & 0.8 & $1.2(0.2-24.2)$ \\
$\begin{array}{l}\text { Median \% Fines } \\
\text { Median velocity }\end{array}$ & 2.8 & 2.0 & $2.1(0.5-8.8)$ \\
Median abundance & 156 & 1.3 & $0.6(0.1-2.4)$ \\
$\begin{array}{l}\text { Median richness } \\
\text { Median EPT }\end{array}$ & 12 & 94 & $107(42-466)$ \\
$\begin{array}{l}\text { abundance } \\
\text { Median EPT }\end{array}$ & 29.5 & 12 & $12(7-17)$ \\
$\begin{array}{l}\text { richness } \\
\text { Median \% EPT } \\
\text { richness }\end{array}$ & 50 & 57 & $47(6-90)$ \\
\begin{tabular}{l} 
Dominant taxa \\
\hline
\end{tabular} & Chironimidae & Glossosomatidae & Chironimidae \\
\hline
\end{tabular}




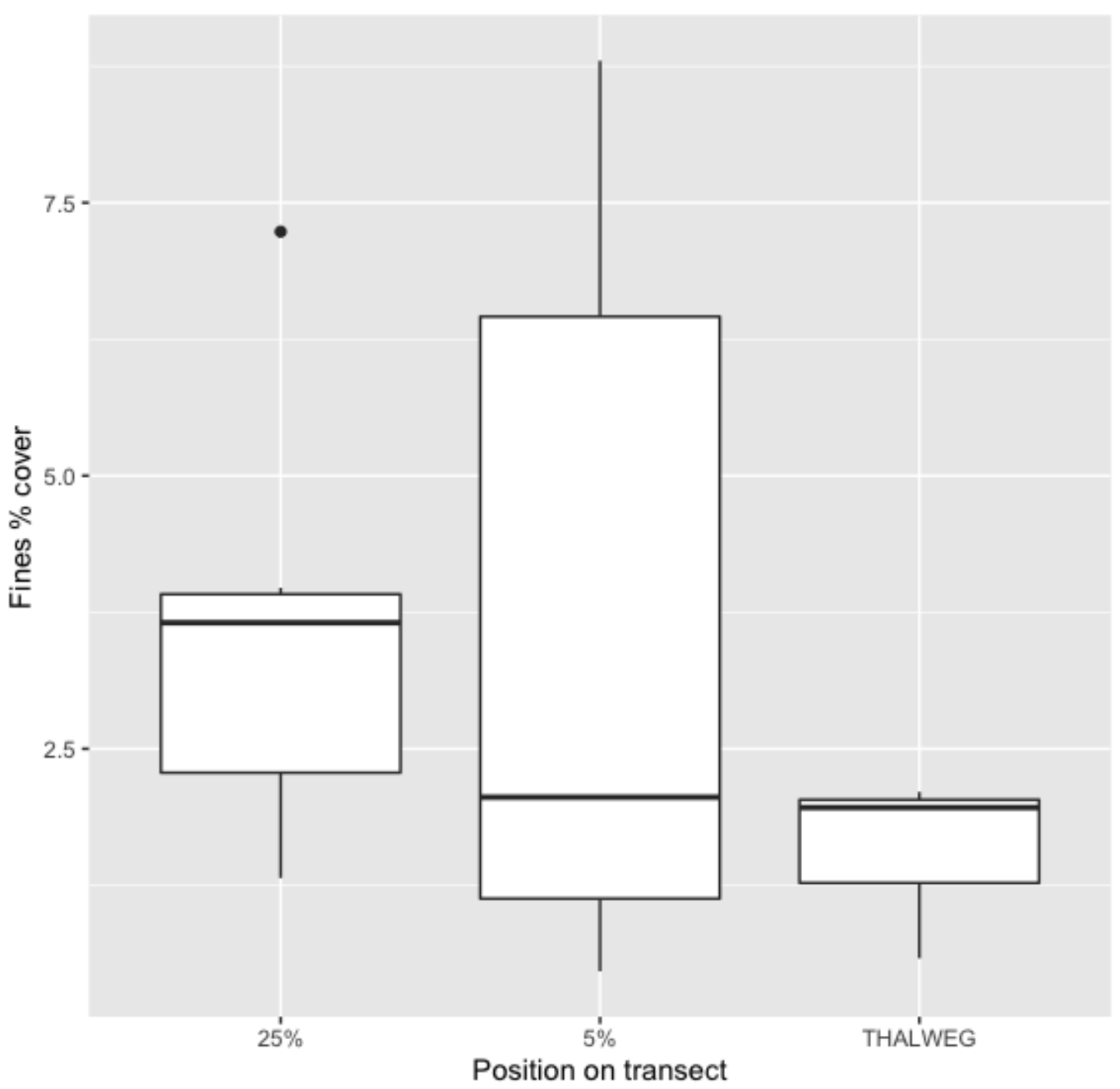

Figure 2.2.5 Boxplots indicating fine sediment percent cover data by sampling location on transect. 


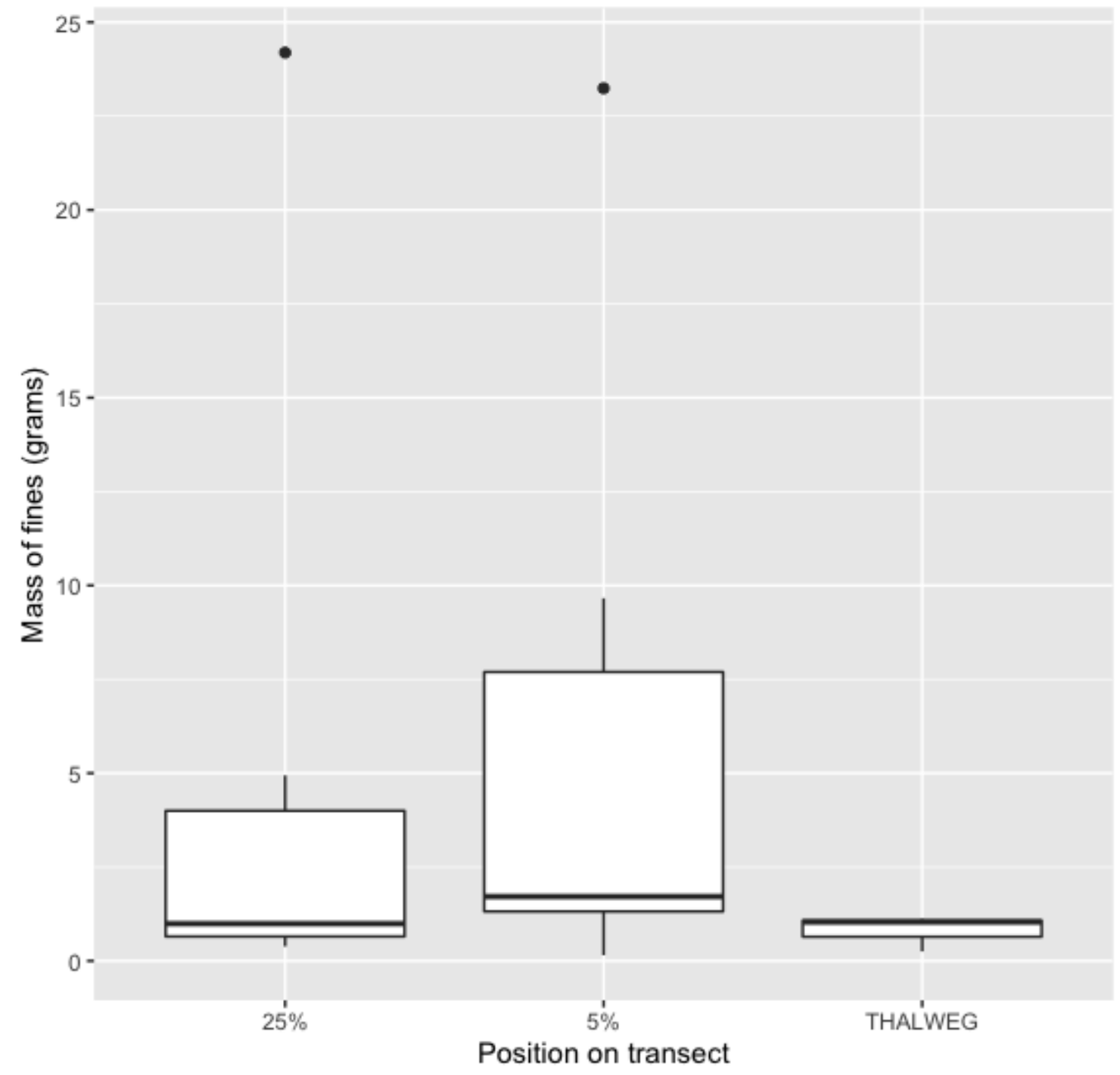

Figure 2.2.6 Boxplots indicating fine sediment mass data by sampling location on transect. 


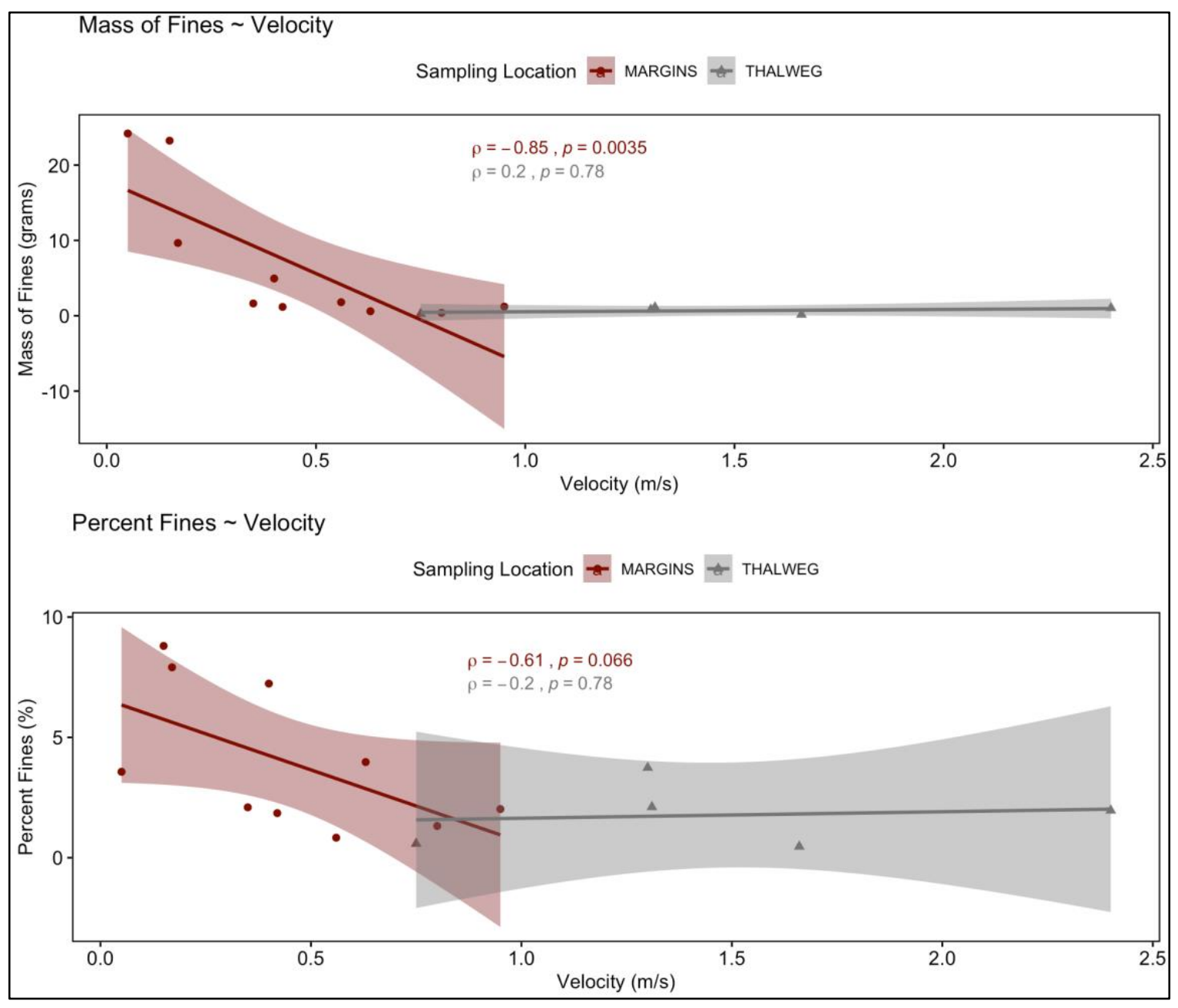

Figure 2.2.7 Scatterplots with 95\% confidence intervals (shaded region) showing mass of fines and velocity (top) and percent fines and velocity (bottom). Colors indicate sampling locations in depositional or erosional zones. 


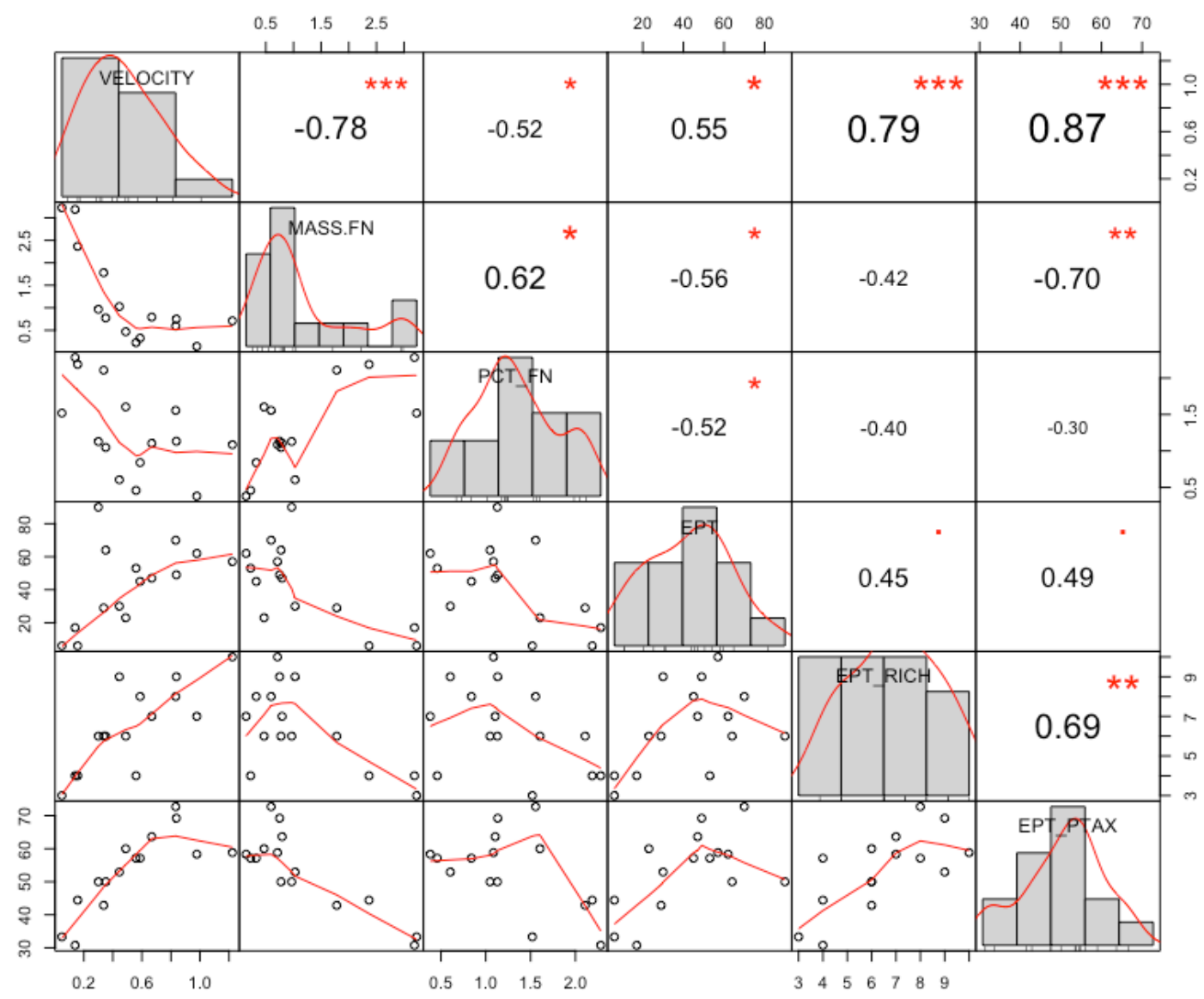

Figure 2.2.8 Correlation matrix showing scatterplots and histograms. Values indicate Spearman's rho and associated p-value significance ( $p<0.05^{*}, p<0.01^{* *}, p<0.001^{* * *}$ ) between a priori relevant variables. Log-transformed predictor variables: grams of fines/sample (MASS.FN), proportion of fines per sample (PCT_FN), and velocity (VELOCITY). Response variables were EPT abundance (EPT), EPT richness (EPT_RICH) and percent EPT richness (EPT_PTAX). 


\section{Discussion}

In this investigation, the aim was to better characterize benthic fine sediment conditions when developing macroinvertebrate indicators. Stream velocity should have a strong relationship with fine sediment because carrying capacity and stream power are a primary driver of sediment distribution. Results from the Feasibility Study supported this relationship, where strong correlations existed between percent fine sediment and velocity (rho $=-0.52, \mathrm{p}<0.05$ ) using the bilge pump method. Contrary to expectations, the correlation between flow and percent fine sediment cover is almost nonexistent using data generated from pebble count protocols in the Exploratory Analysis (rho $=-0.11, \mathrm{p}>$ 0.05). The implications are that pebble count protocols may lead to overestimations of percent fine sediment coverage at the reach scale, and correspondingly, underestimations of invertebrate sensitivity to excess fine sediment. Moreover, when sampling macroinvertebrates throughout an entire reach, this characterizes how the macroinvertebrate community is responding more generally.

The second major finding was that more EPT taxa were found in samples as velocity increased and fines decreased. The percent of EPT taxa out of the total richness was especially sensitive to changes in fine sediment mass. Additionally, the results indicate that sampling position along a transect may influence the amount of sediment and taxa that are collected. Similar findings were found in the EMAP Mid-Atlantic Highlands Assessment and Mid-Atlantic Integrated Assessment where EPT taxa richness was significantly higher in riffles compared to pools (pools were considered flow too slow to extend the invertebrate sample-collection net) (Klemm, et al., 2002; Stoddard, et 
al., 2006). Although, this finding contrasts with a number of studies that have determined sampling macroinvertebrates from an array of habitat types detects disturbance gradients as well as single habitat types (Parsons \& Norris, 1996; Ostermiller \& Hawkins, 2004).

One limitation to this study is the relatively narrow percent fine sediment gradient $(0.5 \%-8.8 \%)$. This was surprising to find at Clear Creek, given that fine sediment was visually dominant in the stream margins, which was confirmed by touch. A possible explanation is the way in which percent fine sediment is determined, which is a proportion of the total inorganic mass. Because sand and gravels are heavier particles, they will dominate percent coverage classifications in heterogenous substrate, regardless of the actual volume of fine sediment. Using the bilge pump method, percent fine sediment cover will likely be lower than what is found in pebble count measurements. Again, this reinforces the idea that pebble counts may overestimate fine sediment. For comparison, $35 \%$ of sites in the WEMAP Cascades data experienced percent fine sediment cover greater than $8 \%$, and three sites above $20 \%$. The Cascade sites had an average reach slope gradient of $20.5 \%$, while the Clear Creek study reach had an average reach slope of $1.6 \%$, as it was at a much lower elevation (Cascades mean site elevation $=$ $1179 \mathrm{~m}$, Clear Creek mean site elevation $=29 \mathrm{~m}$ ). It should be expected that high elevation sites with higher gradients would not support fine sediment accumulations because of the associated sheer stress in the water column. Overall, this information strengthens the idea that methodology plays a strong role in determining larger values of percent fine sediment cover. 
When developing indicators, having sediment mass measurements is important because it reflects how macroinvertebrates are responding to an absolute value, not a relative value that is addressing other sediment sizes (i.e. gravel, sand). Further work establishing the precision of the vacuum bilge pump would enhance the confidence of its application. Repeat sediment measurements at all 15 sampling locations could allow for a comparison of values between visits. Comparing bilge pump macroinvertebrate metrics to D-net or Serber sample metrics would create a fuller picture of its effectiveness characterizing relationships at the patch scale.

It would be advantageous to sample sites with a known gradient of fine sediment conditions and collect from neither the margins nor thalweg, but an intermediate location along the transect of a run or glide. This may reduce the possibility of collecting from habitats that have higher velocity, more EPT, and minimal fines. Sampling intermediary habitats then could provide the appropriate setting to use this methodology and better understand the relationship between EPT and fine sediments for biomonitoring. The WEMAP protocol evaluated eleven transects with one macroinvertebrate sample at each transect. This sampling protocol is well designed for collecting multiple habitat types and substrates to average out spatial variability across transects, characterizing the entire reach. The bilge pump method better characterizes small scale processes. I do not recommend the sampling design used in the Feasibility Study to address reach or watershed scale environmental conditions. Future studies would benefit from directly comparing the bilge pump method with pebble count methods using the same sampling design. This would provide an opportunity to fairly assess how the bilge pump method 
characterizes fine sediment conditions and macroinvertebrates at the reach scale using composited data. 


\section{CHAPTER 3: The Use of EPT as Indicators of Fine Sediment Pollution in Salmon- Bearing streams of the John Day Basin}

The John Day basin is the largest basin in Oregon managed for wild salmonids, and is an important reference stream for the Columbia River basin considering the absence of hatchery releases. Its productive tributaries are home to spring Chinook salmon, as well as endangered Bull Trout, summer steelhead, and west slope cutthroat. Fine sediment loading beyond a stream's natural carrying capacity can cause widening and shallowing of channels, contribute to solar heating, and produce poor fish spawning habitat (Butcher, et al., 2010). The John Day basin is the largest basin in Oregon managed for wild salmonids, and is an important reference stream for the Columbia River basin considering the absence of hatchery releases. Its productive tributaries are home to spring Chinook salmon, as well as endangered Bull Trout, summer steelhead, and west slope cutthroat. In the Total Maximum Daily Load (TMDL) and Water Quality Management Plan for the John Day Basin, the Oregon Department of Environmental Quality reported "Excess fine sediment in streambeds leads to unsuitable spawning grounds, also jeopardizing fish populations. Fine sediment loading that exceeds a stream's carrying capacity tends to cause widening and shallowing of channels, further contributing to stream solar heating." Additionally, there is an information gap pertaining to reference conditions and methodology:

"The Department is in the process of developing quantitative methods and benchmarks to evaluate sedimentation impairment in Oregon streams. Because this work is not yet 
complete issuance of a sedimentation TMDL will be postponed until these methods are in place." Better understanding fine sediment dynamics and pollution in the basin will aid in the protection of these sensitive fish species.

The primary purpose of this study is to address the need for a study design focused on the fine sediment gradient while controlling for the confounding effects of other watershed stressors. The main objective was to evaluate the response of two EPT related metrics (EPT richness and \% EPT richness) along a gradient of fine sediment (less than $0.063 \mathrm{~mm}$ ) conditions. I hypothesized that EPT metrics would decline as fine sediment mass and percent cover increased.

\section{Methods}

Study Area and Site Selection

The John Day River and its tributaries in Central/Northeast Oregon is one of the longest undammed rivers in the continental U.S. and drains much of the western side of the Blue Mountains into the Columbia River. It flows through sparsely populated arid and forested mountain regions of the state, and provides habitat for federally protected Chinook Salmon, steelhead, Pacific lamprey, and Bull Trout, with parts designated as wild and scenic. It resides in the rain shadow of the Cascade Range (mean annual precipitation: $\sim 35-55 \mathrm{~cm}$; annual temperature range $=-10-30^{\circ}$ Celsius) and is underlain by Cretaceous volcanic, marine sedimentary, and granitic rocks covered by Miocene Picture Gorge Basalt of the Columbia River Basalt Group (Walker \& MacLeod, 1991). Communities of flora are dispersed along elevation gradients between mesic highlands, 
mixed spruce and fir forests, and sage grasslands of plateau/steppe habitat. The study area is within the upper and Middle Fork John Day subbasins, Hydrologic Unit Codes 17070201 and 17070203 , respectively. Combined, their basins drain a $6109 \mathrm{~km}^{2}$ area, roughly half of which resides in the Malheur National Forest and other public land. The population density is less than one person per square kilometer. Grazing and logging are common at lower elevations in each subbasin, with approximately 50 percent of the private forestland under industrial forest ownership (Natural Resources Conservation Service, 2005). These subbasins are an appropriate setting for assessing the effects of fine sediment because of the contrast in geology, lack of anthropogenic stress, and unregulated stream flow.

I utilized spatially balanced survey data from the Western Environmental Monitoring and Assessment Program (WEMAP) conducted by the US EPA (Stoddard, et al., 2005) to build a site selection criterion (Figure 3.1) for empirically testing EPT responses to fine sediment. Compared to other areas studied in WEMAP, the sites from the John Day region offered the widest gradient of fine sediment conditions $(0-92 \%$ fine sediment cover) and presented 69 sites to choose from within a relatively concentrated area. I selected 16 of the 69 sites based on the following conditions: Located on National Forest and easily accessible by road. I used GIS and the Gridded Soil Survey Geographic Database (United States Department of Agriculture, National Resource Conservation Service., 2019) to separate geologies into two categories (erosive or resistant) based on grain size of eroded material and erodibility of formations. I determined geologic dominance by overlaying the site drainage layer (U.S. Geological Survey., 2019) over the 
lithology layer and calculating the percent of basin that was erosive or resistant beyond $50 \%$. This yielded 7 erosive (5 heterogenous and 2 homogenous) and 9 resistant (3 heterogenous and 6 homogenous) basins for sampling. In an effort to create the widest gradient of dominant geologies I added two homogenous erosive and two heterogenous resistant basin sites.

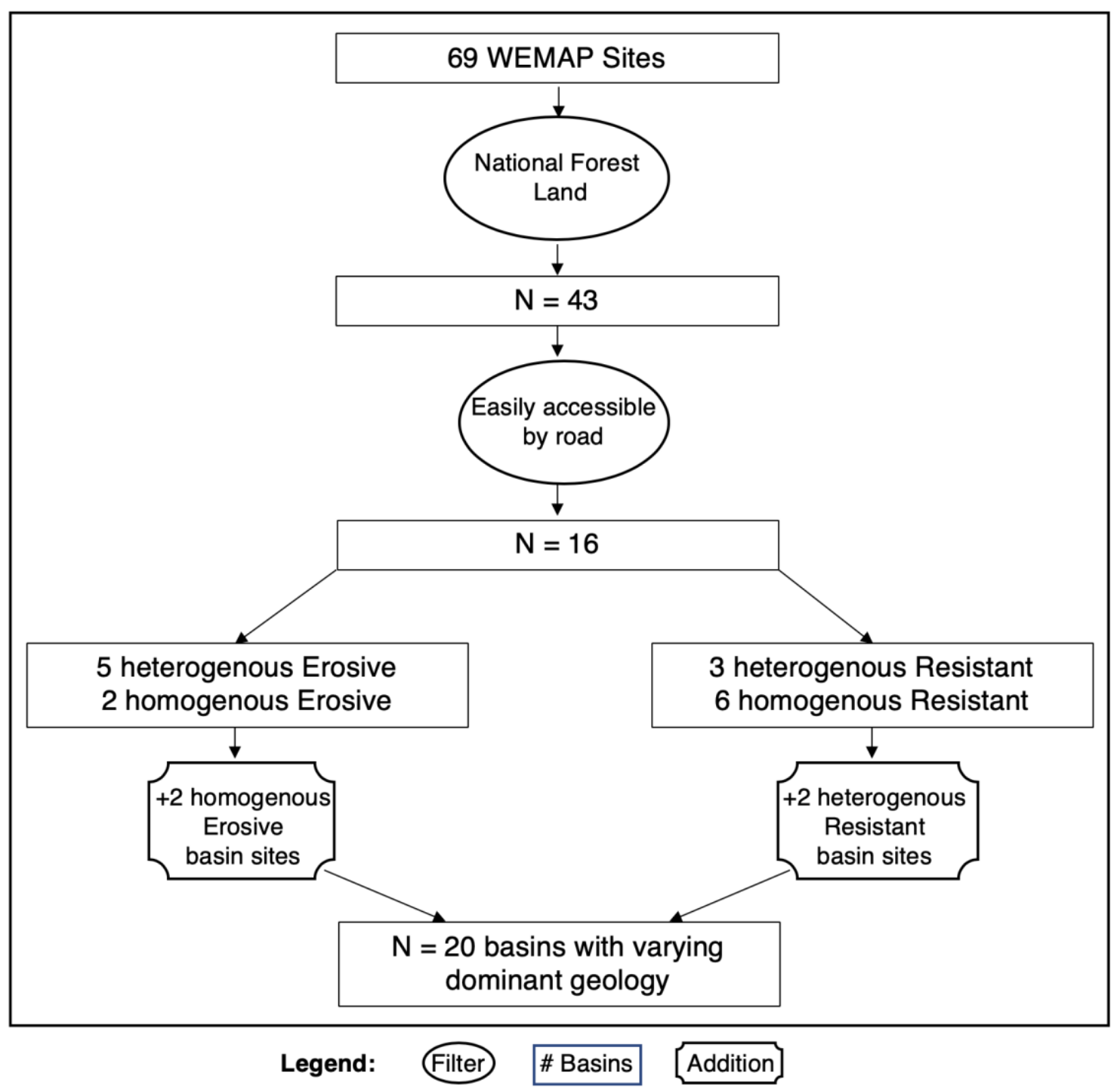

Figure 3.1 Schematic diagram of the site selection process. 


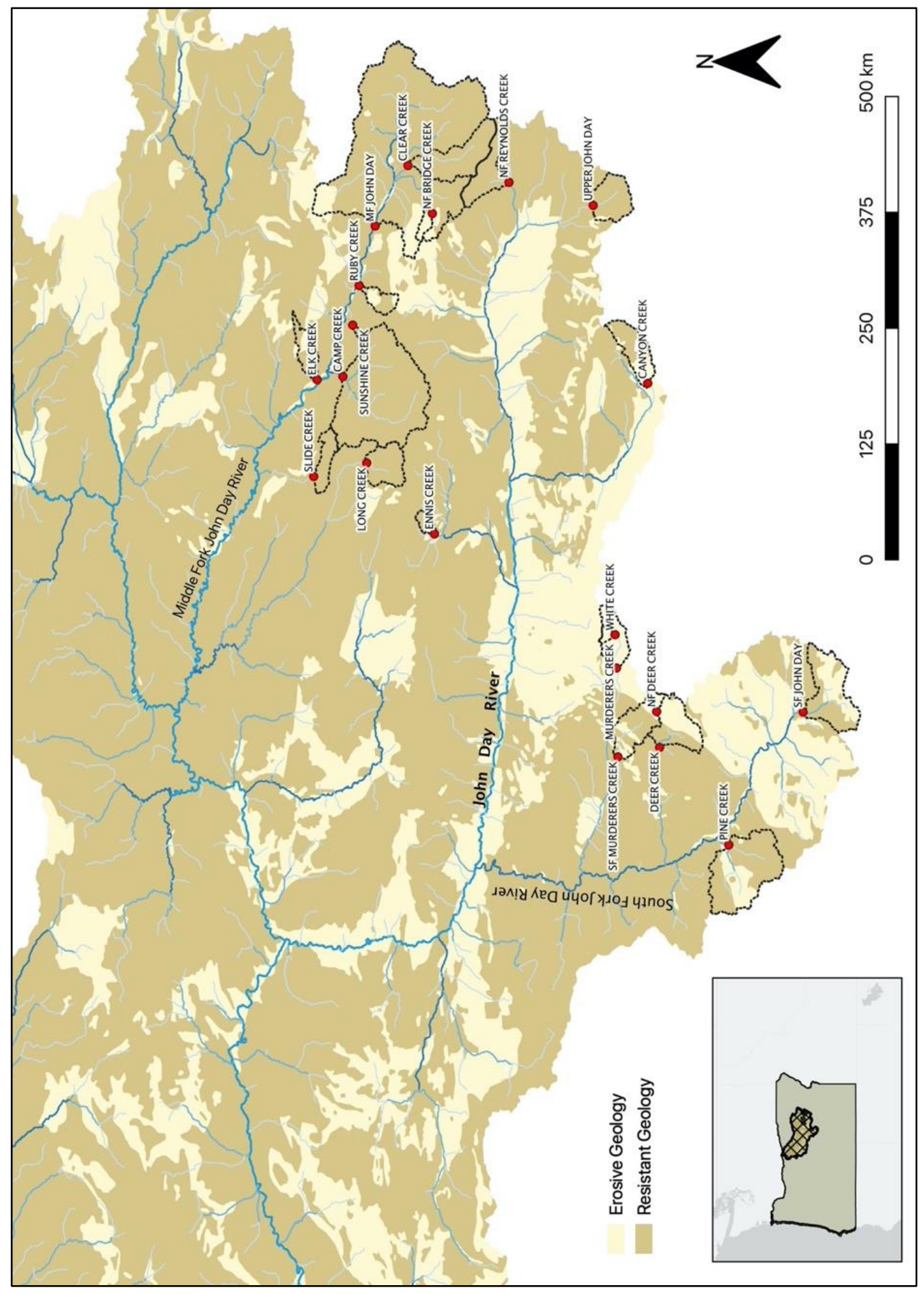

Figure 3.2 Map of study area and sample locations in the John Day Basin including dominant geology. 


\section{Physical and Chemical Variables, Sediment, and Macroinvertebrate Data}

Sample sites for each stream consisted of one transect with two samples that were composited in the field. I selected the transect based three criteria: 1) run or glide hydraulics (laminar flow where feasible) 2) uniform flow across the transect, and 3) minimal riffles (erosional) and pools (depositional) adjacent to the transect. I then measured the transects for the wetted width distance. I multiplied this value by 0.33 and 0.66 to have two sampling locations that were evenly spaced along the transect and located in neither the margins or the thalweg (Figure 3.3 and 3.4). Results from the feasibility study indicated that mean velocity differences between $5 \%$ habitat types and $25 \%$ habitat types were within $0.1 \mathrm{~m} / \mathrm{s}$. Stream margins have little to no flow and therefore high concentrations of benthic fine sediments where they settle. The thalweg may have faster more scouring flows, resulting in stable substrates and coarser bed material allowing fewer opportunities for fine sediment to settle (Gibbins, et al., 2010). The rationale was that collecting samples taken at $33 \%$ and $66 \%$ of the wetted width targets a gradient of benthic substrates (McCaffrey, 2019) without a dominance of erosional or depositional flow types.

I measured canopy cover and stream water chemistry at each transect using a densiometer, grab samples, and handheld field instrument (Model YSI 556 MPS). I used the YSI to measure temperature, $\mathrm{pH}$, conductivity, and dissolved oxygen. Depth was measured at each sampling location using a rod and tape measure, then averaged for the composite. I measured stream velocity using a velocimeter (Flo-Mate Model 2000) at each sampling location, then averaged for the composite. I placed the velocimeter probe 
on the wading rod at 0.6 of the measured depth below the water surface, placing the probe directly into the current. Measurements were taken after 30 seconds. I measured Chlorophyll a by scraping periphyton off of three rocks, then using an Aquaflour fluorometer following EPA methodology 445.0 (Arar \& Collins, 1997). I obtained total nitrogen, total phosphorus, and orthophosphate by grab samples in the field. Grab samples were immediately chilled and frozen within 24 hours and later analyzed using the standard methods for the examination of water and wastewater (American Public Health Association, 2005) by the Cooperative Chemical Lab in Corvallis Oregon. Basin characteristics and site measurements are in table 3.1.

I subsampled macroinvertebrates by evenly placing materials in the sample bucket over a 3x6 plastic grid and using an excel random number generator to pick a cell between one and eighteen. Once I selected a cell, I manually removed macroinvertebrates from the sediment by using a 10x magnification dissecting microscope (Lieder Model \# MZ 730X). I repeated the process with a subsample target of 300 macroinvertebrates or until all eighteen cells were extracted and examined. Subsampling is common among state and federal bioassessment programs (Barbour, et al., 1999), and prior investigations using the vacuum bilge methodology found the average number of individuals to be 159 macroinvertebrates per sample. Hence, I selected a subsample target of 300 to accommodate the two composite samples at each transect. I dissected entire composite samples until 300 macroinvertebrates were identified or until all cells were explored. Upon reaching 300, I counted the cell under investigation completely for thoroughness. I placed sediments back inside the bucket to be further analyzed. I counted all 
macroinvertebrates found and identified to genus level where possible. I identified midges and non-insects to the family level. I used Aquatic Insects of North America (Merritt, et al., 2008) for macroinvertebrate identification. Samples and specimens were then labeled and preserved for quality control.

I measured sediment sample mass by decanting water from buckets and drying for 24 hours at $100^{\circ} \mathrm{C}$ and weighed and burned at $500^{\circ} \mathrm{C}$ for one hour. I calculated organic sediment content by the difference between the inorganic mass and dry mass of the sample. I passed the samples through a sieve into three size classes: course substrate (gravel) greater than $2 \mathrm{~mm}$ in diameter, sands smaller than $2 \mathrm{~mm}$ in diameter and larger than $0.063 \mathrm{~mm}$ diameter, and fines smaller than $0.063 \mathrm{~mm}$ in diameter. $\mathrm{I}$ then weighed the sediment classes for proportions and mass of each sediment class per sample. I used the sampling area to convert the laboratory weights to a mass of sediment per square meter of stream bed sampled. 


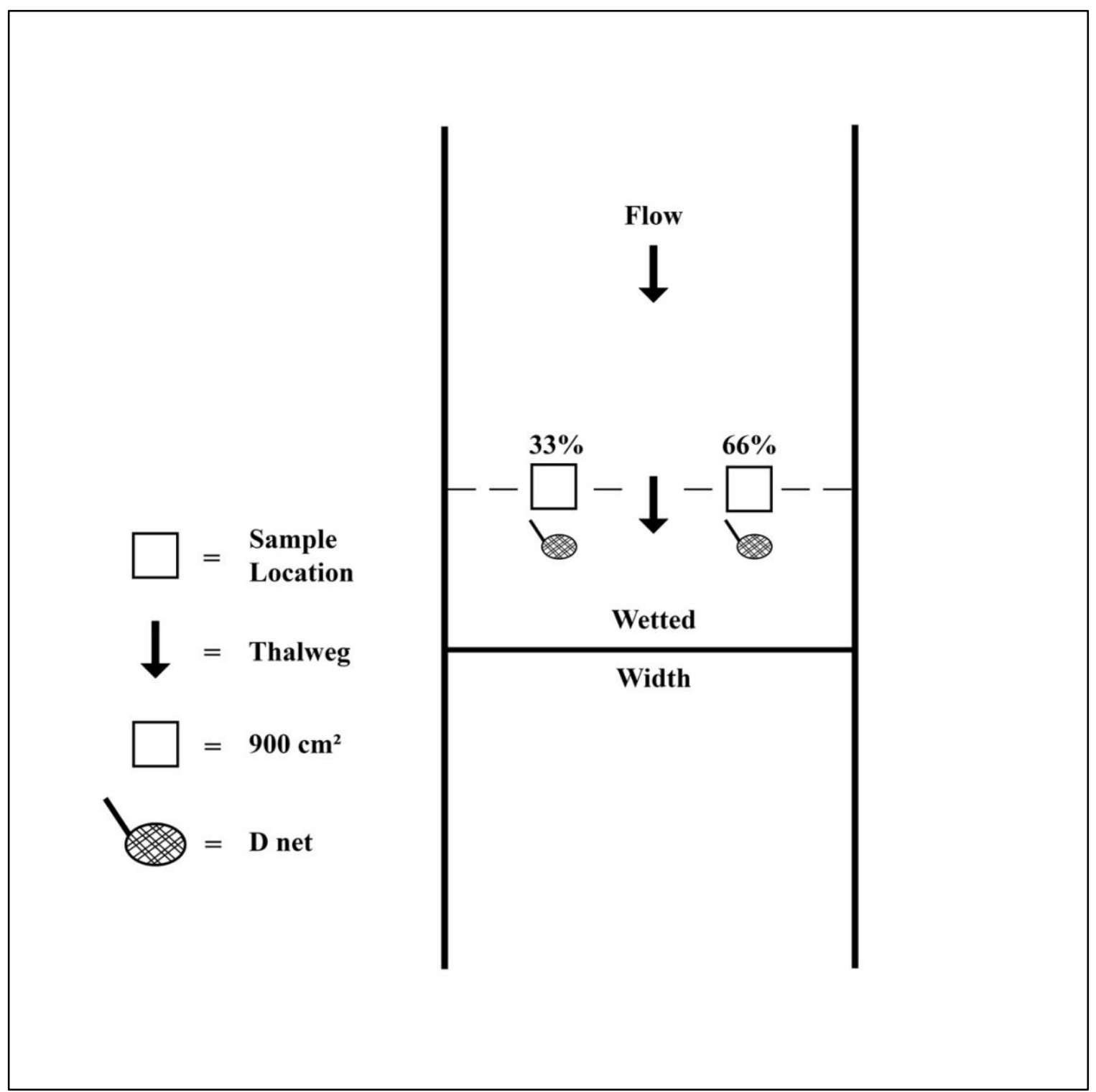

Figure 3.3 Birds eye view of sampling schematic in transect indicating placement of D net, the two sampling locations to be composited, and typical thalweg location. 


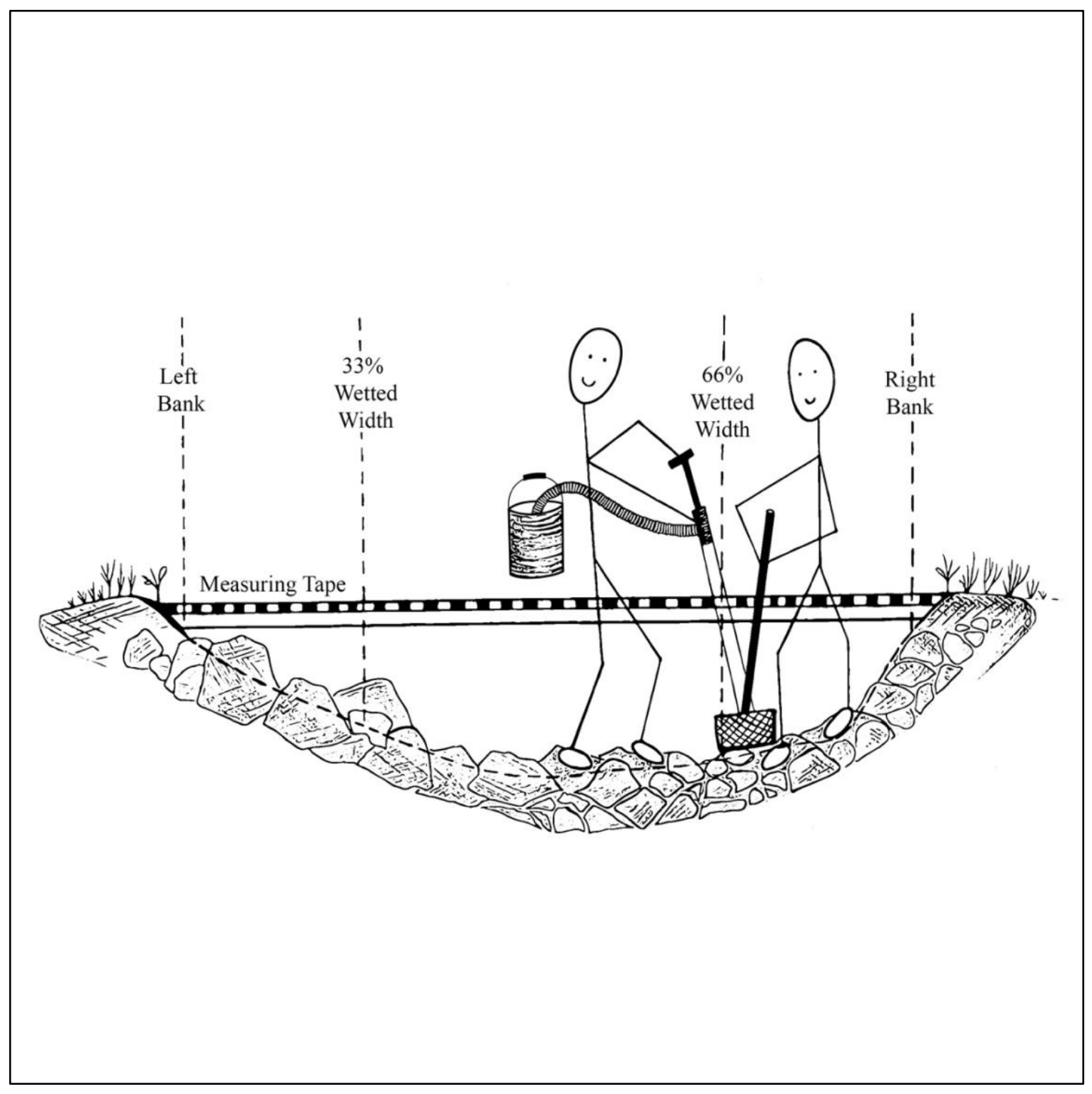

Figure 3.4 Cross section diagram of sampling substrate and macroinvertebrates indicating placement of D net, bilge pump, and the two sampling locations to be composited. 


\section{Statistical Analysis}

Data Exploration and Variable Selection

The overarching objective of the analysis was to quantify the relationship between fine sediment and EPT richness and percent EPT richness. I explored pairwise relationships between the EPT metrics (EPT richness and percent EPT taxa) and 21 physical and chemical variables using correlation coefficients and corresponding $\mathrm{p}$ values. I used Spearman Rank correlation coefficients for variable section, to decide which environmental variables had the strongest associations with the EPT response variables. Between the environmental predictors and EPT response metrics, I retained variables with negative correlation coefficients $>0.70$. Outside of the selection criteria, I included velocity in model development because sediment deposition is a direct function of hydrology (Dietrich, 1982). I also force selected dominant geology into model development as geology effects sediment distribution. If a pair of variables were highly collinear (i.e., rho $=>|0.75|$ ) I retained the variable having the most ecological relevance for interpretation. This resulted in a subset of four predictor variables included in the linear model.

\section{Comparison of fine sediment thresholds using Partial Dependence Plots (PDP)}

I developed a Random Forest model using EPT richness as the response variable and four predictor variables that met the selection criteria for linear model development. I constructed the PDP to detect any thresholds between EPT richness and percent fine sediment cover (Figure 3.10). This approach is useful because it plots the expected 
response as a function of the predictor variable of interest, with the other predictors marginalized. I purposely removed many of the environmental predictors for two reasons. The first was to avoid the selection of correlated predictors in the tree building process (Strobl, et al., 2008), as percent fines was the variable of interest in this case. The second reason was to have the ability to compare thresholds from PDP plots generated using pebble count data (WEMAP). The WEMAP data contained three times as many predictors then the John Day dataset. I developed an EPT richness Random Forest model and PDP plot (Figure 3.11) using the five predictor variables included in the linear model (Table 2.1.3), to allow for an equitable comparison of any thresholds between percent fine sediment cover and EPT richness.

Exploratory analysis of traits and fine sediment

A number of studies have utilized macroinvertebrate traits to measure the response of macroinvertebrates to increasing fine sediment conditions (Buendia, et al., 2013; Longing, et al., 2010; Wagenhoff, et al., 2012; Bona, et al., 2015; Gieswein, et al., 2018). A benefit of this approach is that it can help to identify which aspect of the EPT community is changing in response to specific stressors. I assigned traits from Poff et al. (2006) to the EPT genera and calculated the relative abundance of each EPT trait modality based on the total amount of EPT macroinvertebrates. I examined correlations between EPT trait modalities with fine sediment to evaluate the strength of relationships. I performed the analysis on 59 EPT trait modalities and their relationship with both mass of fine sediment and percent fine sediment cover. 


\section{Model Development}

I used generalized linear modeling (GLM) to model the effects of the environmental predictors on the EPT response metrics. I selected the Poisson distribution to model the residual variation because the EPT metrics were derived from count data. I scaled all predictor variables prior to the analysis. I fit the model by using an AIC stepwise variable selection procedure. This procedure adds or subtracts predictor variables one at a time (at each step) in an effort to sequentially add the most contributive predictors and remove any ones that do not provide an improvement to the model fit and lower the AIC statistic. I assessed goodness of fit using the proportion of deviance explained by the fitted model:

Pseudo $R^{2}=1-\frac{\text { residual deviance }}{\text { null deviance }}$

I selected final models based on a combination of the lowest AIC and highest pseudo $\mathrm{R}^{2}$ values. I compared full and reduced model AIC values with AICc values, as the AICc penalizes data with a small sample size. I used R 3.5.2 (R Core Team, 2020) with the additional package MASS (Ripley, et al., 2019) and Hmisc (Harrell, 2020) for statistical analyses. 


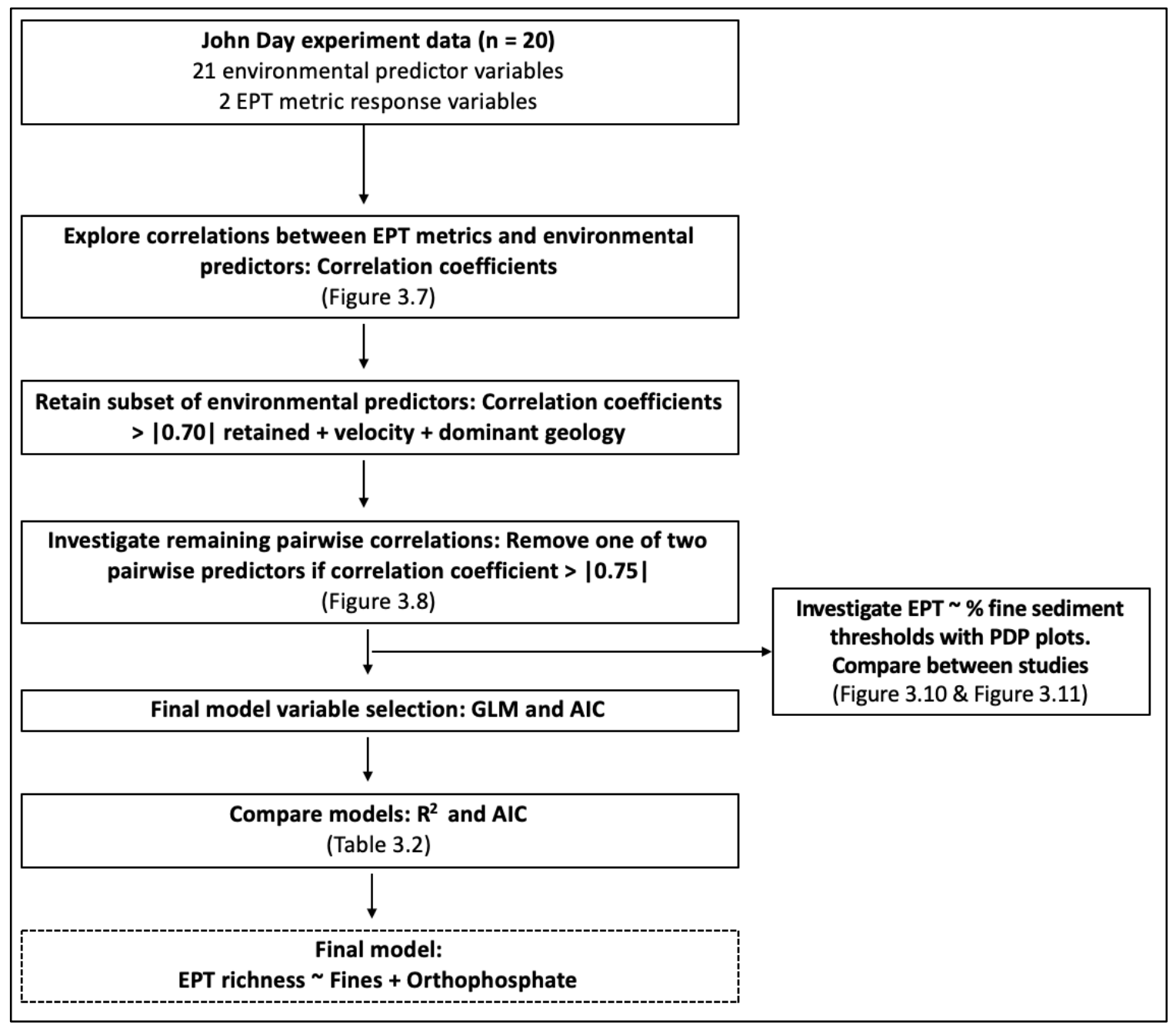

Figure 3.5 Schematic showing analytical pathway of this research and relevant figure or table.

\section{Results}

Sands dominated the proportion of sediment cover across all sites $($ mean $=$ $64.1 \%$ ), while the proportion of fines ranged from $1.8-11.6 \%$. There were very few significant correlations between the proportion of fine sediment and the EPT metrics (EPT richness and \% EPT richness) or environmental variables. Fine sediment mass 
across sites ranged from 49.9 to $1005.5 \mathrm{~g} / \mathrm{m}^{2}$ (median: $166.7 \mathrm{~g} / \mathrm{m}^{2}$, table 3.1). Sites with predominantly erosive geology had greater quantities of fine sediment $($ median $=305.5$ $\mathrm{g} / \mathrm{m}^{2}$ ) than resistant types (median $\left.=122.2 \mathrm{~g} / \mathrm{m}^{2}\right)$ (Figure 3.7). Fine sediment mass showed significant positive correlations with the amount of organic material (Spearman's rho $=0.81, \mathrm{p}<0.0001)$ and salinity (Spearman's rho $=0.70, \mathrm{p}<0.001)$.

Spearman's Rank correlation analysis revealed 5 predictors that met the model inclusion criteria which included mass of fines, mass of organic material, conductivity, salinity, and orthophosphate (Figure 3.8). After further screening, I removed salinity and mass of organic material from further analysis due to their collinearity with other predictors (conductivity and fines, respectively). Velocity and fine sediment percent cover had a significant negative correlation (Spearman's rho $=-0.49, \mathrm{p}<0.05$ ).

The sites within erosive geologic catchments had on average roughly $76 \%$ less abundance, $57 \%$ less richness, and $\sim 68 \%$ less EPT richness than the resistant catchment sites. In total I identified 3448 macroinvertebrates including 49 different taxa. Riffle beetles (Elmidae) were the most common macroinvertebrate and were found at $80 \%$ of the sites. Chironimidae were present at every site and were also highly abundant. Of the EPT taxa, Ephemeroptera were found at the most sites (80\%), and the Baetis were found at $75 \%$ of the sites. Trichoptera were the least abundant (mean relative abundance $=5 \%$ ) of the EPT taxa while Plecoptera were the most abundant on average (mean relative abundance $=20 \%$.

I constructed two PDP plots to examine if any thresholds were apparent between percent fine sediment cover and EPT richness, and to compare if thresholds varied using 
different methodologies. An obvious threshold was visible in the PDP using WEMAP data (Figure 3.11), but less apparent in the John Day Basin Study PDP (Figure 3.10). From the WEMAP data, I found a 25\% decrease in EPT taxa between zero and $40 \%$ fine sediment cover. From the John Day Basin data, I found a 12\% decrease in EPT taxa between zero and seven percent fine sediment cover, but then spiked upwards between eight percent and ten percent fine sediment cover.

A simple correlation analysis was used to explore whether any EPT trait modalities exhibited strong correlations with fine sediment mass or fine sediment percent cover. Percent fine sediment cover was poorly correlated with the trait modalities. Fine sediment mass was most strongly correlated with the relative abundance of EPT taxa having no rheophilic preference (rho $=-0.53, \mathrm{p}<0.05$ ), the relative abundance of soft bodied EPT taxa $($ rho $=-0.54, \mathrm{p}<0.05)$, followed by the relative abundance of EPT clingers $($ rho $=-0.46, p<0.05)$ and the relative abundance of EPT taxa that utilize external gill structures for respiration ( $r$ o $=-0.48, \mathrm{p}<0.05$ ).

The AIC selection process resulted in the selection of two models with $\mathrm{R}^{2}$ values of 0.77 and 0.82 , and significant $\mathrm{p}$-values for fine sediment mass and orthophosphate (Table 3.2). Both EPT richness and \% EPT richness exhibited a strong negative correlation with mass of fine sediment, and a strong positive correlation with orthophosphate (Figure 3.9). Figure 3.10 shows variables included in model development. Two linear models were developed, and mass of fines was the only predictor to be AIC selected for both models. Conductivity was not AIC selected in either of the final models, indicating it did not provide improvements to model fit (Table 3.2). 
The AIC values differed very little from the small sample AICc statistic between full and reduced models. The final EPT richness model in table 3.2 exhibited the lowest AIC value and highest pseudo $\mathrm{r}^{2}$. Of the EPT metrics under investigation EPT richness was also most sensitive to changes in fine sediment with a coefficient of -1.06 . For exploratory purposes, I performed a forced variable selection and included percent fine cover in the AIC selection process, but it was not selected in either model.

Table 3.1 Summary information on the 20 study transects. Landcover statistics were determined for the total area upstream from each transect (Homer, et al., 2011; U.S. Forest Service, 2020)

\begin{tabular}{lccc}
\hline & $\begin{array}{c}\text { Erosive } \\
\text { Geology }\end{array}$ & $\begin{array}{c}\text { Resistant } \\
\text { Geology }\end{array}$ & All Sites \\
\hline Site Characteristics & Median & Median & Median (range) \\
\hline Stream Width $(\mathrm{m})$ & 1.9 & 2.9 & $2.6(1.3-7.2)$ \\
Stream Depth $(\mathrm{m})$ & 0.2 & 0.2 & $0.2(0.05-0.3)$ \\
Velocity $(\mathrm{m} / \mathrm{s})$ & 0.1 & 0.1 & $0.1(0.01-0.4)$ \\
Canopy Cover $(\%)$ & 21.0 & 16.0 & $20.0(3.0-100.0)$ \\
Temperature $\left({ }^{\circ} \mathrm{C}\right)$ & 14.7 & 13.4 & $14.1(9.8-22.9)$ \\
Cond $(\mu \mathrm{S} / \mathrm{cm})$ & 354.0 & 59.0 & $176.5(30.0-558.0)$ \\
DO $(\mathrm{mg} / \mathrm{L})$ & 12.1 & 6.0 & $8.3(0.2-16.3)$ \\
pH & 9.0 & 9.1 & $9.1(7.9-9.7)$ \\
Chlorophyll a $\left(\mu \mathrm{g} / \mathrm{cm}^{2}\right)$ & 0.5 & 1.5 & $1.1(0.1-4.5)$ \\
TN $(\mathrm{mg} / \mathrm{L})$ & 0.2 & 0.1 & $0.1(0.05-0.6)$ \\
PO4-P $(\mathrm{mg} / \mathrm{L})$ & 0.01 & 0.05 & $0.03(0.004-0.08)$ \\
TP $(\mathrm{mg} / \mathrm{L})$ & 0.03 & 0.05 & $0.04(0.008-0.18)$ \\
Slope Average $(\%)$ & 20.7 & 24.3 & $21.9(15.1-34.7)$ \\
Watershed Area $\left(\mathrm{km}^{2}\right)$ & 20.5 & 16.6 & $17.8(2.2-362.2)$
\end{tabular}




\begin{tabular}{|c|c|c|c|}
\hline Elevation Average (m) & 1564.9 & 1575.3 & $\begin{array}{c}1570.0(1369.0- \\
1899.0)\end{array}$ \\
\hline Forest Cover $(\%)$ & 93.4 & 86.6 & $86.6(23.3-98.4)$ \\
\hline Shrubland Cover $(\%)$ & 6.6 & 10.6 & $(1.6-73.6)$ \\
\hline Inorganic Substrate $\left(\mathrm{g} / \mathrm{m}^{2}\right)$ & 6977.1 & 3616.6 & $\begin{array}{c}4080.5(1027.8- \\
17905.4)\end{array}$ \\
\hline $\begin{array}{l}\text { Substrate Cover Fines }(< \\
0.06 \mathrm{~mm})(\%)\end{array}$ & 7.2 & 4.5 & $4.7(1.8-11.7)$ \\
\hline $\begin{array}{l}\text { Substrate Cover Sand (0.06 - } \\
2 \mathrm{~mm})(\%)\end{array}$ & 60.3 & 66.5 & $64.1(41.9-82.1)$ \\
\hline $\begin{array}{l}\text { Substrate Cover Gravel (> } \\
2 \mathrm{~mm})(\%)\end{array}$ & 32.0 & 29.0 & $30.5(10.4-56.1)$ \\
\hline Mass of Fines $\left(\mathrm{g} / \mathrm{m}^{2}\right)$ & 305.5 & 122.2 & $166.7(50-1005.5)$ \\
\hline $\begin{array}{l}\text { Sites with Upstream } \\
\text { Riparian/In-stream Restoration }\end{array}$ & 3 & 2 & 5 (total) \\
\hline
\end{tabular}




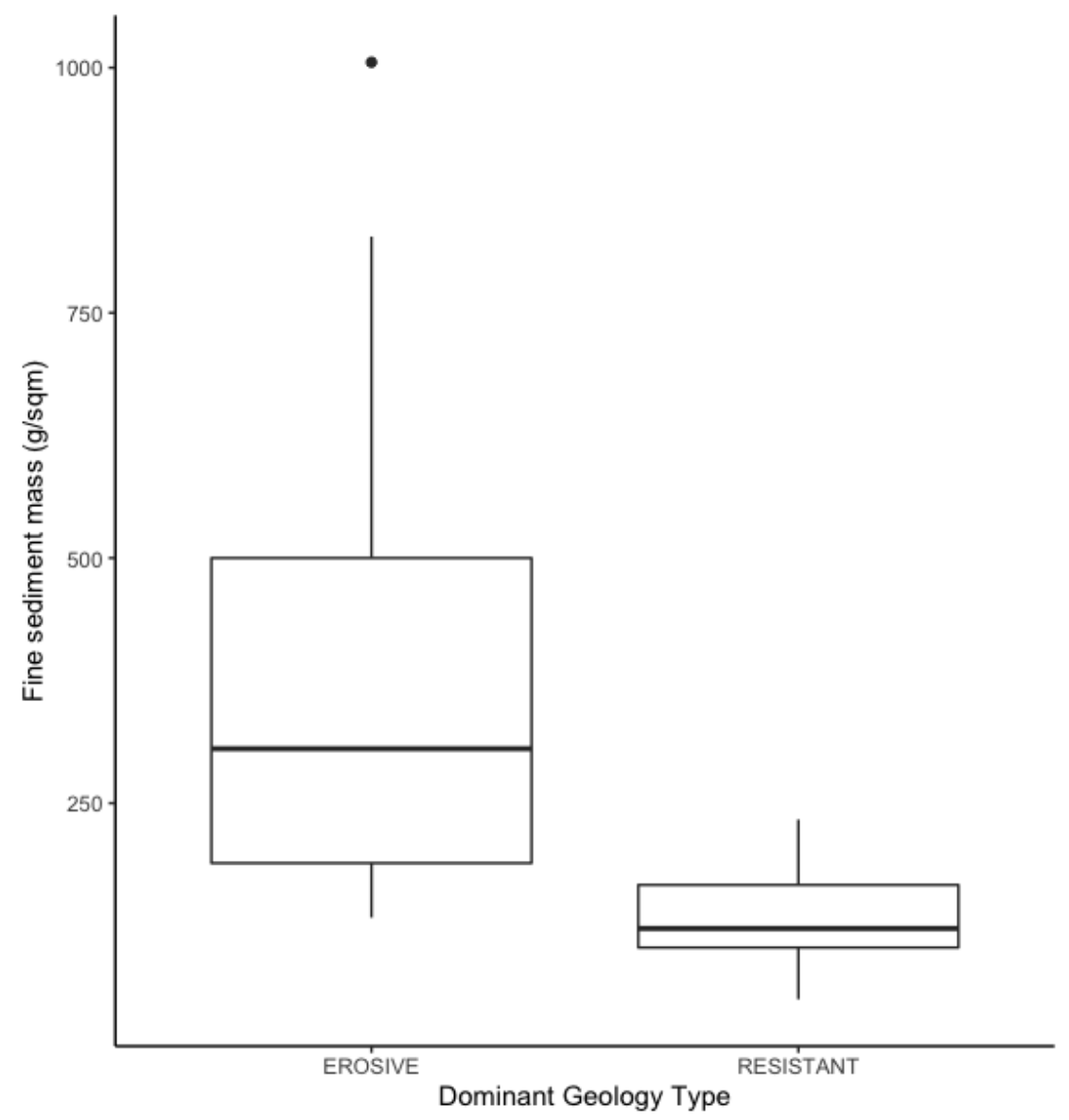

Figure 3.6 Variability of the mass of fine sediment at sites grouped by dominant geology of catchment. Each box corresponds to $25 \%$ and $75 \%$ quartiles. The dark line inside the box represents the median. Whiskers show minimum and maximum values. 


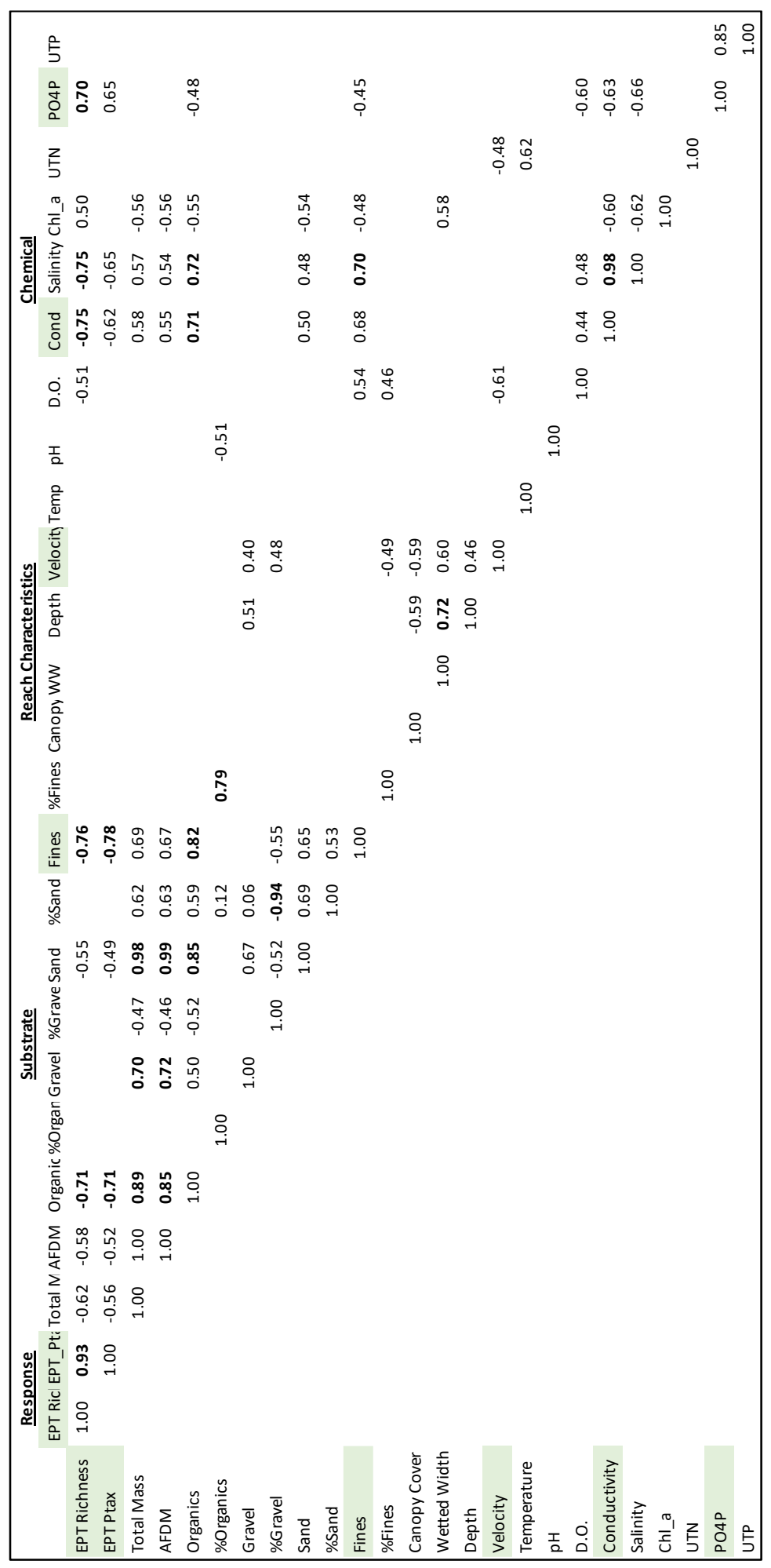

Figure 3.7 Spearman's cross-correlations including the EPT metrics and all environmental variables. Only significant correlations $(\mathrm{p}<0.05)$ are listed. Correlations $>0.70$ are bolded and variables used in GLM are highlighted. 


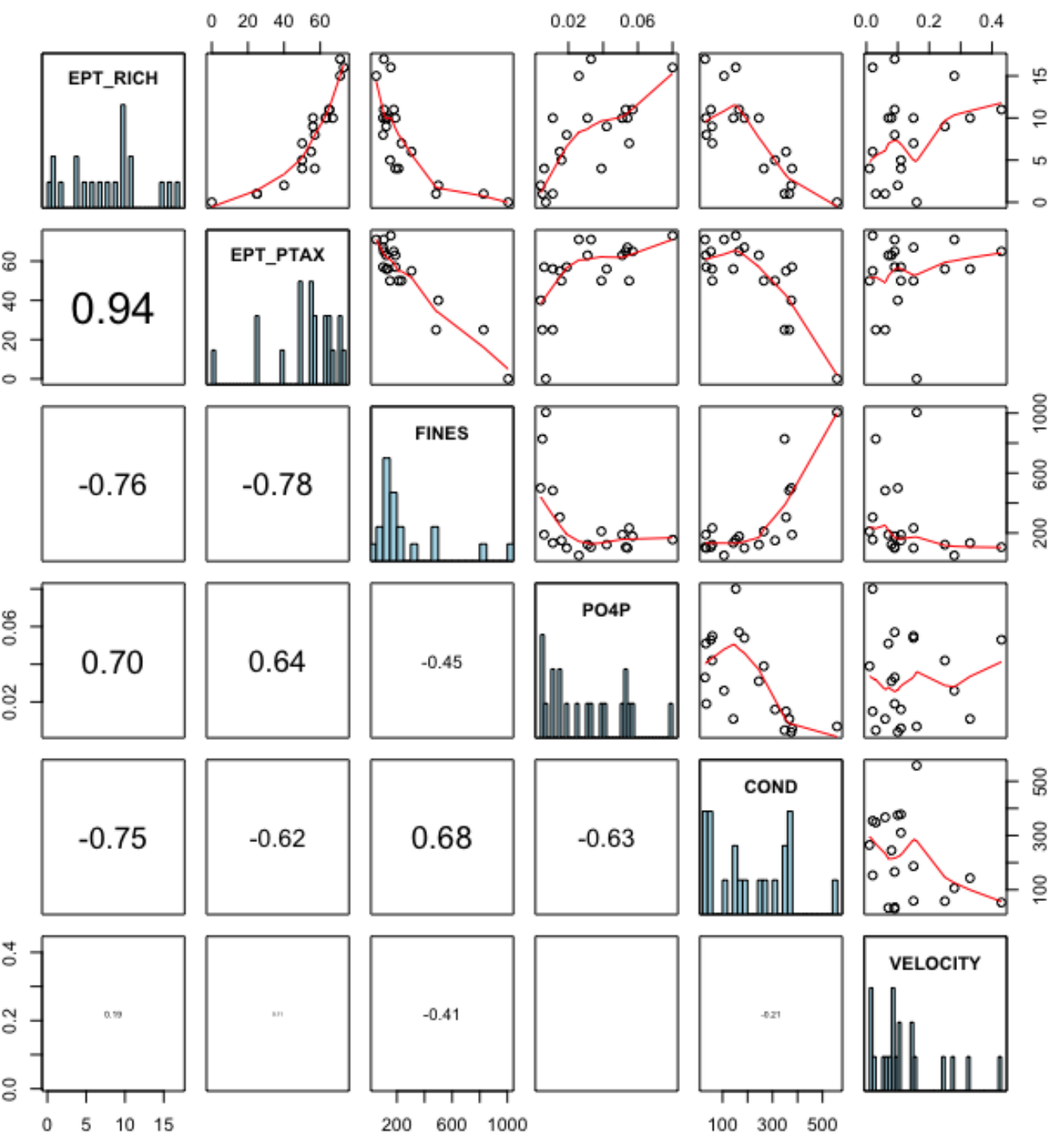

Figure 3.8 Spearman's Rank correlation coefficients and scatterplots between variables selected and included in GLM models. Predictor variables: $\mathrm{g} / \mathrm{m}^{2}$ of fines (FINES), conductivity (COND), orthophosphate (PO4P), velocity (VELOCITY). Selected response variables were EPT richness (EPT_RICH) and percent EPT richness (EPT_PTAX). 


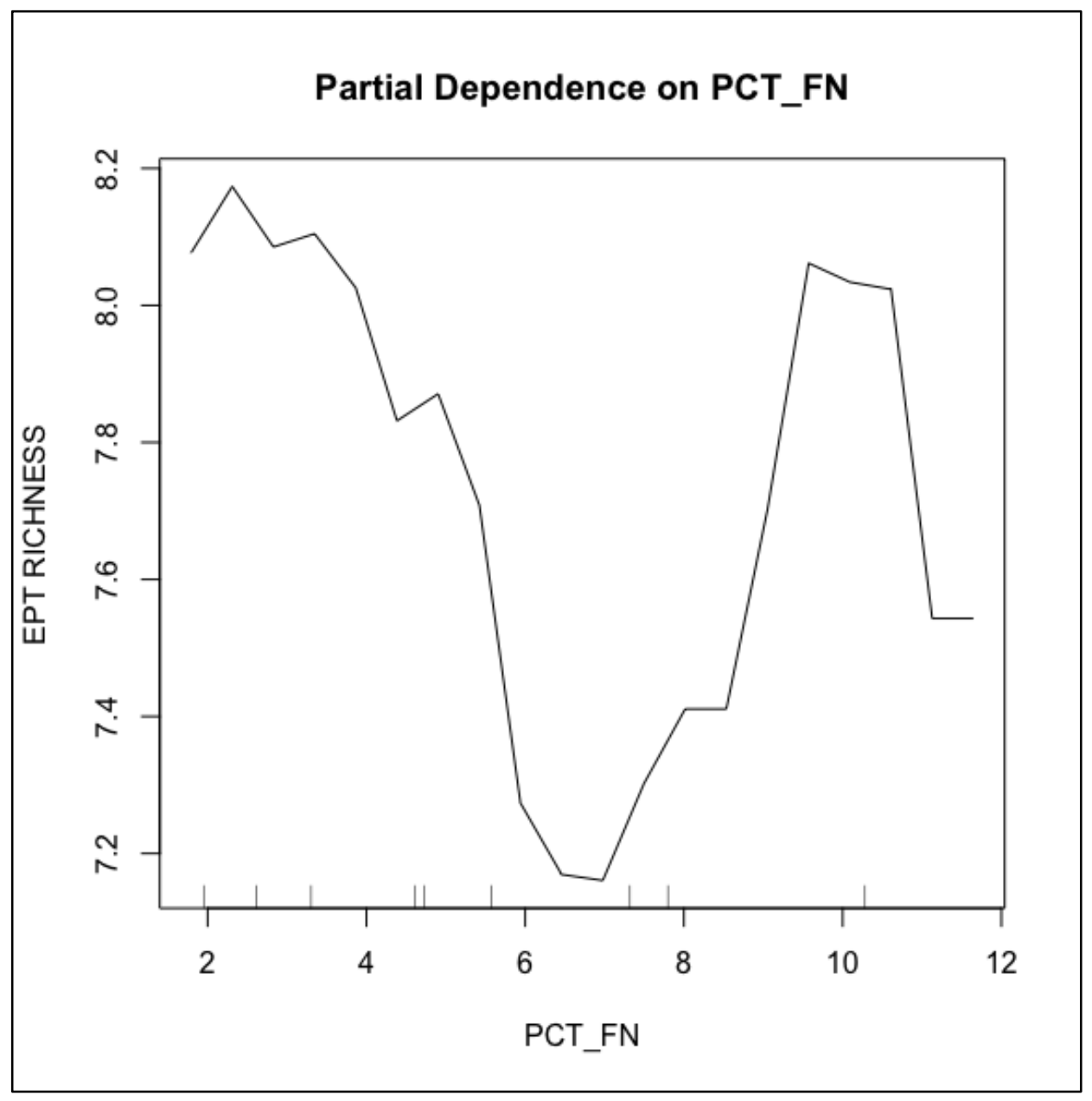

Figure 3.9 John Day Basin Study PDP showing the expected response of EPT richness as a function of percent fine sediment cover (PCT_FN) when the other predictor variables are marginalized. Random Forest tree development predictor variables were velocity, conductivity, orthophosphate, and percent fine sediment cover. 


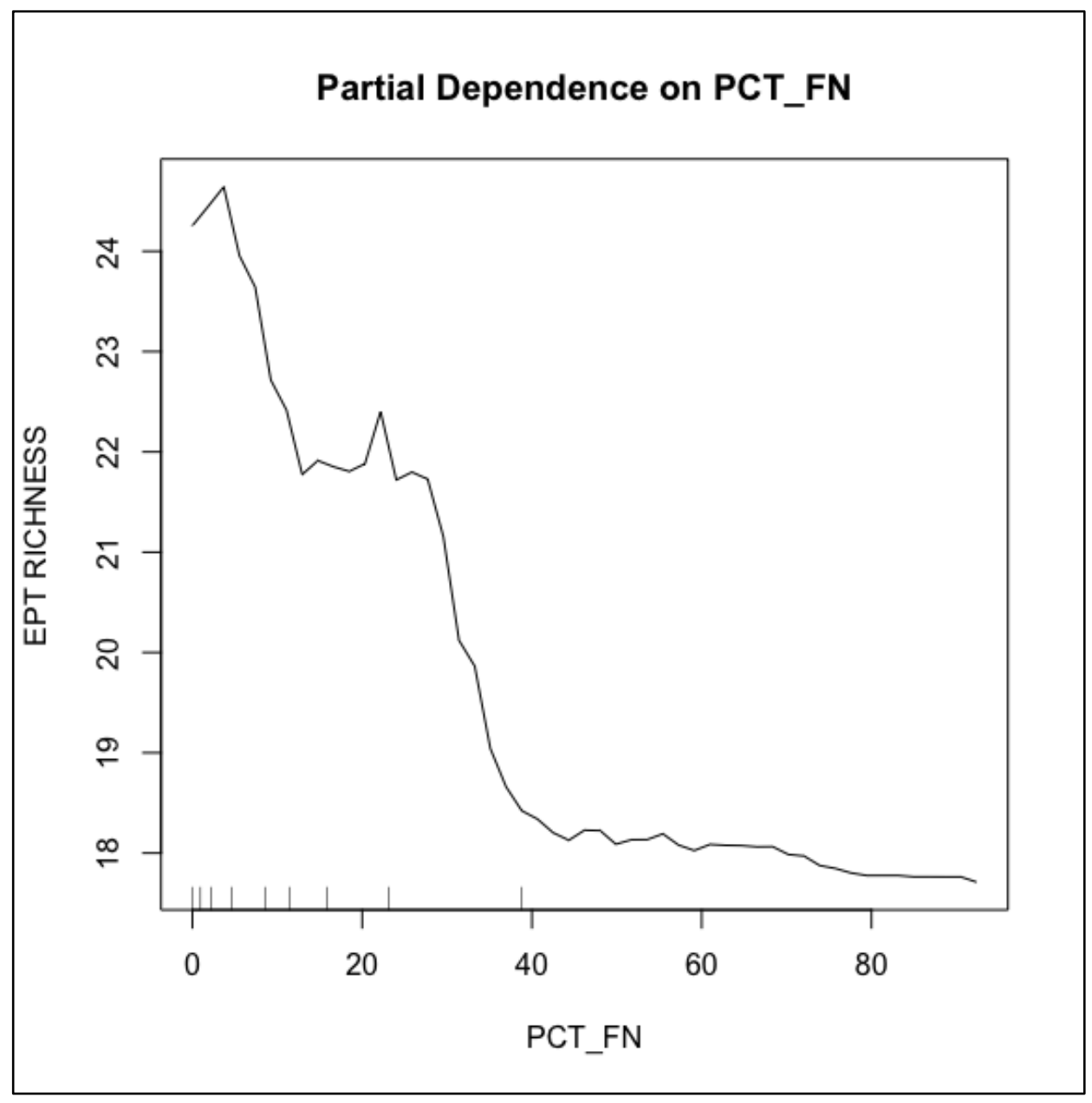

Figure 3.10 Exploratory Analysis PDP showing the expected response of EPT richness as a function of percent fine sediment cover (PCT_FN) when the other predictor variables are marginalized. Random Forest tree development predictor variables were percent fast water in the reach, conductivity, chloride, riparian canopy density, and percent fine sediment cover. 
Table 3.2 GLM model summary. Models were selected using AIC step-wise selection. Predictor variables: mass of fines at site (Fines), and orthophosphate (PO4P). $p<0.025^{*}, p<0.01 * *, p<0.001^{* * *}$ with Bonferroni correction.

\begin{tabular}{|c|c|c|c|c|c|}
\hline $\begin{array}{c}\text { RESPONSE VARIABLE } \\
(\mathbf{y})\end{array}$ & $\begin{array}{r}\text { Predictor Varia } \\
\text { Coeff }\end{array}$ & $\begin{array}{l}\text { le and Model } \\
\text { ent }\end{array}$ & $\mathbf{R}^{2}$ & $\begin{array}{l}\text { Model } \\
\text { DF }\end{array}$ & AIC \\
\hline EPT Richness & -1.06 Fines $* * *$ & 0.21 PO4P* & 0.82 & 17 & 89.73 \\
\hline
\end{tabular}




\section{Discussion}

The third regulatory issue addressed in this thesis, was the need for a study design that is focused on the fine sediment gradient while controlling for the confounding effects of other watershed stressors. In the John Day basin, I found a wide gradient of deposited fine sediment mass across sites, exhibiting how EPT richness and \% EPT richness values respond at varying levels of sediment accumulation. The EPT richness metric was more sensitive to changes in fine sediment, as indicated by the GLM fine sediment mass coefficient. The proportion of fine sediment cover was narrow in this study, and results did not align with predictions as correlations between percent fine sediment cover and EPT metrics were not significant. This is likely due to the dominance of sand and gravel by mass, which makes using percent cover less meaningful when characterizing heterogenous substrates. Even if there is an abundance of finer sediments, they do not weigh as much and will not account for a large percent of the benthic cover.

In these basins of the John Day, both EPT metrics were significantly and negatively correlated with fine sediment mass. This finding is important because it reflects how using a different approach while limiting the amount of confounding factors may improve results, as evident in the comparison of $\mathrm{R}^{2}$ values between the Field Study $\left(\mathrm{R}^{2}=0.82\right)$ and Exploratory Analysis $\left(\mathrm{R}^{2}=0.43\right)$. EPT richness appears to be the more robust of the two response metrics, with much of the variation in EPT richness attributed to mass of fine sediment and orthophosphate. Orthophosphate exhibited a positive significant coefficient in the final EPT richness model developed in the John Day study. This is contradictory to other findings which reported increased mortality with 
Ephemeroptera species when combined with fine sediment or added as a treatment on its own (Everall, et al., 2018). Sites with the highest orthophosphate levels were characterized by higher elevations, dense forests and an abundance of canopy cover, conditions which appear to favor EPT taxa across ecoregions.

\section{Characterizing fine sediment}

Sediment measurement masses and percent cover were comparable to other studies despite different research objectives and methods. Several studies that used the sediment remobilization technique refined by Collins and Walling (2007) did experience similar findings with regards to mass of particles smaller than $2 \mathrm{~mm}$. Buendia et al. (2013) and Gieswin et al. (2018) reported ranges from $90-1800 \mathrm{~g} / \mathrm{m}^{2}$ and $1122-13,528$ $\mathrm{g} / \mathrm{m}^{2}$, respectively, while my study was somewhere between those values $(1122-13,528$ $\mathrm{g} / \mathrm{m}^{2}$ ). Although, these studies were conducted in course substrate dominated mountain streams of the Central Pyrenees and Western Germany. Previous pilot studies conducted using the bilge pump technique in the Willamette Valley of Oregon, revealed a range of $85-7400 \mathrm{~g} / \mathrm{m}^{2}$ for particles less than $2 \mathrm{~mm}$, with a median of $455 \mathrm{~g} / \mathrm{m}^{2}$. Gieswin et al. (2018) also examined smaller particles $(<0.063 \mathrm{~mm})$ and found the median of that size class to be $596 \mathrm{~g} / \mathrm{m}^{2}$, whereas my study had a median of $167 \mathrm{~g} / \mathrm{m}^{2}$.

Percent fine sediment cover for my study had a narrow range $(2-12 \%)$ with a median of 5\% which is in line with other studies. Bryce et al. (2010) and Hubler et al. (2016) used pebble count techniques and experienced high ranges of $0-100 \%$ fine sediment cover but had median percent fine sediment values of $3.8 \%$ and $7-9 \%$, 
respectively. These studies occurred throughout WEMAP sampling sites in the Western states (Bryce, et al., 2010) and spatially balanced survey sites across Oregon (Hubler, et al., 2016). Although differences exist between these studies, the values suggest the need for consistent regional advances in which to quantify fine sediment conditions, and establishment of background fine sediment reference levels to facilitate management

goals. An important discovery from my study was that the amount of vacuumed material at each site was not nearly as dependent on the velocity as anticipated, offering confidence in the ability of the bilge pump methodology to detect fine sediment conditions despite variance in velocity among sites. Measuring and compositing two nonriffle sampling locations in a transect may offset extreme differences in velocity. For example, Pine Creek which had the greatest mass of material extracted and most fine sediment, was above the $75^{\text {th }}$ percentile for velocity.

\section{Management Implications}

This study raises important questions about the development of bioindicators for excess fine sediment. The findings will be of interest to stream managers in the Pacific Northwest and can help guide 303(d) listings for sediment impairment in streams supporting sensitive Salmonid populations. The evidence from this study demonstrates the importance of sampling design, scale, and limiting confounding factors when developing macroinvertebrate indicators for excess fine sediment. The present results are significant in at least two major respects: 1) Conventional monitoring protocols use pebble count protocols to collect sediment data across the transect which may be biased 
towards depositional conditions in the margins of the stream, and 2) reach-scale macroinvertebrate samples may not produce optimal data for developing indicators because mechanisms affecting macroinvertebrates take place at the smallest of scales.

Developing fine sediment threshold levels is an important factor in the development of 303(d) listings and TMDLs in streams. Comparisons of the two PDP plots indicate larger thresholds from the WEMAP data (25-40\% fine sediment cover) and then thresholds in the John Day Basin Study. This may be explained by one of several possibilities. The range of percent fine sediment cover in the John Day Basin data was relatively narrow (2-12\%), which is likely due to the sampling design (collected at $33 \%$ and $66 \%$ of wetted width) and methodology (sediment percentages are accurately measured in the laboratory with a sieve). Either, the threshold would have to be lower compared to the WEMAP data where the gradient was very wide (0-92\%), or using a patch-scale sampling design approach shows an increase in fine sediment sensitivity. This needs further investigation, as the John Day Basin fine sediment percent cover thresholds were inconclusive. The observed drop and subsequent spike in the PDP is likely due to the very low inorganic material that was found at Long Creek ( $80 \%$ less than the average among sites). Long Creek contained the highest EPT richness of all sites, and the second highest percent fine sediment cover. This finding was puzzling because it did not fit the general trend. Upon further investigation, Long Creek had the second lowest fine sediment mass, which highlights the importance of sediment mass measurements when developing indicators. If Long Creek were to be removed from the analysis, there would be a 19\% decrease in EPT richness between zero and seven percent fine sediment cover. 
This combination of findings provides some support for the conceptual premise that pebble counts are overestimating percent fine sediment cover, and underestimating EPT sensitivity.

Understanding how metrics respond to individual stressors is important for biomonitoring purposes. The present study raises the possibility that EPT richness is a valuable metric used for monitoring fine sediment conditions and may be useful for determining the ecosystem function component of the biological condition gradient indices (Davies \& Jackson, 2006), or as an intolerant sediment metric for use in the Indices of Biotic Integrity. EPT richness seems more appropriate as a biometric for fines than for sands, which is supported by a limited number of studies exhibiting negative relationships between macroinvertebrates and fine sediment (Kaller \& Hartman, 2004; Hubler, et al., 2016; Edwards, et al., 2020). This may be due to the more long-term persistent stress associated with fine sediment which lead to a reduction in food quality (Parkhill \& Gulliver, 2002) and loss of habitat (Wood \& Armitage, 1997; Waters, 1995). Additionally, sampling intermediary habitats outside of riffles and erosional areas provides a granular approach to understanding the relationship between fine sediment and macroinvertebrates, as indicated by the Clear Creek Feasibility Study results.

Currently, the amount of effort to assess sedimentation in streams is not feasible by most state, tribal, and watershed councils, so the use of EPT richness to infer conditions may be practical. However, the results from this study also indicate that geology can act as a filter for macroinvertebrate communities and EPT metrics. For example, shale or mudstone formations will likely not provide the optimal conditions that 
sediment sensitive macroinvertebrates require. Hence, sediment biotic criteria will need be adjusted accordingly with geologic dominance in mind.

\section{Study Limitations and Conclusions}

It is important to note when interpreting these results that this study assessed the effects of sedimentation on macroinvertebrate communities. Hence, it is not feasible for the data to disentangle effects of the physical impacts of fine sediment on macroinvertebrates (e.g. loss of interstitial space, reduced anchoring ability) from physico-chemical alterations (e.g. changes in oxygen concentrations or $\mathrm{pH}$ ) which can occur within the benthos from sedimentation (Ryan, 1991). The results from this field study are promising due to the high correlation values between EPT and fines as well as the steep fines coefficient in the linear model. Buendia, et al., (2013) assessed relations between EPT metrics and fine sediment using a Generalised Additive Model. The percent deviance explained for their EPT richness model was 71.9\%, although other metrics were found to be more sensitive.

Acknowledging that natural gradients (i.e. stream size, slope) affect EPT (Beerman, et al., 2018) makes confident applications of EPT richness as a biometric difficult for stream managers. EPT metrics are able to detect changes in water quality degradation from different sources including urban development, agriculture, and sediment. Biological responses to anthropogenic pollution also rely on natural conditions. The main limitation in the regulatory setting is determining EPT declines from excess fine sediment and not other sources. Disentangling natural variability from anthropogenic 
fine sediment by-products presents a major issue. The objective for watershed management measures should be to detect excess fine sediment, not natural variability, using appropriate diagnostic indices and metrics (Collins, et al., 2012).

A possible remedy is understanding how EPT change - which trait modalities within EPT taxa are declining in response to fine sediment. Results indicate strong correlations exist between mass of fines, EPT taxa with mixed rheophilic preference, soft bodied EPT with no armoring, EPT clingers, and EPT external gill respiration. Because the aim of the sampling design targeted intermediary habitats, it is not too surprising to find that EPT taxa having no preference for erosional or depositional flows decreased with fines. What is surprising is the strong correlation with fines, given that mixed rheophilic EPT taxa make up less than $50 \%$ of EPT taxa in the study. I would expect highly rheophilic (preference for erosional flows) EPT taxa to be much more sensitive to fine sediment mass but instead were not significantly correlated $($ rho $=-0.29, p>0.20)$. Any mechanistic interpretations are challenging to make in this case. In an effort to develop EPT trait modalities that are indicative of excess fine sediment, it is unclear how much weight to give this finding. EPT clingers may be a more telling indicator given the negative correlation with mass of fines and previous studies that have noted their association with deposited sediment $(<2 \mathrm{~mm})$. Longing et al. (2010) found that percent clingers were the only metric in their study to vary across three sedimentation categories for percent fines $<2 \mathrm{~mm}(\mathrm{r}=-0.49, \mathrm{P}=.005)$ and percent embeddedness $(\mathrm{r}=-0.40, \mathrm{P}=$ 0.03). Rabeni et al. (2005) found clingers to decrease in density and richness across a continuum of deposited sediment $(<2 \mathrm{~mm})$ from 0 to $100 \%$ surface cover. A mechanistic 
explanation for this relationship may be explained by an increase in embedded cobbles that reduce the surface area for EPT clingers. An increase in fine sediment deposits will then reduce the available habitat area. It is important to note here that the mean relative abundance of EPT clinger taxa were 13\%. The implication is that EPT clingers were not highly abundant across sites, which may limit their use as a reliable indicator.

The most promising trait modalities were soft bodied EPT and EPT that use external gills for respiration because of their mean relative abundance among sites ( $29 \%$ and $20 \%$, respectively), and many genera within each group. The relationship between soft bodied EPT and fine sediment is likely related to physical damage from abrasion of fine particles. Unprotected fleshy body parts like gills and filter-feeding structures are especially prone to damage from saltating particles (Jones, et al., 2012b). Of the 33 EPT genera found in this study, 26 use external gills. Moreover, In accordance with the present results, previous studies have demonstrated that gill respiration, among 48 other traits, was consistently found to be more inversely associated with increasing fine sediment mass than any other traits (Buendia, et al., 2013; Descloux, et al., 2014; Mondy \& Usseglio-Polatera, 2013). A possible explanation for gill sensitivity may be the abrasion of exposed gill surfaces that can lead to infection (Lemly, 1982), or clogging of gill structures from fine sediment particles (Jones, et al., 2012b). The use of EPT traits may be more valuable than community wide trait analysis because taxa that are tolerant of fine sediment and pollution may be grouped into the same functional trait groups with sensitive taxa. For example, aquatic caterpillars use gills for respiration but are tolerant to 
anthropogenic disturbance. Creating an index by combining soft bodied EPT and EPT gill-use metrics may be a particularly useful tool for detecting excess fine sediment.

The purpose of this study was to examine EPT metrics as bioindicators for a gradient of fine sediment conditions, to be used in biomonitoring for salmon-bearing streams in the Blue Mountain ecoregion of Oregon. Awareness of the ecological importance of fine sediment deposition is growing, especially in regions with resources such as salmonids or organisms with conservation value (Owens, et al., 2005). Quantifying fine sediment reference conditions using consistent techniques need be further researched and practiced among resource managers. This will help to standardize findings and support management targets (Hubler, et al., 2016; Gieswein, et al., 2018). With the uncertainties associated with measuring fine sediment, including the bilge pump method, confidence in the use of EPT richness as a diagnostic tool will rely on additional sediment data beyond the spatial and temporal limitations of this study. To develop a full picture of how EPT respond to fine sediment, integrating sediment dynamics before sampling efforts may lead to interesting research opportunities. A more extensive study could make use of a wider gradient of the proportion of fine sediment conditions, as well as fine sediment masses, which would likely involve more sample sites. Had more resources been available, inclusion of data from multiple transects in a reach may have improved the accuracy of the project.

EPT richness is a valuable biometric for estimating fine sediment conditions and could be used in the Blue Mountain ecoregion for optimizing applications of riparian or upland restoration. Future research should be undertaken to further investigate the 
responsiveness of EPT functional traits to fine sediment deposition, and directly compare the bilge pump method with pebble count methods using the same design approach. 


\section{REFERENCES}

Albertson, L. K., Sklar, L. S., Cooper, S. D., \& Cardinale, B. J. (2019, January 2). Aquatic macroinvertebrates stabilize gravel bed sediment: A test using silk netspinning caddisflies in semi-natural river channels.

American Public Health Association. (2005). Standard Methods for the Examination of Water and Wastewater. (21 ed.). Washington, D.C.: American Public Health Association.

Angradi, T. (1999). Fine sediment and macroinvertebrate assemblages in Appalachian streams: a field experiment with biomonitoring applications. Journal of the North American Benthological Society, 18, 49-66.

Arar, E., \& Collins, G. (1997). In Vitro Determination of Chlorophyll a and Pheophytin a in Marine and Fresheater Algae by Fluorescence. Cincinnati, Ohio: National Exposure Research Laboratory: Office of Research and Development. US EPA.

Ashton, N. N., Roe, D. R., Weiss, R. B., Cheatham, T. E., \& Stewart , R. J. (2013). Biomacromolecules, 3668-3681.

Barbour, M., Gerritsen, J., Snyder, B., \& Stribling, J. (1999). Rapid Bioassessment Protocols for Use in Streams and Wadeable Rivers: Periphyton, Benthic Macroinvertebrates and Fish, Second Edition. Washington, D.C.: U.S. Environmental Protection Agency.

Beerman, A., Elbrecht, V., Karnatz, S., Ma, L., Matthaei, C., Piggot, J., \& Leese, F. (2018). Multiple-stressor effects on stream macroinvertebrate communities: A mesocosm experiment manipulating salinity, fine sediment and flow velocity. Science of the Total Environment, 611,961-971.

Binkley, D., \& Brown, T. (1993). Forest practices as nonpoint sources of pollution in North America. Water Resources Bulletin.

Bona, F., Doretto, A., Falasco, E., La Morgia, V., Piano, E., Ajassa, R., \& Fenoglio, S. (2015). Increased sediment loads in alpine streams: an integrated field study. . River Research and Applications, 32, 1316-1326. 
Bonada, N., Prat, N., Resh, V. H., \& Statzner, B. (2006, January). DEVELOPMENTS IN AQUATIC INSECT BIOMONITORING: A Comparative Analysis of Recent Approaches. Annual Review of Entomology, pp. 469-523.

Bonada, N., Prat, N., Resh, V., \& Statzner, B. (2006). Developments in aquatic insect biomonitoring: a comparative analysis of recent approaches. Annual Review of Entomology, 51, 495-523.

Bond, N., \& Downes, B. (2003). The independent and interactive effects of fine sediment and flow on benthic inverterbate communities characteristic of small upland streams . Freshwater Biology, 48, 455-465.

Breiman, L. (2001). Random Forests. Machine Learning, 5-32.

Broekhuizen, N., Parkyn, S., \& Miller, D. (2001). Fine sediment effects on feeding and growth in the invertebrate grazers Potamopyrgus antipodarum (Gatropoda, Hydrobiidae), and Deleatidium sp.(Ephemeroptera, Leptophlebiidae). Hydrobiologia, 457, 125-132.

Brusven, M., \& Prather, K. (1974). Influence of stream sediment on distribution of Macrobenthos . Journal of Entomological Society of British Columbia, 71, 25-32.

Bryce, S., Lomnicky, G., \& Kaufmann, P. (2010). Protecting sediment-sensitive aquatic species in mountain streams through the application of biologically based streambed sediment criteria. Journal of the North American Benthological Society, 29(2), 657-672.

Buendia, C., Gibbins, C., Vericat, D., \& Batalla, R. (2014). Effects of flow and fine sediment dynamics on the turnover of stream invertebrate assemblages. . Ecohydrology14, 7, 1105-1123.

Buendia, C., Gibbins, C., Vericat, D., Batalla, R., \& Douglas, A. (2013). Detecting the structural and functional impacts of fine sediment on stream invertebrates. Ecological Indicators, 25, 184-196. 
Buendia, C., Vericat, D., Batalla, R., Vericat, D., \& Douglas, A. (2013). Scale-dependent effects of fine sediments on temperate headwater invertebrate. Ecological Indicators, 25, 184-196.

Bunte, K., \& Abt, S. (2001). Sampling surface and subsurface particle-size distribution in wadeable gravel and cobble-bed streams fo analyses in sediment transport, hydraulics, and streambed monitoring. Fort Collins, Colorado: U.S. Department of Agriculture, Forest Service, Rocky Mountain Research Station.

Burdon, F., McIntosh, A., \& Harding, J. (2013). Habitat loss drives thershold response of benthic invertebrate communities to deposited sediment in agricultural streams. Ecological Application, 23, 1036-1047.

Buss, D., Carlisle, D., Chon, T., Culp, J., Harding, J., Keizer-Vlek, H., . . Hughes, R. (2015). Stream biomonitoring using macroinvertebrates around the globe: a comparison of large scale programs. Environ. Monit. Assess., 187, 1-21.

Butcher, D., Crown, J., Brannan, K., Kishida, K., \& Hubler, S. (2010). John Day River basin Total Maximum Daily Load (TMDL) and Water Quality Management Plan $(W Q M P)$. Portland, OR: Oregon Department of Environmental Quality.

Cairns Jr., J., \& Pratt, J. (1993). A history of biological monitoring using benthic macroinvertebrates. In D. Rosenburg, \& V. Resh (Eds.), Freshwater Biomonitoring and Benthic Macroinvertebrates (pp. 10-27). New York: Chapman and Hall.

Campbell, I., \& Doeg, T. (1989). Impact of timber harvesting and production on stream; a review. Marine and Freshwater Research, 40, 519-539.

Carling, P., \& Reader, N. (1981). A freeze-sampling technique suitable for coarse river bed-material. Sedimentary Geology, 29, 233-239.

Carter, J., \& Resh, V. (2001). After site selection and before data analysis: sampling, sorting, and laboratory procedures used in stream benthic macroinvertebrate monitoring programs by USA state agencies. Journal of the North American Benthological Society, 20(4), 658-682. 
Chessman, B. C., Fryirs, K. A., \& Brierley, G. J. (2006). Linking geomorphic character, behaviour and condition to fluvial biodiversity: implications for river management. Aquatic Conservation: Marine and Freshwater Ecosystems, 267288.

Clapcott, J., Young, R., Harding, J., Matthaei, C., Quinn, J., \& Death, R. (2011). Sediment Assessment Methods: Protocols and Gidelines for Assessing the Effects of Deposited Fine Sediment on In-stream Values. Nelson, New Zealand: Cawthron Institue.

Clapcott, J., Young, R., Harding, J., Matthaei, C., Quinn, J., \& Death, R. (2011). Sediment asssessment methods: protocols and guidelines for assessing the effects of deposited fine sediment on in-stream values. Nelson, New Zealand: Cawthron Institute.

Cobb, D., Galloway, T., \& Flannagan, J. (1992). Effects of discharge and substrate stability on density and species composition of stream insects. Canadian Journal of Fisheries and Aquatic Sciences, 49, 1788-1795.

Collins, A., Foster, I., Zhang, Y., Gooday, R., Lee, D., Sear, D., . . . Jones, I. (2012). Assessing "modern background sediment delivery to rivers" across England and Wales and its use for catchment management. . In A. G. Collins (Ed.), Erosion and Sediment Yields in the Changing Environment. (pp. 125-131). Wallingford, U.K.: International Association of Hydrological Sciences.

Cormier, S., Paul, J., Spehar, R., Shaw-Allen, P., Berry, W., \& Suter, G. (2008). Using field data and weight of evidence to develop water quality criteria. Integrated Environmental Assessment and Management, 4(4), 490-504.

Cuffney, T., Brightbill, R., May, J., \& Waite, I. (2010). Responses of benthic macroinvertebrates to environmental changes associated with urbanization in nine metropolitan areas. . Ecological Applications, 20(5), 1384-1401.

Davies, S., \& Jackson, S. (2006). The Biological Condition Gradient: A Descriptive Model for Interpreting Change in Aquatic Ecosystems. Ecological Applications, $16,1251-1266$. 
De'ath, G., \& Fabricius, K. E. (2000). Classification and regression trees: A powerful yet simple technique for ecological data analysis. Ecology, 3178-3192.

Descloux, S., Datry, T., \& Marmonier, P. (2013). Benthic and hyporheic invertebrate assemblages along a gradient of increasing streambed colmation by fine sediment. Aquatic Sciences, 493-507.

Descloux, S., Datry, T., \& Usseglio-Polatera, P. (2014). Trait-based structure of invertebrates along a gradient of sediment colmation: Benthos versus hyporheos responses. Science of the Total Environment, 467, 265-276.

Descloux, S., Datry, T., Philippe, M., \& Marmonier, P. (2010). Comparison of different techniques to assess surface and subsurface streambed colmation with fine sediments. . International Review of Hydrobiology, 95, 520-540.

Dethier, D. P. (1979). Atmospheric contribution to stream water chemistry in North Cascades Range, Washington. Water Resources Research, 15, 787-794.

Dietrich, E. (1982). Settling velocity of natural particles. Water Resources Research, 1626-1982.

Doretto, A., Bona, F., Piano, E., Zanin, I., Eandi, A., \& Fenoglio, S. (2017). Trophic availability buffers the detrimental effects of clogging in an alpine stream. Science of The Total Environment, 595, 503-511.

Duerdoth, C., Arnold, A., Murphy, J., Naden, P., Scarlett , P., Collins, A., . . Jones, J. (2015). Assessment of a rapid method for quantitative reachscale estimates of deposited fine sediment in rivers. Geomorphology, 230, 37-50.

Duerdoth, C., Arnold, A., Murphy, J., Naden, P., Scarlett, P., Collins, A., . . Jones, J. (2015). Assessment of a rapid method for quantitative reach-scale estmates of depostied fine sediment in rivers. Geomorphology, 230, 37-50.

Edington, J., \& HIldrew, A. (1995). Caseless Caddis Larvae of the British Isles. 53. Ambleside. 
Edmonds, R., Blew, R., Marra, J., Blew, J., Barg, A., Murray, G., \& Thomas, T. (1998). Vegetation patterns, hydrology, and water cheistry in small watershed in the Hoh river valley, Olympic National Park. USDI National Park Service Science Monograph.

Edwards, P., Danehy, B., \& Hubler, S. (2020). Habitat-specific response of stream macroinvertebrates to Sand $(<2.0 \mathrm{~mm})$ and Fine $(<0.06 \mathrm{~mm})$ substrates in streams of the Coast Range Ecoregion. Portland: Unpublished.

Emelko, M., Stone, M., Silins, U., Allin, D., Collins, A., Williams, C., .. . Bladon, K. (2016). Sediment-phosphorus dynamics can shift aquatic ecology and cause downstream legacy effects after wildlife in large river systems. Global Change Biology, 22, 1168-1184.

Environmental Agency. (2003). River Habitat Survey in Britain and Ireland: Field Survey Guidance Manual. River Habitat Survey Manual: 2003 version. . Bristol, U.K.: Environmental Agency.

Everall, N., Johnson, M., Wood, P., \& Mattingley, L. (2018). Sensitivity of the early life stages of a mayfly to fine sediment and orthophosphate levels. Environmental Pollution, 237, 792-802.

Extence, C., Balbi, D., \& Chadd, R. (1999). River flow indexing using British benthic macroinvertebrates: a framework for setting hydroecological objectives. Regulated Rivers: Research \& Management, 15(6), 545-574.

Extence, C., Chadd, R., England, J., Dunbar, M., Wood, P., \& Taylor , E. (2011). The assessment of fine sediment accumulations in rivers using macroinvertebrate community response. River Research and Application, 29, 17-55.

Fairchild, J., Boyle, T., English, W., \& Rabeni, C. (1987). Effects of sediment and contaminated sediment on structural and functional components of experimental stream ecosystems. Water, Air, and Soil Pollution, 36, 271-293. 
Faustini, J., \& Kaufmann, P. (2007). Adequacy of visually classified particle count statistics from regional stream habitat surveys. Journal of the American Water Resources, 43, 1293-1315.

Feller, M. C. (2005). Forest harvesting and streamwater inorganic chemistry in Western North America: A review. Journal of AMerican Water Resources Association, 41(4), 785-811.

Feller, M., \& Kimmins, J. (1979). Effects of clearcutting and slashburning on streamwater chemistry and watershed nutrient loss in southwestern British Columbia. Water Resources Research, 15, 247-258.

Friedman, J. H. (2001). Greedy function approximation: a gradient boosting machine. Annals of statistics, 1189-1232.

Friedman, J., Hastie, T., \& Tibshirani, R. (2001). The Elements of Statistical Learning. (1 ed.). New York, NY: Springer Series.

Fripp, J., \& Diplas, P. (1993). Surface sampling in gravel streams. Hydraulic Engineering, 119, 473-490.

Gee, J. (1979). A comparison of gravimentric and photographic methods of stream substrate analysis in a study of benthos microdistribution. Oikos, 33, 74-79.

Gentai-Kato, M., Mitsuhashi, H., Kohmatsu, Y., Miyasaka, H., Nozaki, K., \& Nakanishi, M. (2005). A seasonal change in the distribution of a stream-dwelling stoneflly nymph reflects oxygen supply and water flow. Ecological Research, 20, 223-226.

Gerth, W., Li, J., \& Giannico, G. (2016). Agricultural land use and macroinvertebrate assemblages in lowland temporary streams of the Willamette Valley, Oregon, USA. Agriculture, Ecosystems, and Environment, 236, 154-165.

Gibbins, C., Vericat, D., \& Batalla, R. (2010). Relations between invertebrate drift and flow velocity in sand-bed and riffle habitats and the limits imposed by substrate stability and benthic density. Freshwater Science, 29(3), 945-958. 
Gieswein, A., Hering, D., \& Lorenz, A. W. (2018). Development and validation of a macroinvertebrate-based biomonitoring tool to assess fine sediment impact in small mountain streams. Science of the Total Environment, 652, 1290-1301.

Harrell, F. E. (2020). Package "Hmisc". Retrieved April 2020, from https://github.com/harrelfe/Hmisc

Harvey, B., White, J., \& Nakamoto, R. (2011). The Effect of Deposited Fine Sediment on Summer Survival and Growth of Rainbow Trout in Riffles of a Small Stream. North American Journal of Fisheries Management, 29(2), 434-440.

Herbst, D., \& Kane, J. (2006). Fine Sediment Deposition and Invertebrate Communities in the middle Truckee River, California: Development of Criteria for Establishing $T M D L s$. Lahontan Regional Water Quality Control Board Report.

Hering, D., Feld, C., Moog, O., \& Ofenbock, T. (2006). Cook book for the development of a multimetric index for biological condition of aquatic ecosystems:

Experiences from the European AQEM and STAR projects and related initiatives. Hydrobiologia, 566, 311-342.

Hodkinson, I., \& Jackson, J. (2005). Terrestrial and aquatic invertebrates as bioindicators for environmental monitoring, with particular reference to mountain ecosystems. Envrironmental Management, 35(5), 649-666.

Homer, C., Dewitz, J., Yang, L., Jin, S., Danielson, P., Xian, G., . . Megown, K. (2011). Completion of the 2011 National Land Cover Database for the conterminous United States-Representing a decade of land cover change information. Photogrammetric Engineering and Remote Sensing, 81(5), 345-354.

Hornig, C., \& Brusven, M. (1986). Effects of suspended sediment on leaf processing by Hesperophylax occidentalis (Trichoptera, Limnephilidae) and Pteronarcys californica (Plecoptera, Pteronarcidae). Great Basin Naturalist, 46, 33-38.

Hubler, S., Huff, D. D., Edwards, P., \& Pan, Y. (2016). The Biological Sediment Tolerance Index: Assessing fine sediments conditions in Oregon streams using macroinvertebrates. Ecological Indicators, 132-145. 
Ibbeken, H., \& Schleyer, R. (1986). . Photo-sieving: a method for grain-size analysis of coarse-grained, unconsolidated bedding surfaces. Earth Surface Processes and Landforms, 11, 59-77.

Javie, H., Sharpley, A., Withers, P., Scott, J., Haggard, B., \& Neal, C. (2013). Phosphorus mitigation to control river eutrophication: Murky waters, inconvenient truths, and "postnormal" science. Journal of Environmental Quality, 42, 295-304.

Jensen, D., Steel, A., Fullerton, A., \& Pess, G. (2009). Impact of Fine Sediment on EggTo-Fry Survival of Pacific Salmon: A Meta-Analysis of Published Studies. Reviews in Fisheries Science, 17(3), 348-359.

Jones, J., Collins, A., Naden, P., \& Sear, D. (2012a). The relationship between fine sediment and macrophytes in rivers. . River Research Applications, 28, 10061018 .

Jones, J., Duerdoth, C., Collins, A., Naden, P., \& Sear, D. (2014). Interactions between diatoms and fine sediment. Hydrological Processes, 28, 1226-1237.

Jones, J., Murphy, J., Collins, A., Sear, D., Naden, P., \& Armitage, P. (2012b). The impact of fine sediment on macro-invertebrates. River Research and Applications, 28(8), 1055-1071.

Jowett, I. (2003). Hydraulic constraints on habitat suitability for benthic invertebrates in gravel- bed rivers. River Research and Applications, 19, 495-507.

Kaller, M. D., \& Hartman, K. J. (2004). Evidence of a threshold level of fine sediment accumulation for altering benthic macroinvertebrate communities. Hydrobiologia, 95-104.

Kaller, M., \& Hartman, K. (2004). Evidence of a threshold level of fine sediment accumulation for altering benthic macroinvertebrate communities.

Hydrobiologica, 518, 95-104. 
Kaller, M., Hartman, K., \& Angradi, T. (2001). Experimental determination of benthic macroinvertebrate metric sensitivity to fine sediment in Appalachian streams. Proc Annu Conf SEAFWA, 55, 105-115.

Karr, J. (1981). Assesment of Biotic Integrity Using Fish Communities . Fisheries, 6, 21 27.

Karr, J. R., \& Chu, E. W. (1998). Restoring Life in Running Waters: Better Biological Monitoring. Washington, DC: Island Press.

Kaufmann, P. R., Levine, P., Robison, G. E., Seeliger, C., \& Peck, D. V. (1999). Quantifying Physical Habitat in Wadeable Streams. Washington, D.C. : U.S. Environmental Protection Agency.

Kefford, B. (2018). Why are mayflies (Ephemeroptera) lost following small increases in salinity? Three conceptual osmophysiological hypotheses. Philosophical transactions of the Royal Society of London., 374.

Kellerhals, R., \& Bray, D. (1971). Sampling procedures for course fluvial sediments. Journal of the Hydraulics Division, 97, 1165-1180.

Kemp, P., Sear, D., Collins, A., Naden, P., \& Jones, I. (2011). The impacts of fine sediment on riverine fish. Hydrological Processes, 25, 1800-1821.

Kerans, B., \& Karr, J. (1994). A benthic index of biotic integrity (B-IBI) for rivers of the Tennesee Valley. Ecological Applications, 4, 768-785.

Kerans, B., Karr, J., \& Ahlstedt, S. (1992). Aquatic invertebrate assemblages: spatial and temporal differ- ences among sampling protocols. North American Benthological Society, 11, 377-390.

Klemm, D., Blocksom, K., Thoeny, W., Fulk, F., Herlihy, A., Kaufmann, P., \& Cormier, S. (2002). Methods development and use of macroinvertebrates as indicators of ecological condtitions for streams in the Mid-Atlantic Highlands region.

Environmental Monitoring and Assessment, 78, 169-212. 
Kochersberger, J. (2008). Linking Embeddedness and Macroinvertebrate Healthin Two Southwest Ohio Streams. Wright-Patterson Air Force Base, Ohio: Air Force Institue of Technology.

Kozerski, H.-P. (2002). Determination of areal sedimentation rates in rivers by using plate sediment trap measurements and flow velocity-settling flux relationship. Water Research, 36(12), 2983-2990.

Kreutzweiser, D., Capell, S., \& Good, K. (2005). Effects of fine sediment inputs from a logging road on stream insects assemblages: a large scale experimental approach in a Canadian headwater stream. Aquatic Ecology, 39, 55-66.

Lambert, C., \& Walling, D. (1988). Measurement of channel storage of suspended sediment in a gravel-bed river. Catena, 15, 65-80.

Larsen, S., Vaughan, I., \& Ormerod, S. (2008). Scale-dependent effects of fine sediments on temperate headwater invertebrate. Freshwater Biology, 54, 203-219.

Lemly, A. (1982). Modification of benthic insect communities in polluted streams: combined effects of sedimentation and nutrient enrichment. Hydrobiologia, 79, 187-194.

Leopold, L., Wolman, M., \& Miller, J. (1964). Fluvial Processes in Geomorphology. San Francisco, CA.: Freeman.

Ligeiro, R., Hughes, R., Kaufmann, P., Macedo, D., Firmiano, K., Ferreira, W., . . . Callisto, M. (2013). Defining quantitative stream disturbance gradients and the additive role of habitat variation to explain macroinvertebrate taxa richness. Ecological Indicators, 25, 45-57.

Logan, O. D. (2007). Effects of Fine Sdiment Deposition on Benthic Invertebrate Communities. New Brunswick: The University of New Brunswick.

Logan, P., \& Brooker, M. (1983). The macroinvertebrate fauna of riffles and pools. Water Research, 263-270. 
Longing, S., Voshell Jr., J., Dolloff, C., \& Roghair, C. (2010). Relationships of sedimentation and benthic macroinvertebrate assemblages in headwater streams using systematic longitudinal sampling at the reach scale. Environ. Monit. Assess, $161,517-530$.

Lorenz, A., Hering, D., Feld, C., \& Rolauffs, P. (2004). A new method for assessing the impact of hydromorphological degradation on the macroinvertebrate fauna in five German stream types. Hydrobiologia, 516, 107-127.

Lorenz, A., Kirchner, L., \& Hering, D. (2004). 'Electronic subsampling' of macrobenthic samples: how many individuals are needed for a valid assessment result? Hydrobiologia, 516, 299-312.

Luedtke, R., \& Brusven, M. (1976). Effects of sand sedimentation on colonization of stream insects. Journal of the Fisheries Research Board of Canada, 33, 18811886.

Magurran, A. (1988). Ecological Diversity and Its Measurement. Princetown, NJ: Prinetown University Press.

Marion, A., \& Faccarollo, L. (1997). New conversion model for areal sampling of fluvial sediments. Joiurnal of Hydraulic Engineering, 123, 1148-1151.

Matthaei, C., Peacock, K., \& Townsend, C. (1999). Patchy surface stone movement during disturbance in a New Zealand stream and its potential significance for the fauna. Limnology and Oceanography, 44, 1091-1102.

Matthaei, C., Weller, F., \& Kelly, D. (2006). Impacts of fine sediment addition to tussock, pasture, dairy, and deer farming streams in New Zealand. Freshwater Biology, 51, 2154-2172.

Mazor, R., Rehn, A., Ode, P., Engeln, M., Schiff, K., Stein, E., . . Herbst, D. (2016). Bioassessment in complex environments: designing an index for consistent meaning in different settings. Freshwater Science, 35(1), 249-271. 
McCaffrey, C. (2019). Feasibility Study: Field Method. Portland: Unpublished.

McCullough, D., \& Greene, M. (2001-2003). Monitoring Fine Sediment; Grande Ronde and John Day Rivers. Portland: Bonneville Power Administration.

Merritt, R., Cummins, K., \& Berg, M. (2008). Aquatic Insects of North America (4th ed.). Dubuque, Iowa: Kendall Hunt.

Minshall, G. (1984). Aquatic insect- substratum relationships. In V. Resh, \& D. Rosenberg (Eds.), The ecology of aquatic insects (pp. 358-400). New York, NY: Praeger.

Mondy, C., \& Usseglio-Polatera, P. (2013). Using conditional forest trees and life history traits to assess specific risks of stream degradation under multiple pressure scenario. . Science of the Total Environment, 462, 750-760.

Monk, W., Wood, P., Hannah, D., \& Wilson, D. (2008). Macroinvertebrate community response to inter-annual and regional river flow regime dynamics. . River Research and Applications, 24, 988-1001.

Natural Resources Conservation Service. (2005, August). 8-Digit HUC Watershed Profiles in Oregon . Retrieved May 2020, from https://www.nrcs.usda.gov/wps/portal/nrcs/detail/or/water/resources/?cid=nrcs 142 p2_045940

Olsen, A., \& Peck, D. (2008). Monitoring design and extent estimates for national Wadeable Stream Assessment. Journal of North American Benthological Society, 27(4), 822-836.

Ostermiller, J., \& Hawkins, C. (2004). Effects of sampling error on bioassessments of stream ecosystems: application to RIVPACS-type models. Journal of the North American Benthological Society, 23, 363-382. 
Owens, P., Batalla, R., \& Collins, A. (2005). fined-grained sediment in river systems: environmental significance and management issues. River Reseach and Application, 21, 693-717.

Palmer, C., O'Keefe, J., \& Palmer, A. (1991). Are macroinvertebrate assemblages in the Buffalo River, southern Africa, associated with particular biotopes? Journal of the North American Benthological Society, 10, 349-357.

Pan, Y., Stevenson, R., Hill, B., Herlihy, A., \& Collins, C. (1996). Using diatoms as indicators of ecological conditions in lotic systems: a regional assessment. Journal of the North American Benthological Society, 15, 481-494.

Parkhill, K., \& Gulliver, J. (2002). Effect of inorganic sediment on whole-stream productivity. Hydrobiologia, 472(1-3), 5-17.

Parsons, M., \& Norris, R. (1996). The effect of habitat specific sampling on biological assessment of water quality using a predictive model. Freshwater Biology, 36, 419-434.

Peck, D. V., Herlihy, A., Hill, B. H., Hughes, R. M., Kaufmann, P. R., Klemm, D. J., . . . Cappaert, M. (2006). Environmental Monitoring and Assessment ProgramSurface Waters Western Pilot Study: Field Operations Manual for Wadeable Streams. Washington D.C.: U.S. Environmental Protection Agency, Offic of Research and Development.

Peckarsky, B. (1991). Habitat selection by stream-dwelling predatory stoneflies. Canadian Journal of Fisheries and Aquatic Sciences, 48(6), 1069-1076.

Peeters, E., Brugmans, B., Beijer, J., \& Franken, R. (2006). . Effect of silt, water and periphyton quality on survival and growth of the mayfly Heptagenia sulphurea. Aquatic Ecology, 40(3), 373-380.

Piggott, J. J., Townsend, C. R., \& Matthaei, C. D. (2015). Climate warming and agricultural stressors interact to determine stream macroinvertebrate community dynamics. Global Change Biology, 21, 1887-1906. 
Platts, W., Megahan, W., \& Minshall, G. (1983). Methods for evaluating stream, riparian, and biotic conditions. Ogden, Utah: U.S. Department of Agriculture Forest Service.

Poff, N. (1997). Landscape filters and species traits: towards mechanistic understanding and prediction in stream ecology. Journal of the North American Benthological Society, 16, 391-409.

Poff, N., Olden, J., Vieira, N., Finn, D., Simmons, M., \& Kondratieff, B. (2006). Functional trait niches of North American lotic insects: traits-based ecoloigcal applications in light of phylogenetic relationships. Journal of the North American Benthological Society, 24(4), 730-755.

Pollard, A., \& Yuan, L. (2010). Assessing the consistency of response metrics of the invertebrate benthos: a comparison of trait and identity-based measures. Freshwater Biology, 55, 1420-1429.

R Core Team. (2020). $R$ : A language and environment for statistical computing. $R$ Foundation for Statistical Computing, Vienna, Austria. Retrieved April 2020, from https://www.R-project.org/.

Rabeni, C., Doisy, K., \& Galat, D. (2002). Testing the biological basis of a stream habitat classification using benthic invertebrates. Ecological Applications, 12, 782-796.

Rabeni, C., Doisy, K., \& Zweig, L. (2005). Stream invertebrate community functional responses to depostied sediment. Aquatic Sciences, 64, 395-402.

Rehg, K., Packman, A., \& Ren, J. (2005). Effects of suspended sediment characteristics and bed sediment transport on streambed clogging. Hydrological Processes, 19, 413-427.

Relyea, C., Minshall, G., \& Danehy, R. (2000). Stream insects as bioindicators of fine sediment. Water Environment Federation. 
Relyea, C., Minshall, G., \& Danehy, R. (2000). Stream Insects as bioindicators of fine sediment. In: Watershed Management Conference Proceedings. . Vancouver, B.C.: Water Environment Federation Speciality Conference.

Relyea, C., Minshall, G., \& Danehy, R. (2012). Development and validation of an Aquatic Fine Sediment Biotic Index. Environmental Management, 49, 242-252.

Richardson, B. (1985). The impact of forest road construction on the benthic invertebrate and fish fauna of a coastal stream in southern New South Wales. Australian Society for Limnology Bulletin, 10, 65-88.

Ríos-Pulgarín, M., Barletta, M., Arango-Jaramillo, M., \& Mancera-Rodríguez, N. (2016). The role of the hydrological cycle on the temporal patterns of macroinvertebrate assemblages in an Andean foothill stream in Colombia. Journal of Limnology, 75, 107-120.

Ripley, B., Venables, B., Bates, D. M., Hornik, K., Gebhardt, A., \& Firth, D. (2019, December). Package 'MASS'. Retrieved April 2020, from http://www.stats.ox.ac.uk/pub/MASS4/

Roper, B., Buffington, J., Bennett, S., Lanigan, S., Archer, E., Faustini, J., . . Moyer, C. (2010). A comparison of the performance and caompatibility of protocols used by seven monitoring groups to measure stream habitat in the Pacific Northwest. North Am. J. Fish. Manage., 30, 565-587.

Rosenberg, D., \& Resh, V. (1993). Freshwater Biomonitoring and Benthic Macroinvertebrates. New York: Chapman and Hall.

Rosenburg, D., \& Resh, V. (1996). Introduction to freshwater biomonitoring and benthic macroinvertebrates. In D. Rosenburg, \& V. Resh (Eds.), Freshwater biomonitoring and benthic macroinvertebrates. (pp. 1-10). New York, New York: Chapman and Hall.

Roy, A., Rosemond, A., Leigh, D., Paul, M., \& Wallace, J. (2003). Habitat- specific responses of stream insects to land cover disturbance: biological consequences 
and monitoring implications. . Journal of the North American Benthological Society, 22(2), 292-307.

Ryan, P. (1991). Environmental effects of sediment on New Zealand streams: a review. New Zealand Journal of Marine and Freshwater Research, 25, 207-221.

Sheilbley, R., Morace, J., Journey, C., Van Metre, P., Bell, A., Nakagaki, N., ... Qi, S. (2015). Design and Methods of the Pacific Northwest Stream Quality Assessment (PNSQA), 2015. Reston, VA: U.S. Geological Survey.

Statzner, B., Doledec, S., \& Hugueny, B. (2004). Biological trait composition of European stream invertebrate communities: assessing the effects of various trait filter types. Ecography, 27, 470-488.

Statzner, B., Hildrew, A., \& Resh, V. (2001). Species traits and environmental, constraints: entomological research and the history of ecological theory. Annual Review of Entomology, 46, 291-316.

Stoddard, J., Herlihy, A., Hill, B., Hughes, R., Kaufmann, P., Klemm, D., . . Paulsen, S. (2006). Mid-Atlantic Integrated Assessment (MAIA) State of the Flowing Waters Report. Washington D.C.: U.S. Environmental Protection Agency.

Stoddard, J., Herlihy, A., Peck, D., Hughes, R., Whittier, T., \& Tarquinio, E. (2008). A process for creating multi-metric indices for large-scale aquatic surveys. . $J$. $N$. Am. Benthol. Soc., 27, 878-891.

Stoddard, J., Peck, D., Paulsen, S., Van Sickle, J., Hawkins, C., Herlihy, A., . . Whittier, T. (2005). An Ecological Assessment of Western Streams and Rivers. Washington D.C.: U.S. Environmental Protenction Agency.

Strand, R., \& Merritt, R. (1997). Effects of episodic sedimentation on the net-spinning caddisflies Hydropsyche betteni and Ceratopsyche sparna. Environmental Pollution, 98, 129-134. 
Strobl, C., Boulesteix, A., Kneib, T., Augustin, T., \& Zeileis, A. (2008). Conditional variable iportance for random forests. BMC Bioinformatics, 9(307).

Strobl, C., Boulesteix, A., Zeileis, A., \& Hothorn, T. (2007). Bias in random forest variable imprtance measures: Illustrations, sources, and a solution. $B M C$ Bioinformatics, 8(25).

Suren, A. (2005). Effects of deposited sediment on patch selection by two grazing stream invertebrates. Hydrobiologia, 549(1), 205-218.

Suren, A., \& Jowett, I. (2001). Effects of deposited sediment on invertebrate drift: an experimental study. N. Z. J. Mar. Freshwater, 35, 725-737.

Sutherland, A., Culp, J., \& Benoy, G. (2010). Characterizing depostied sediment for stream habitat assessment. Limnology and Oceanography: Methods, 8, 30-44.

Tomanova, S., Goitia, E., \& Helesic, J. (2006). Trophic levels and functional feeding groups of macroinvertebrates in neotropical streams. . Hydrobiologia, 556, 251264.

Turley, M., Bilotta, G., Chadd, R., Extence, C., Brazier, R., Burnside, N., \& Pickwell, A. (2016). A sediment-specific family-level biomonitoring tool to identify the impacts of fine sediment in temperate rivers and streams. Ecological Indicators, $70,151-165$.

U.S. Environmental Protection Agency . (2016). A Practioner's Guide to the Biological Condition Gradient: A Framework to Describe Incremental Change in Aquatic Ecosystems. Washington, DC.: U.S. Environmental Protection Agency.

U.S. Environmental Protection Agency. (2011). A Primer on Using Biological Assessments to Support Water Quality Management. Washington, D.C.: US EPA Office of Water.

U.S. Forest Service. (2020). S_USA.Allotment. Retrieved 2019, from http://data.fs.usda.gov/geodata/edw/datasets.php 
U.S. Geological Survey. (2019). USGS TNM Hydrography (NHD). Retrieved June 7, 2019, from https://hydro.nationalmap.gov/arcgis/rest/services/nhd/MapServer.

United States Department of Agriculture, National Resource Conservation Service. (2019). Gridded Soil Survey Geographic (gSSURGO) Database for Oregon. Retrieved June 2019, from https://gdg.sc.egov.usda.gov/

United States Environmental Protection Agency. (2017). Region 10 Summary of State Information. Retrieved November 2020, from https://ofmpub.epa.gov/waters10/attains_region_cy.control?p_region=10\#imp_wa ter_by_state

US Environmental Protection Agency. (2000). Atlas of America's polluted waters. Washington, DC: Office of Water, US Environmental Protection Agency.

USEPA . (2016). National Rivers and Streams Assessment 2008-2009 technical report. Washington, DC: Office of Water and Office of Research and Development, US Environmental Protection Agency,.

USEPA. (2017). National Rivers and Streams Assessment 2018/19: Field Operations Manual - Wadeable. EPA-841-B-17-003a. Washington, D.C.: U.S. Environmental Protection Agency.

Vannote, R., Minshall, G., Cummins, K., Sedell, J., \& Cushing, C. (1980). The river continuum concept. Canadian Journal of Fisheries and Aquatic Sciences, 37, $130-137$.

Von Bertrab, M., Krein, A., Stendera, S., Thielen, F., \& Hering, D. (2013). Is fine sediment deposition a main driver for the composition of benthic macroinvertebrate assemblages? Ecological Indicators, 24, 589-598.

Wagenhoff, A., Townsend, C. R., \& Matthaei, C. D. (2012). Macroinvertebrate responses along broad stressorgradients of deposited fine sediment and dissolvednutrients: a stream mesocosm experiment. Journal of Applied Ecology, 49, 892-902. 
Waite, I., Brown, L., Kennen, J., May, J., Cuffney, T., Orlando, J., \& Jones, K. (2010). Comparison of watershed disturbance predictive models for stream benthic macroinvertebrates for three distinct ecoregions in western US. Ecological Indicators, 10, 1125-1136.

Waite, I., Sobieszcyk, S., Carpenter, K., Arnsberg, A., Johnson, H., Hughes, C., . . . Rinella, F. (2008). Effects of Urbanization on Stream Ecosystems in the Willamette River Basin and Surrounding Area, Oregon and Washington. U.S. Geological Survey Scientific Investigations Report 2006-5101-D.

Walker, G., \& MacLeod, N. (1991). Geologic map of Oregon. U.S. Geological Survey.

Wallace, J., Grubaugh, J., \& Whiles, M. (1996). Biotic indices and stream ecosystem processes: results from an experimental study. Ecological Applications, 6, 140151.

Waters, T. (1995). Sediment in streams. Sources, biological effects, and control. . Bethesda, MD: American Fisheries Society Monograph 7.

Weber, W. S., Mou, Q., Ashton, N. N., Addison, J. B., Stewart, R. J., Holland, G. P., \& Yarger, J. L. (2014). Reversible Assembly of beta-Sheet Nonocrystals within Caddisfly Silk. Biomacromolecules, 1269-1275.

Wentworth, C. (1922). a scale of grade and class terms for clastic sediments. The Journal of Geology, 30, 377-392.

Whitacre, H., Roper, B., \& Kershner, J. (2007). A Comparison of Protocols and Observer Precision for Measuring Physical Stream Attributes. Journal of The American Water Resources Association, 43, 923-937.

Whitman, M., Moran, E., \& Ourso, R. (2003). Photographic techniques for characterizing streambed particle sizes. . Transactions of the American Fisheries Society, 132, 605-610. 
Wigington Jr., P. J., Church, M., Strickland, T., Eshleman, K., \& Van Sickle, J. (1998). Autumn chemistry of Oregon Coast Range Streams. Journal of the American Water Resources Association, 34, 1035-1049.

Wolman, M. (1954). A method of sampling course river-bed material. Eos, transactions American Geophysical Union, 35(6), 951-956.

Wood, P., \& Armitage, P. (1997). Biological effects of fine sediment in the lotic environment. Environmental Management, 21, 203-217.

Zanetell, B., \& Peckarsky, B. (1996). Stoneflies as ecological engineers- hungry predators reduce fine sediment in stream beds. Fresheater Biology, 36, 569-577.

Zweig, L., Rabeni, C., \& Leana, D. (2001). Biomonitoring for depostied sediment using benthic invertebrates: a test on 4 Missouri streams. Journal of North American Benthological Society, 20(4), 643-657. 


\section{APPENDIX}

Appendix A-1. Environmental variable descriptions for variables used in the WEMAP Random Forest analysis in Chapter 2.1.

\begin{tabular}{ll}
\hline Variable & Description \\
\hline AG_TOT & \% of watershed in agricultural lands \\
ANC & Acid neutralizing capacity (meq/L) \\
CA & Calcium (ueq/L) \\
CO3 & Carbonate (meq/L) \\
COND & Stream conductivity (uS/cm) \\
DOC & Dissolved organic carbon (mg/L) \\
ELEVMEAN & Mean elevation of watershed (m) \\
FLOW_CFS & Instantaneous discharge \\
FOR_TOT & \% of watershed in in all forested lands \\
HCO3 & Bicarbonate (meq/L) \\
K & Potassium (ueq/L) \\
KM_SEA & Approximate distance to ocean \\
LAT_DD & Latitude \\
LON_DD & Longitude \\
MG & Magnesium (ueq/L) \\
NH4 & Ammonium (ueq/L) \\
NO3 & Nitrate (ueq/L) \\
NCT_BDRK & Total nitrogen (ug/L) \\
\hline
\end{tabular}




\begin{tabular}{|c|c|}
\hline PCT_BIGR & Substrate $\%$ coarse gravel and larger $(>16 \mathrm{~mm})$ \\
\hline PCT_DRRS & $\%$ dry or subsurface flow \\
\hline PCT_FA & $\%$ falls \\
\hline PCT_FAST & $\%$ falls + cascades + rapids + riffles \\
\hline PCT_FN & Substrate $\%$ fine $(<0.06 \mathrm{~mm})$ \\
\hline PCT_HP & Substrate $\%$ hard pan \\
\hline PCT_ORG & Substrate $\%$ wood or detritus \\
\hline PCT_POOL & $\%$ all pool types \\
\hline PCT_SA & Substrate $\%$ sand $(0.06-2 \mathrm{~mm})$ \\
\hline PCT_SIDE & $\%$ side channels \\
\hline PCT_SLOW & $\%$ of reach with slow water types \\
\hline POPDENKM & Population density (popest/sq. km) \\
\hline PRECIP_M & Approximal annual meters of precipitation \\
\hline PRECIP_MM & Approximal annual millimeters of precipitation \\
\hline RD_DEN & Road density (total road/area watershed) \\
\hline RNG_TOT & $\%$ of watershed in rangelands \\
\hline ROUGHNES & Channel roughness \\
\hline $\mathrm{SIO} 2$ & Silicon dioxide (mg/L) \\
\hline SLOPMEAN & Mean reach gradient $(\%)$ \\
\hline $\mathrm{SO} 4$ & Sulfate (ueq/l) \\
\hline TMAX_YR & Mean max annual stream temperature (degrees C) \\
\hline TMEAN_YR & Mean annual stream temperature (degrees C) \\
\hline URB_TOT & $\%$ of watershed in urban lands \\
\hline V1TM100 & LWD volume in and above channel (m3/reach) \\
\hline V4W_MWQ & Volume per m2 of wet class 4 large woody debris \\
\hline W1_HAG & Riparian human disturbance index - agricultural types \\
\hline
\end{tabular}




$\begin{array}{ll}\text { W1_HALL } & \text { Riparian human disturbance index - all types } \\ \text { WSAREA } & \text { Watershed area (m2) } \\ \text { XBKA } & \text { Mean bank angle (degrees) } \\ \text { XBKF_W } & \text { Mean bankful width (m) } \\ \text { XC } & \text { Fraction of reach covered by canopy } \\ \text { XCDENBK } & \text { Mean of } \% \text { canopy coveer at LF \& RT banks } \\ \text { XDEPTH } & \text { mean thalweg depth (cm) } \\ \text { XFX_ALG } & \text { Fraction of reach covered by algal } \\ \text { XFC_AQM } & \text { Fraction of reach covered by macrophyte } \\ \text { XFC_LWD } & \text { Fraction of reach covered by large woody debris } \\ \text { XFC_OHV } & \text { Fraction of reach covered by overhang } \\ \text { XFC_UCB } & \text { Fraction of reach covered by undercut } \\ \text { ZN } & \text { Zinc (mg/L) }\end{array}$


Appendix A-2. Macroinvertebrate metrics and descriptions used in the WEMAP Random Forest analysis in Chapter 2.1.

\begin{tabular}{|c|c|}
\hline Metric & Description \\
\hline TOTLNIND & Total insect count \\
\hline TOTLRICH & Total taxa richness \\
\hline TOTLDENS & Total insect density at site \\
\hline SIMPSON & Simpson's biotic index \\
\hline HBI & Hilsenhoffs biotic index \\
\hline CHIRRICH & Chironomid taxa richness \\
\hline CHIRPTAX & Proportion chironomid taxa richness \\
\hline CHIRPIND & $\%$ chironomid \\
\hline EPHERICH & Ephemeroptera taxa richness \\
\hline EPHEPTAX & Proportion ephemeroptera taxa richness \\
\hline EPHEPIND & $\%$ ephemeroptera \\
\hline EPT_RICH & EPT taxa richness \\
\hline EPT_PTAX & Proportion EPT taxa richness \\
\hline EPT_PIND & $\%$ EPT \\
\hline NOINRICH & Non-insect taxa richness \\
\hline NOINPTAX & Proportion non-insect taxa richness \\
\hline NOINPIND & $\%$ non-insect \\
\hline MEGLRICH & Megaloptera taxa richness \\
\hline MEGLPTAX & Proportion megaloptera taxa richness \\
\hline MEGLPIND & $\%$ megaloptera \\
\hline OLLERICH & Oligochaeta taxa richness \\
\hline OLLEPTAX & Proportion oligochaeta taxa richness \\
\hline OLLEPIND & $\%$ oligochaeta \\
\hline
\end{tabular}




\begin{tabular}{|c|c|}
\hline PLECRICH & Plecoptera taxa richness \\
\hline PLECPTAX & Proportion plecoptera taxa richness \\
\hline PLECPIND & $\%$ plecoptera \\
\hline TRICRICH & Trichoptera taxa richness \\
\hline TRICPTAX & Proportion trichoptera taxa richness \\
\hline TRICPIND & $\%$ trichoptera \\
\hline COFIRICH & Collector-filterer taxa richness \\
\hline COFIPTAX & Proportion collector-filterer taxa richness \\
\hline COFIPIND & $\%$ collector-filterer \\
\hline COGARICH & Collector-gatherer taxa richness \\
\hline COGAPTAX & Proportion collector-gatherer taxa richness \\
\hline COGAPIND & $\%$ collector-gatherer \\
\hline OMNIRICH & Omnivore taxa richness \\
\hline OMNIPTAX & Proportion omnivore taxa richness \\
\hline OMNIPIND & $\%$ omnivore \\
\hline PREDRICH & Predator taxa richness \\
\hline PREDPTAX & Proportion predator taxa richness \\
\hline PREDPIND & $\%$ predator \\
\hline SCRPRICH & Scraper taxa richness \\
\hline SCRPPTAX & Proportion scraper taxa richness \\
\hline SCRPPIND & $\%$ scraper \\
\hline SHRDRICH & Shredder taxa richness \\
\hline SHRDPTAX & Proportion shredder taxa \\
\hline SHRDPIND & $\%$ shredder \\
\hline INTLRICH & Intolerant taxa richness \\
\hline INTLPTAX & Proportion intolerant taxa richness \\
\hline
\end{tabular}




$\begin{array}{ll}\text { INTLPIND } & \% \text { intolerant } \\ \text { FACLRICH } & \text { Facultative taxa richness } \\ \text { FACLPTAX } & \text { Proportion facultative taxa richness } \\ \text { FACLPIND } & \% \text { facultative } \\ \text { TOLRRICH } & \text { Tolerant taxa richness } \\ \text { TOLRPTAX } & \text { Proportion tolerant taxa richness } \\ \text { TOLRPIND } & \% \text { tolerant }\end{array}$




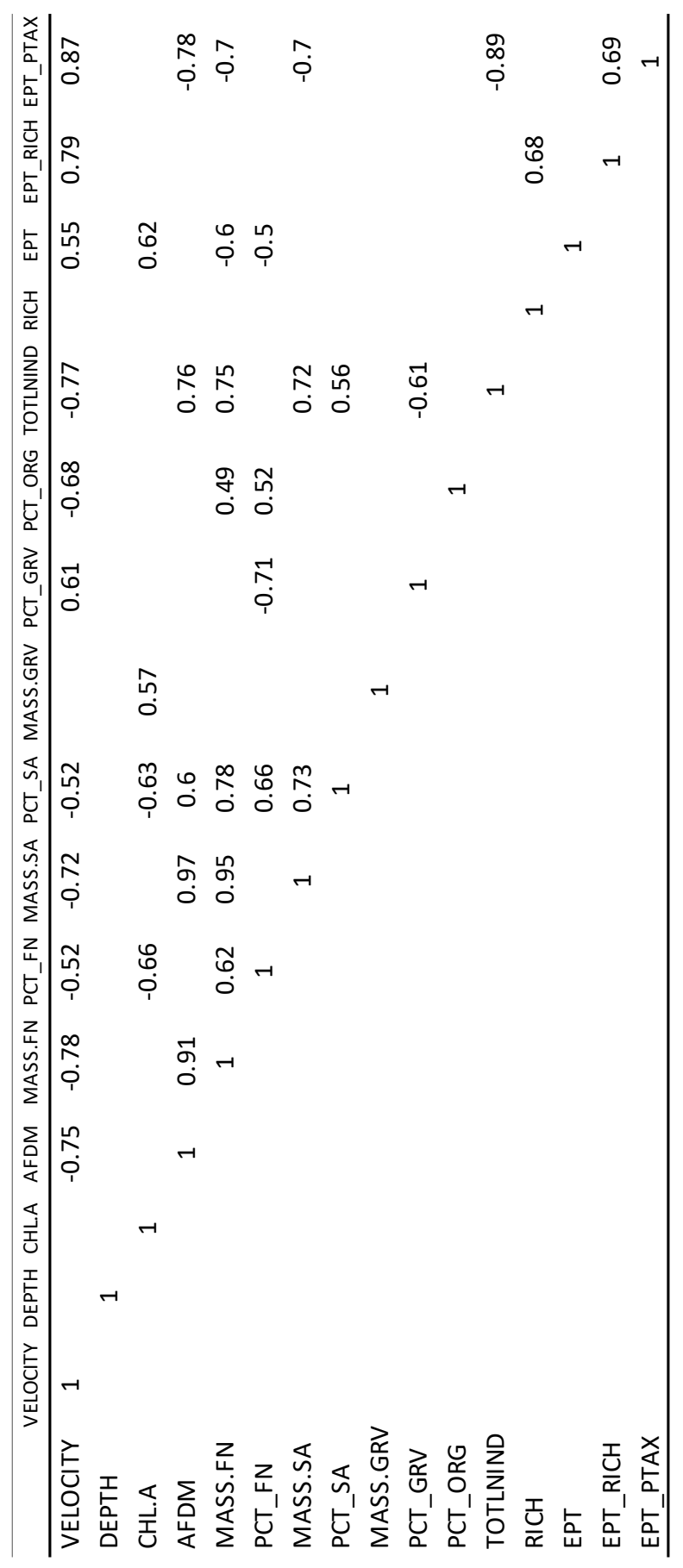

Appendix A-3.Spearman's cross-correlation matrix with data from the Clear Creek Study (Chapter 2.2), showing only significant relationships ( $p$-value $<0.05$ ).

Environmental predictors: velocity (VELOCITY), depth (DEPTH), chlorophyll a (CHL.A), ash-free dry mass (AFDM), mass of fines (MASS.FN), \% substrate that is fines (PCT_FN), mass of sands (MASS.SA), \% substrate that is sand (PCT_SA), mass of gravels (MASS.GRV), \% of substrate that is gravel (PCT_GRV), \% of substrate that is organic material (PCT_ORG). Response variables: total abundance (TOTLIND), total richness $(\mathrm{RICH})$, EPT abundance 